University of Louisville

ThinkIR: The University of Louisville's Institutional Repository

$5-2012$

\title{
The effects of computer assisted instruction and structured curriculum on struggling mathematics students.
}

Amy English Hunter

University of Louisville

Follow this and additional works at: https://ir.library.louisville.edu/etd

\section{Recommended Citation}

Hunter, Amy English, "The effects of computer assisted instruction and structured curriculum on struggling mathematics students." (2012). Electronic Theses and Dissertations. Paper 656.

https://doi.org/10.18297/etd/656

This Doctoral Dissertation is brought to you for free and open access by ThinkIR: The University of Louisville's Institutional Repository. It has been accepted for inclusion in Electronic Theses and Dissertations by an authorized administrator of ThinkIR: The University of Louisville's Institutional Repository. This title appears here courtesy of the author, who has retained all other copyrights. For more information, please contact thinkir@louisville.edu. 


\title{
THE EFFECTS OF COMPUTER ASSISTED INSTRUCTION AND STRUCTURED
} CURRICULUM ON STRUGGLING MATHEMATICS STUDENTS

\author{
By \\ Amy English Hunter \\ B.S., Arizona State University, 2002 \\ M.A. T., University of Louisville, 2006 \\ A Dissertation Submitted to the Faculty of the \\ College of Education and Human Development of the University of Louisville \\ in Partial Fulfillment of the Requirements \\ for the Degree of \\ Doctor of Philosophy \\ Department of Teaching and Learning \\ University of Louisville \\ Louisville, KY
}

May 2012 
Copyright 2012 by Amy English Hunter

All rights reserved 
THE EFFECTS OF COMPUTER ASSISTED INSTRUCTION AND STRUCTURED CURRICULUM ON STRUGGLING MATHEMATICS STUDENTS

\section{By}

Amy English Hunter

B.S., Arizona State University, 2002

M.A.T., University of Louisville, 2006

A Dissertation Approved on

March 30, 2012

By the following Dissertation Committee:

Dr. Jennifer M. Bay-Williams

Dissertation Co-Director

Dr. Namok Cloi

Dissertation Co-Director

Dr. William Bush

Dr. Maggie McGatha 


\section{DEDICATION}

This dissertation is dedicated to my husband,

Mr. Seth Hunter

who inspires me every day not only to be a better mathematics teacher,

but a better person. 


\section{ACKNOWLEDGMENTS}

In 2007 I attended a professional development session where I first learned about the five different representations for mathematics. This talk peaked my curiosity, and I wanted to learn more about how students, especially struggling students, learn mathematics. Later that fall, I met Dr. Charles "Chuck" Thompson, who continued to encourage me to learn about mathematics and inspired me to embark on a doctorate in mathematics education. I am grateful our paths crossed and that he was able to mentor me before he retired. Therefore, my first thanks are to Dr. Chuck Thompson for suggesting I pursue this degree.

I would also like to thank Dr. Jenny Bay-Williams for chairing my program committee, co-chairing my dissertation committee, and providing great advice on how to be a better writer. Additionally, I would like to thank Dr. Namok Choi for co-chairing my dissertation committee and being so dedicated to helping me even when her busy schedule made it difficult. I also want to thank my other committee members, Dr. Maggie McGatha and Dr. Bill Bush, for their continued support.

My friends and family offered continuous support during my studies. Thank you to my colleague Dr. Sarah Bush for her continued collaboration and moral support. Also, thank you to my parents, Bob and Celine English for teaching me how to set and achieve goals. Finally, thank you to my husband, Seth Hunter, for supporting me during the 
difficult times and celebrating with me during my successes. I could not have done this without you. 


\begin{abstract}
THE EFFECTS OF COMPUTER ASSISTED INSTRUCTION AND STRUCTURED CURRICULUM ON STRUGGLING MATHEMATICS STUDENTS
\end{abstract}

Amy English Hunter

March 30, 2012

The purpose of this study was to examine the effects of different instructional types used in a mathematics intervention setting. In recent years, school staff have implemented mathematics intervention programs to aid struggling students and improve student achievement. Advancements in technology have enticed many school staff to purchase computer-based instructional products that are used for mathematics intervention. Often computer-assisted instruction (CAI) is the only mathematics intervention students receive, however staff in the school of this study used a structured curriculum (SC) along with CAI. Therefore, this study examined the effects of CAI compared to a SC delivered by a teacher.

This study used a three-group pre/post-test design, which examined the effects of CAI, SC, and CAI with SC on mathematics achievement and students' attitudes towards mathematics. The follow research questions guided data analyses: 1) Is there a significant instructional type effect on mathematics achievement? 2) Is there a significant 
instructional type effect on mathematics attitude? 3) What is the factor structure of mathematics attitude scores of struggling learners?

Univariate and multivariate analyses revealed no statistically significant instructional type effects on mathematics achievement or attitude towards mathematics. However, factor analyses of pre-survey attitude scores revealed a factor structure different from the one found in current research. Meanwhile, factor analyses of post attitude survey scores resulted in a factor structure resembling that found in current literature, which suggested a shift in struggling students' mathematics attitude structures after they participated in mathematics intervention.

The results of this study provided information about how school leaders and administrators can design and implement mathematics intervention programs as well as the role of CAI in intervention programs. Additionally, lapses in fidelity of program implementation may have influenced results of the study and provide recommendations for teacher professional development and monitoring in order to maintain high levels of fidelity when implementing an intervention program. Finally, the results of this study suggested that struggling learners' attitude structure might be different than that of students in the larger population. The researcher discussed implications these differences may have on the design of mathematics intervention programs. 


\section{TABLE OF CONTENTS}

PAGE

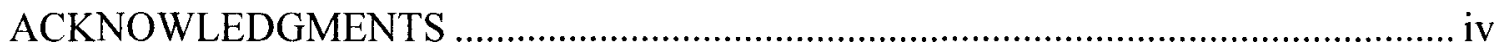

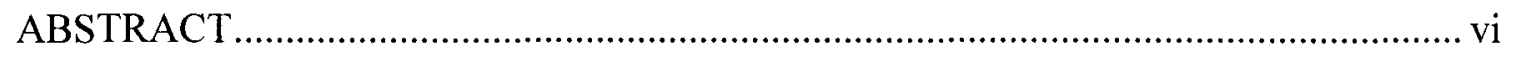

TABLE OF CONTENTS ............................................................................... vii

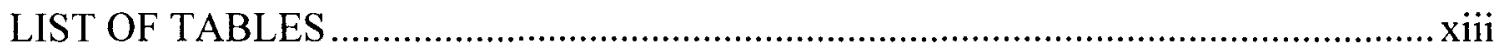

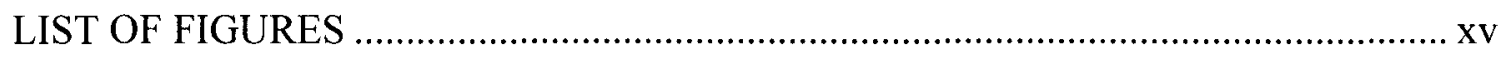

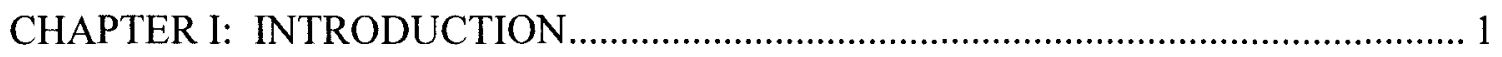

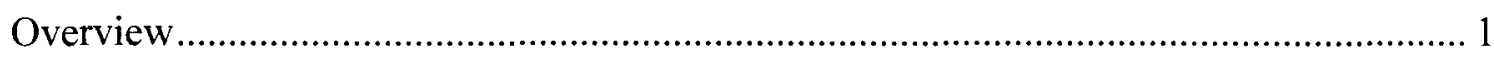

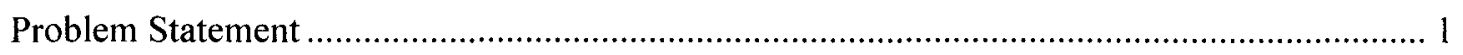

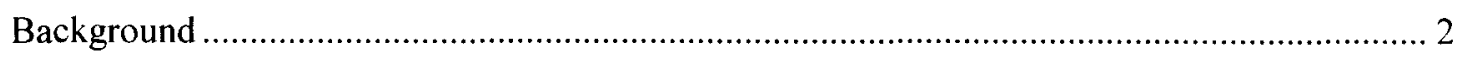

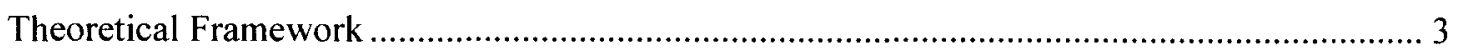

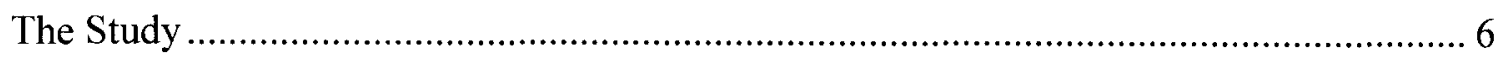

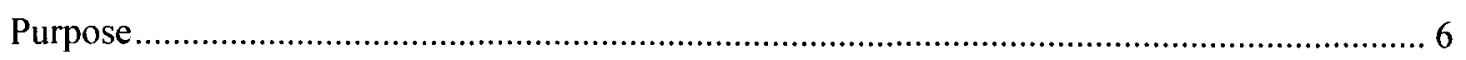

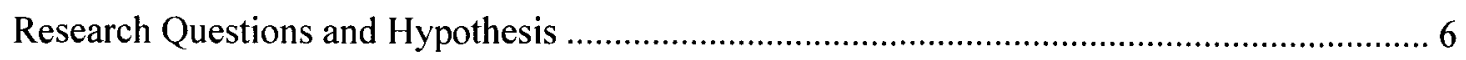

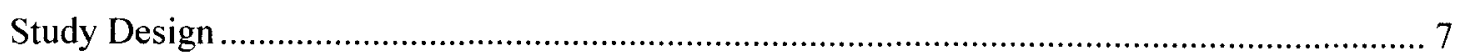




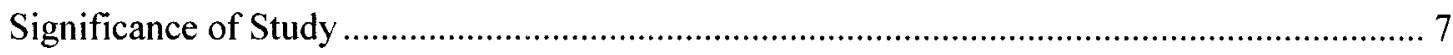

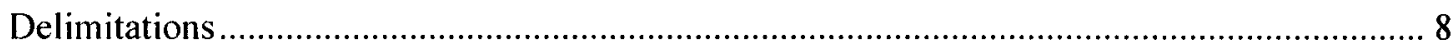

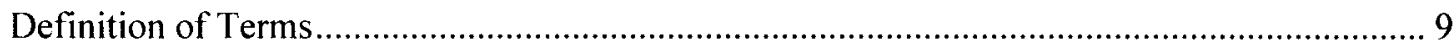

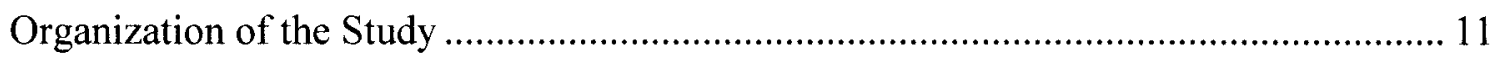

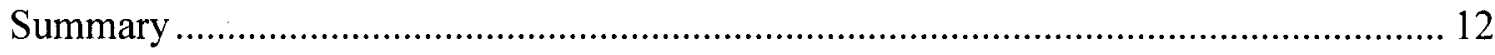

CHAPTER II: LITERATURE REVIEW ......................................................... 13

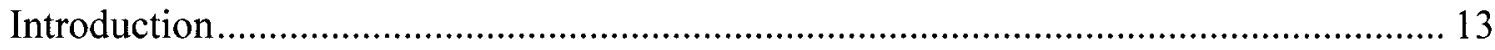

Curriculum Recommendations in Mathematics Education .................................... 15

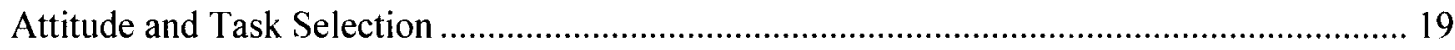

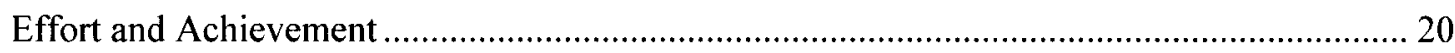

Struggling Students and Mathematics Intervention ......................................... 22

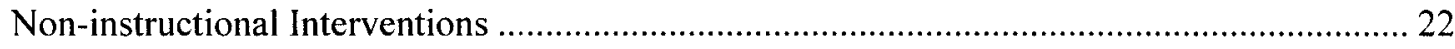

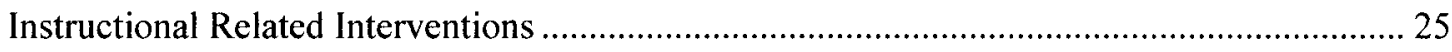

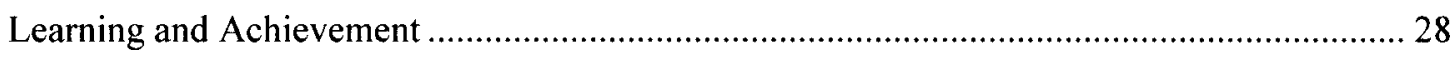

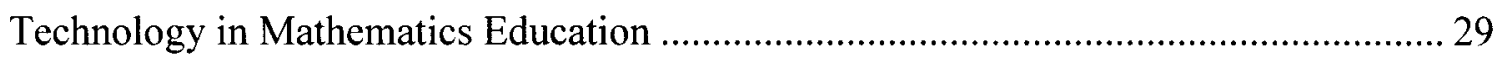

Technology as an Enhanced Representation of Mathematics ......................................... 31

Effective Integration of Technology in Mathematics Instruction ........................................ 42

Impact of Technology Use on Attitude Toward Mathematics ............................................. 47

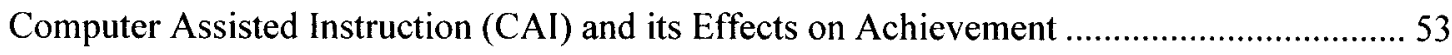

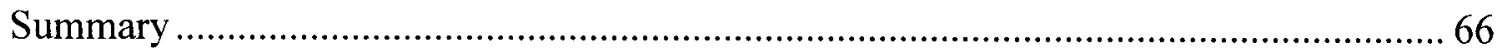

CHAPTER III: METHODOLOGY ................................................................ 68 


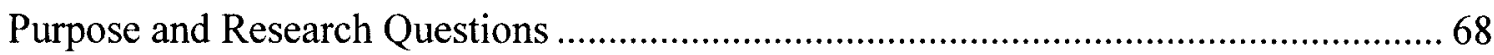

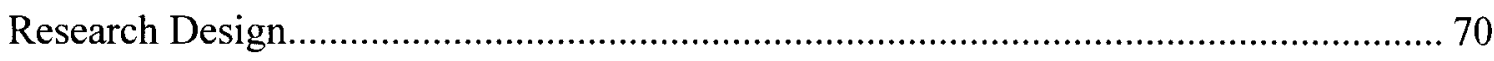

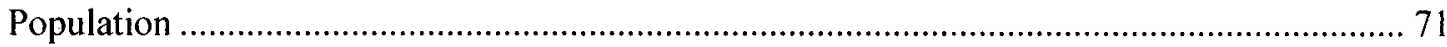

Sample

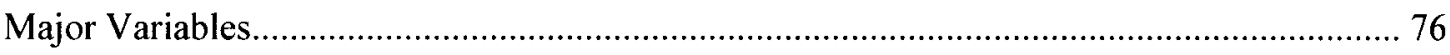

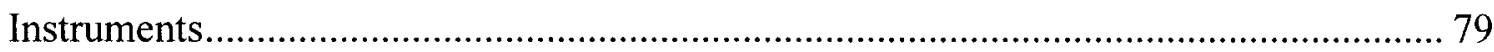

Measures in Academic Progress ………………………................................................ 79

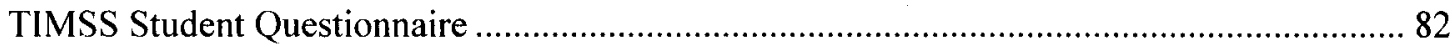

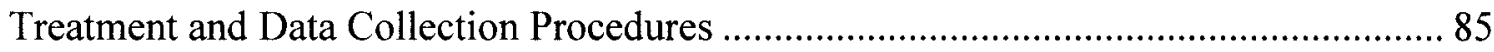

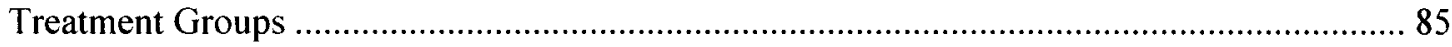

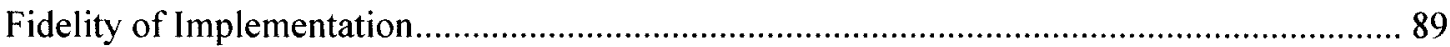

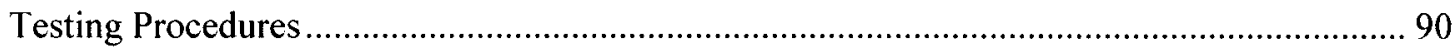

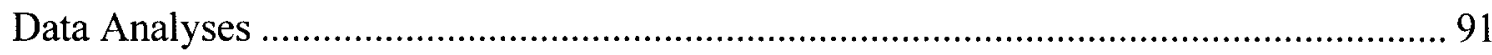

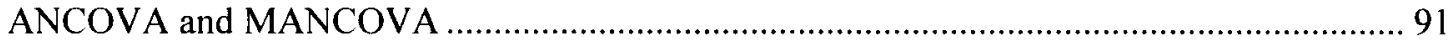

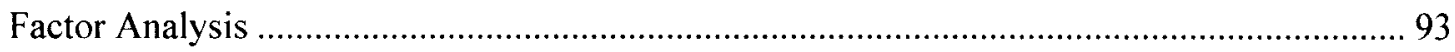

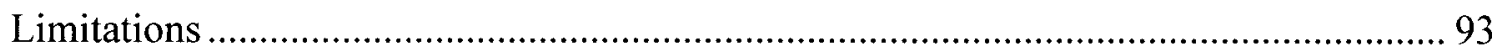

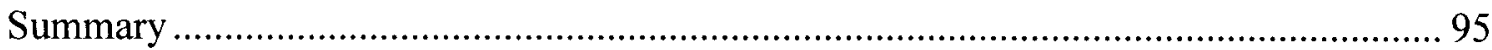

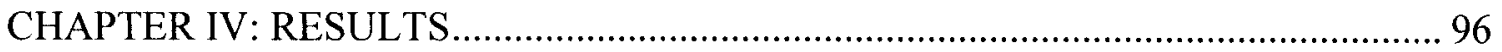

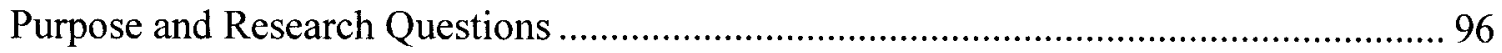

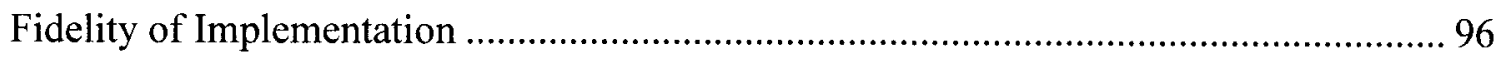

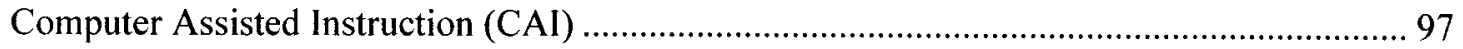


Sample 106

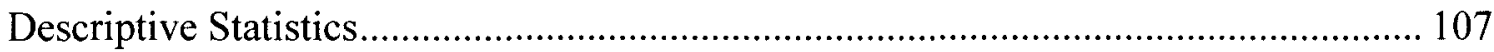

Means and Standard Deviations for Major Variables ......................................................... 108

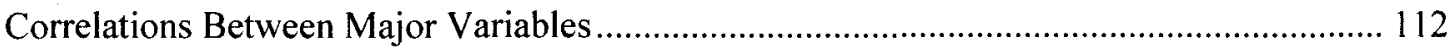

Analysis of Research Questions One and Two ......................................................... 114

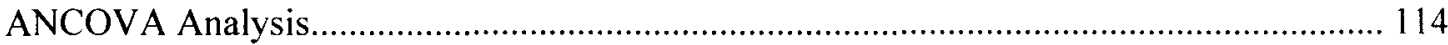

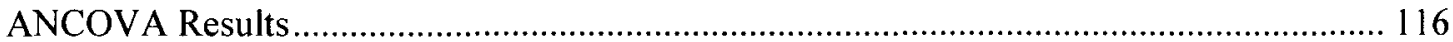

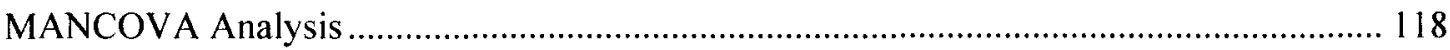

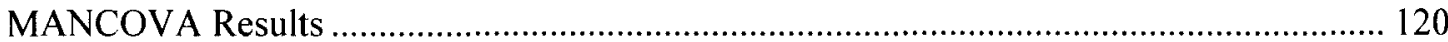

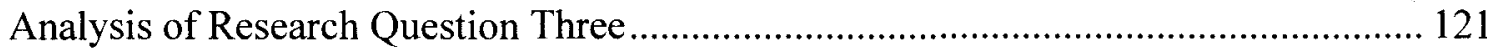

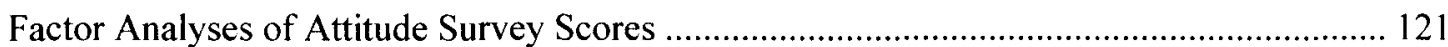

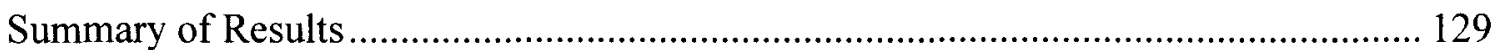

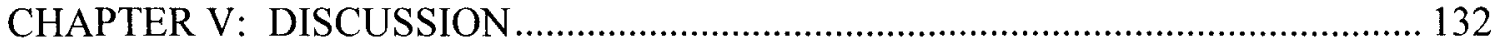

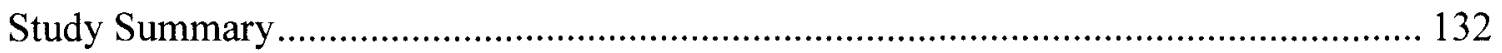

Purpose and Research Questions ............................................................................... 132

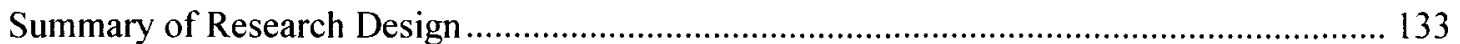

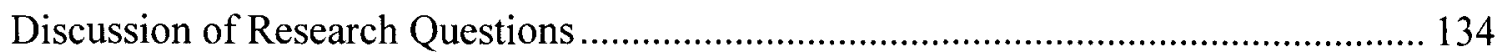

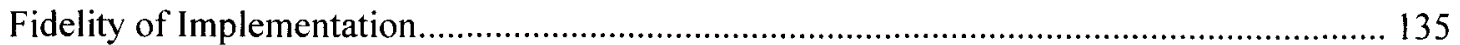

Instructional Type and Mathematics Achievement............................................................. 136

Instructional Type and Attitude Toward Mathematics ...................................................... 139 
Factor Structure for Struggling Student's Attitudes Towards Mathematics

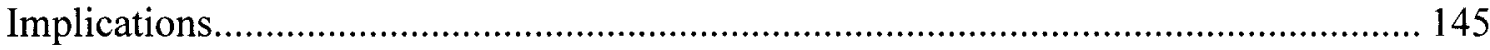

Mathematics Intervention Implementation ..................................................................... 145

Understanding the Struggling Learner .............................................................................. 147

Professional Development ......................................................................................... 149

Intervention and Achievement ................................................................................. 150

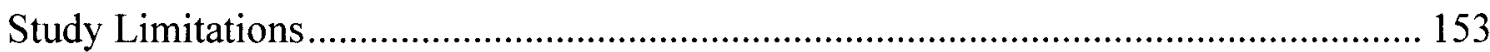

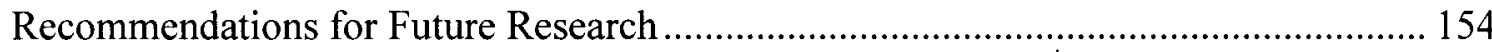

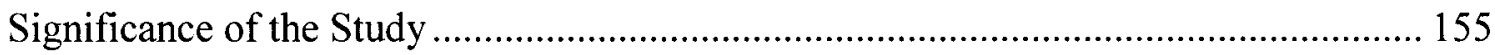

Study Conclusion

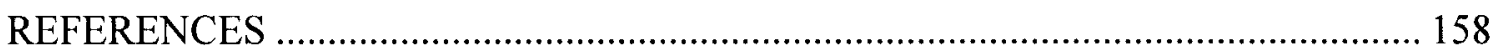

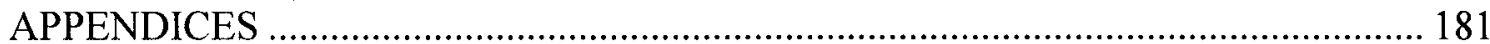

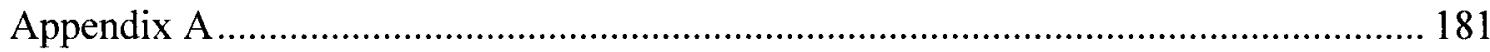

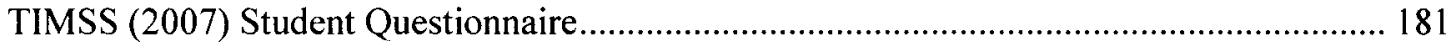

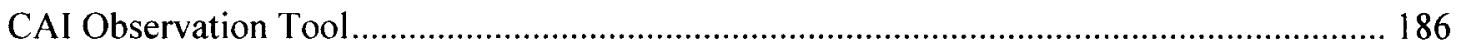

CAI Student-Teacher Interaction Log........................................................................... 187

Structured Curriculum Observations Tool ............................................................................ 191

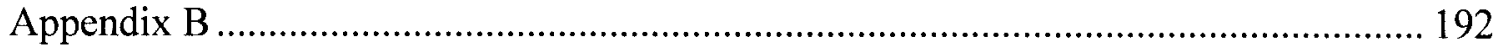

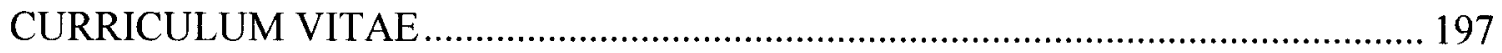




\section{LIST OF TABLES}

TABLE

PAGE

1. Diagram of Intervention Instructional Classes and Estimated Number of SC Lessons and Time Students Used CAI...................................... 86

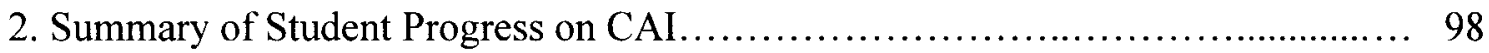

3. Summary of CAI Observations......................................... 101

4. Percent of Type of Interactions Reported by CAI Teacher..................... 103

5. Summary of SC Observations........................................ 105

6. Summary of Number of Students by Instructional Type.................... 107

7. Mean Responses to Computer Comfort-level by Instructional Type............ 109

8. Means and Standard Deviations by Instructional Type for Pre and Post Attitude

Scale.

9. Summary of Means, Standard Deviations, and Correlations for Mathematics

Achievement

10. Means and Standard Deviations for Pre and Post Mathematics Achievement Scores

11. Analysis of Covariance (ANCOVA) for Mathematics Achievement by Instructional 
Type

12. Pre-Survey: Pattern and Structure Coefficients, Communalities, Means, and Standard Deviations for 12 Items

13. Post-Survey: Pattern and Structure Coefficients, Communalities, Means, and Standard Deviations for 12 Items 128

14. Comparison of Pre and Post-Survey Factor Structures to the Literature-Suggested

Factor Structure 


\section{LIST OF FIGURES}

FIGURE

PAGE

1. Diagram of Grade-level Groups....................................... 75

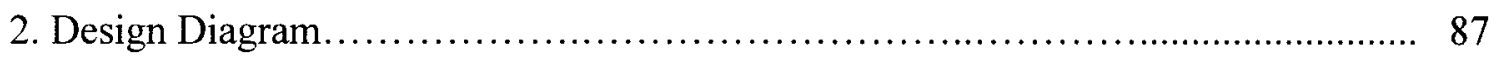

3. Histogram for MAP Scores for CAI Group ......................................... 193

4. Histogram for MAP Scores for SC Group .......................................... 194

5. Histogram for MAP Scores for CAI with SC Group..................................... 194

6. Scatter plot of MAP Pre and Post-test Scores............................................ 195

7. Scatter plot of Pre and Post-mean Scores Overall Attitude Toward Mathematics.... 196

8. Scree Plot for Pre-Survey of Attitude Toward Mathematics................................ 197

9. Scree Plot for Post-Survey of Attitude Toward Mathematics.............................. 197 


\section{CHAPTER I: INTRODUCTION}

\section{Overview}

\section{Problem Statement}

Standards in the United States are increasing and new technologies are changing the way students learn, but U.S.students still struggle in mathematics comparison studies (Education, 2008; Gonzales et al., 2008). The U.S. has a history of low student performance in mathematics compared to student performance other nations. Specifically, the 2007 Third International Mathematics and Science Study (TIMSS) reported that the average mathematics score of U.S. fourth-graders was lower than that in eight other countries, all of which were in Asia or Europe. Meanwhile, U.S. eighthgraders' average was lower than that in five countries, all of them in Asia (Gonzales et al., 2008).

As U.S. schools attempt to improve student performance in mathematics education, the lens has often focued on students who have traditionally been unsuccessful. Therefore schools administratorsseek strategies to build mathematical understanding in their weakest students. Ongoing advancements in technology and excitement about the ways technology can enhance instruction have motivated many school administrators to purchase computer or web-based intervention software. In some cases, technology has been viewed as "the silver bullet" for working with struggling 
learners, and student intervention has often involved an emersion in web-based animated tutoring. Research focused on the use of technology in mathematics teaching and learning is vast and complex. Furthermore, the research related to how technology might support struggling learners is multifaceted. The question of whether (and under what conditions) technology-based instruction is an effective tool for helping struggling learners remains unanswered.

\section{Background}

Many studies examined the teaching and learning of mathematics and, more specifically, how technologies such as Computer Assisted Instruction (CAI) can be used to enhance mathematics instruction (Heid \& Blume, 2008; Jenks \& Springer, 2005; Ku, Harter, Liu, Thompson, \& Cheng, 2007; Slavin \& Lake, 2008; Zbiek, Heid, \& Dick, 2007). Some studies, such as Christmann and Badgett (1997), show that CAI had a small positive impact on mathematics achievement while other studies found the impact to be less impressive (McDermott \& Watkins, 1983). The research, however, concluded that computer-assisted mathematics instruction was at least equal to teacher-lead instruction (Fletcher-Flinn \& Gravatt, 1995) and, in some cases, when combined with conceptuallybased instruction was effective in raising student achievement (Slavin, Lake, \& Groff, 2009). One important finding, however, was that the body of research on CAI is aging and studies conducted in the 1970's, 1980's, and 1990's was far less relevant today due to recent innovations in computer technology. Studies from these earlier years found little evidence that CAI was a superior form of instruction to teacher-lead instruction, but 
these studies were based on the technologies available in those decades, which pre-dated the web and many other technological advances, rendering the findings virtually irrelevant today (Fletcher-Flinn \& Gravatt, 1995; Kulik \& Kulik, 1991; Waxman, Connell, \& Gray, 2002). More recently, CAI has become more sophisticated, with the capacity to personalize instruction using use answer-pattern response programming. Studies based on these more recent CAI have shown positive effects on achievement (Gee, 2008; Kirk, 2003; Manning, 2004), though these did not use control groups or consider identified subgroups of students such as struggling learners.

Recent CAI research focused on different subgroups has had mixed results. In one case, CAI proved to be beneficial in teaching whole-number computation but not effective for basic fact mastery to elementary students (Kroesbergen \& Van Luit, 2003). In contrast, Irish (2002) found CAI was effective in developing fluency and accuracy with multiplication facts for students with intellectual disabilities. Less research targets the use of CAI and students identified as struggling, probably because the term struggling is more ambiguous than identifying a student with a diagnosed intellectual disability. The results, however, are promising in showing that CAI not only improved mathematical skill fluency (Hasselbring, Lott, \& Zydney, 2005; Rasanen, Salminen, Wilson, Aunio, \& Dehaene, 2009) but also attitudes (Reed, Drijvers, \& Kirschner, 2010).

\section{Theoretical Framework}

Recent literature on mathematics interventions provides a lens for how CAI can be integrated into the interventions (Gersten et al., 2009; Heid \& Blume, 2008; 
Kroesbergen \& Van Luit, 2003; Zbiek et al., 2007). Mathematics intervention has been analyzed from two different perspectives, some focusing on components (Fuchs et al., 2008) and others focusing on processes (Rivera \& Bryant, 1992). In order to understand mathematics interventions and the impact of a particular intervention (in this case CAI), this review will consider both components and process. The framework described here provides of layers both components and processes, offering a comprehensive lens from which to consider the impact of CAI.

Components of an intervention model include instructional strategies, opportunities to learn content, and learning environment. The first component, instruction strategies, has received extensive attention in connecting mathematics learning to students with intellectual disabilities. Baker, Gersten, and Lee provided a broad look at effective instructional strategies used for intervention in their 2002 meta-analysis and identified the use of explicit instruction as a key to student achievement. They, and others, define explicit instruction as teacher-lead instruction that intentionally connects concepts and procedures through multiple representations (Baker et al., 2002; Fuchs et al., 2008).

Fuchs and others (2008) argued that explicit instruction alone was not sufficient for supporting students with intellectual disabilities. They defined seven principles for effective mathematics intervention: ( 1 and 2 ) explicit instruction with a strong conceptual base; (3) instructional design to minimize learning challenge; (4) opportunity for drill and practice; (5) cumulative review; (6) motivators to help students regulate their attention and behavior; and (7) ongoing progress monitoring. Within these seven 
principles, CAI could be used to deliver drill and practice opportunities (principle four). Advancements in answer-pattern response have enabled CAI to generate a personalized tutorial experience which tracks progress, in order to minimize learning challenge, and offers cumulative review (principles five, six, and seven). For example, SuccessMaker, a type of CAI, uses answer-pattern response to diagnose and teach based on student responses. If the program diagnoses a deficiency in fluency, the program offers drill and practice on the specific facts. If a student needs additional support with a skill or concept, the program delivers a customized tutorial designed to meet the needs of the learner at his/her current level of proficiency or understanding, minimizing learning difficulty. The program also offers cumulative review of past concepts and skills mastered. Finally, SuccessMaker tracks student progress and produces detailed reports that can be used by teachers for progress monitoring.

Processes are the second important consideration in an intervention model. One goal of an intervention is to develop fluency or mathematical proficiency. Rivera and Bryant (1992) argued that this goal is a developmental process. While effective components must be in place, the focus of the intervention should proceed with an intentional progression. Their framework includes four phases for intervention instruction: (1) acquisition; (2) fluency; (3) generalization; and (4) application. In the acquisition stage, students are introduced to a topic. Then they transition into the fluency phase, which requires modeling, guided practice with frequent feedback, and additional practice. The generalization stage requires students to go beyond fluency, make meaning of concepts, and begin to generalize their understanding across different problems. 
Finally, the application phase requires students to apply their understanding to solve a variety of problems.

CAI provides support for acquisition and fluency with virtual models, guided practice, error monitoring, and frequent feedback. CIA can also guide students through generalization and application.

\section{The Study}

\section{Purpose}

This study focused on understanding how components of a mathematics intervention program affect struggling students. While process was not directly examined, the intervention programs used in this study were designed to address the four phases of intervention instruction discussed above. The purpose of the study was to examine the effects of different instructional types on students' mathematics achievement scores and attitudes towards mathematics. Three instructional strategies were explored:

(1) computer-assisted instruction (CAI); (2) teacher-facilitated explicit instruction using a structured curriculum (SC); and (3) the combination of CAI and SC. The researcher sought to understand the effects that these instructional strategies had on struggling students' performance in mathematics and on their attitudes towards mathematics.

\section{Research Questions and Hypothesis}

Research questions. The following research questions were examined in this study: 
1. Is there a significant effect of instructional type on mathematics achievement?

2. Is there a significant effect of instructional type on mathematics attitude?

3. What is the factor structure of attitude scale scores obtained from the mathematics attitude survey?

Hypothesis. This study tested the hypotheses that combining computer-assisted instruction with a conceptually-based structured curriculum would have positive effects on struggling learners' mathematics achievement and attitudes. This study also sought to determine if CAI alone would positively affect students' attitudes toward mathematics.

\section{Study Design}

This study used a three-group pre/post-test design. The independent variable was instructional type, which consisted of three levels: 1) CAI, 2) SC, and 3) CAI with SC. The independent variables were mathematics achievement and attitude towards mathematics.

\section{Significance of Study}

The results of this study provide important insights into the use of CAI with struggling learners. This research base can be an aid to teacher leaders and administrators in designing mathematics intervention programs that use $\mathrm{CAI}$ in effective ways. In addition, this researach may provide insight into the ways in which struggling learner attiturdes towards mathematics differ from the larger student population and the impact intervention using CAI may have on struggling students' attitudes. Finally, reseach suggests proficiency in mathematics is developed using instruction that emphasizes 
understanding of concepts in conjunctions with procedural fluency (Hiebert \& Grouws, 2007; NRC, 2001) and this study may help explain the role CAI can play in providing a balance of conceptual and procedural mathematics instruction.

\section{Delimitations}

This study was conducted October 2011 through December 2011 in a public school district in Kentucky. The district had a total student population of 98,000 and 24 middle schools, which included students, grades six through eight, ages 11-14.

The sample in the study included students who attended Baxter Middle School. Of the 717 students at this middle school, $66 \%$ were classified as having free or reduced priced lunch. In $2010,30 \%$ of students at Baxter scored below adequate on Kentucky's state test (Kentucky Department of Education, 2010). According to the Kentucky Department of Education (2010), this middle school had demonstrated inadequate performance on state tests consecutively for six years and was classified as Restructuring, a status given to struggling schools.

"Restructuring" schools were required to make documented efforts to improve instruction for all students by developing a plan to intervene with students who struggle in mathematics. Students in Baxter Middle School's intervention program demonstrated gaps in fundamental mathematics skills and concepts that included understanding number concepts, operational meaning, whole number place value development, and whole number computation, measured by Measures in Academic Progress (MAP), a mathematics assessment tool that aligns with Kentucky's state test (Dahlin, 2008). 
The student participants in this study were sixth-, seventh-, and eighth-grade students who received mathematics intervention during the 2011-2012 school year. Teacher participants were those who taught at the middle school during that time and were scheduled to provide mathematics intervention instruction. Teachers were selected based on their willingness to participate in the study and availability to teach one of the treatment groups based on the school's master schedule.

The researcher obtained signed informed consent forms from teachers and parents of the students who participated in the study. Results of the study are generalizable to low-performing middle school students but may not be generalizable to students outside the U.S., elementary students or to high school students.

\section{Definition of Terms}

Procedural Fluency. For this study procedural fluency is defined as skill in carrying out mathematical procedures flexibly, accurately, efficiently, and appropriately.

Conceptual Understanding. For this study conceptual understanding is defined as comprehension of mathematical concepts, operations, and relationships (NRC, 2001).

Computer-assisted instruction (CAI). For this study, CAI is defined as tutorial software designed to diagnose mathematics deficiencies and provide tutorials to teach deficient skills and concepts. The curriculum used was SuccessMaker Enterprise by Pearson. SuccessMaker is a computer-based mathematics intervention curriculum for grades two through eight. It is a supplement to core instruction and aids students in 
learning concepts and practicing mathematics skills presented in previous grades in an effort to facilitate gaining procedural fluency and understanding.

\section{Teacher-facilitated, explicit instruction using structured curriculum (SC).}

For this study, teacher-facilitated, explicit instruction is defined as hands-on lessons where teacher guide students in constructing their understanding of concepts, skills, and procedures, while explicitly helping students make connections to deepen understanding. The curricula used in this study were lessons from Do the Math Now (M. Burns, 2011), a mathematics intervention curriculum. Instructional topics included skill and concept areas identified to be common areas of difficulty according to MAP diagnostic reports from the sample.

Mathematics achievement. For this study, mathematics achievement is defined as grade level equivalency performance on Measures in Academic Performance (MAP) computerized diagnostic assessment.

Mathematics attitude. Attitude towards mathematics is defined as mean responses to TIMSS (2007) Student Questionnaire. The survey consisted of 12 items measuring student attitude towards mathematics in Likert-response format ranging from 1 ("agree a lot") to four ("disagree a lot").

Struggling learner. For this study, struggling learners are defined as students who were in middle school but demonstrated mathematical misunderstanding and used strategies of a typical fourth grader or lower, as measured by MAP. The term struggling learner is used to define students both with and without intellectual disabilities. 
Comprehensive student. Comprehensive students are defined as students who are not identified as struggling or having an intellectual disability. They are students whose academic needs do not require any intervention.

Mathematics intervention. Mathematics intervention is defined in the study as the instructional activities (both teacher-initiated and computer-initiated) that take place during instruction to students on mathematical skills and concepts in which they demonstrate a deficit.

\section{Organization of the Study}

This dissertation is organized into five chapters which include: (1) detailed literature supporting the relevance of the study; (2) description of research design and methodology of the study; (3) explanation of results, and conclusions; (4) implications, and recommendations based on the results. Chapter two provides a relevant review of literature on the topic of the technological trends in mathematics education, the effects of technology on mathematics instruction, and the use of technology and other instructional strategies in mathematics intervention. Chapter three provides a detailed description of the research design and methodology of the study including, descriptive statistics of participants, experiment procedures, instrumentation, data collection, and data analysis and study limitations. The fourth chapter provides analysis and presentation of results, while chapter five provides synthesis of results in explaining implications and recommendations. Finally, a bibliography and appendix concludes this dissertation. 


\section{Summary}

Many studies have examined the use of CAI in mathematics instruction, but few have examined the use of CAI to meet the needs of struggling learners based on researchdefined principles for mathematics intervention. The role CAI plays in mathematics intervention is heavily influenced by the principles of effective intervention (Fuchs et al., 2008; Rivera \& Bryant, 1992). The characteristics of CAI can be matched to characteristics of effective intervention, but CAI cannot meet all of the principles described. Therefore, the role CAI plays in mathematics intervention and how it effects mathematics achievement and attitude should be explored in greater depth.

This study incorporated CAI as a means of delivering explicit instruction, drill and practice, cumulative review to provide a strong procedural base, in combination with teacher-facilitated explicit instruction using a structured curriculum to provide a strong conceptual base. Mathematics achievement and attitude scores of students who received this treatment were analyzed to determine if the combination of CAI with SC served as a meaningful instructional tool for mathematics intervention. 


\section{CHAPTER II: LITERATURE REVIEW}

\section{Introduction}

The United States seeks to be superior in mathematics achievment, and its democratic structure and mantra of equality for all calls for public education to remain free and open to anyone. These goals prompted the U.S. Congress to insitute an education policy that holds all US students to a rigorus academic standard and ensure no child is left behind ("Individuals with Disabilities Education Improvement Act of 2004," 2004; "No Child Left Behind Act of 2001," 2001).

Encouraged by these legislative requirements, state legislators across the country initated reform efforts to focus more specifically on identifying research-based tools and resources to enhance instruction, and make it more accessable to struggling learners. Technology is one of these tools. Principles and Standards for School Mathematics (NCTM, 2000) identified six principles considered "essential components of high-quality school mathematics program," (NCTM, 2000, p. 1). One of these six principles, the Technology Principle, states, "technology is essential in teaching and learning mathematics; it influences the mathematics that is taught and enhances students' learning," (NCTM, 2000, p. 24). 
More recently, the Common Core State Standards Initiative (CCSSI) released a set of eight Mathematical Practices that permeate all mathematics instruction in order to develop mathematically proficient students. One of those Practices is "Use appropriate tools strategically,” (CCSSI, 2010), which states: “...[Mathematically proficient students] are able to use technological tools to explore and deepen their understanding of concepts" (p. 7).

As described in these two curriculum documents, the use of technology is considered an essential component of learning mathematics. However, questions surface about the role technology plays in effective teaching and learning: What impact do various technologies have on low achieving mathematics students both academically and emotionally? How should teachers integrate technology into their instruction to enhance learning?

Research syntheses have addressed these questions. Heid and Blume (2008) noted that while technology is valued in teaching and learning mathematics, how technology enhances student learning and the role it plays in instruction are still areas open to examination. Technology has been found to positively impact mathematics instruction in documented ways, specifically that technology provides enhanced visual representations, flexibility to adapt and differentiate instruction, and ease-of-movement between concrete and abstract representations (Heid \& Blume, 2008). Slavin, Lake, and Groff (2009) reported in their meta-analysis of middle and high school mathematics programs that well-structured cooperative learning curricula and supplemental computer-assisted 
instruction (CAI) may have greater effects on mathematics achievement when combined than by themselves (Slavin et al., 2009).

Some research has focused on the connection between technology use and struggling learners. Kroesbergen and Van Luit (2003), in their research synthesis, reported minimal differences in student achievement when providing mathematics intervention for students with special needs via CAI or teacher-facilitated instruction. More recently, Reed Drijvers, and Kirschner (2010) found that attitude towards computer use was positively related to achievement in lower ability students.

In order to provide context for the study, the research reported here addresses key findings in mathematics education with regard to how student attitude impacts learning and how instructional choices impact student attitude, mathematics education for struggling learners, and technology in mathematics education. Technology in mathematics education, is explored in more detail reporting on research related to: (1) technology as an enhanced mathematical strategy for building procedural skills and conceptual understanding; (2) research reported guidelines for efficient and effective use of technology; (3) the effects of technology on student attitude towards mathematics; and (4) the effects of $\mathrm{CAI}$ on mathematics achievement. Throughout this latter section, connections are made to the broader research topics addressed above.

\section{Curriculum Recommendations in Mathematics Education}

Answering a call for a researched-based foundation for mathematics education, the National Research Council (2001) issued an in-depth analysis of the elements of highquality mathematics instruction. They framed their argument around the idea that "all 
young Americans must learn to think mathematically, and they must think mathematically to learn," (NRC, 2001, p. 2). The NRC defined mathematical proficiency as an integrated balance of:

"(1) conceptual understanding- comprehension of mathematical concepts, operations, and relations; (2) procedural fluency- skill in carrying out procedures flexibly, accurately, efficiently, and appropriately; (3) strategic competence- ability to formulate, represent, and solve mathematical problems; (4) adaptive reasoning- capacity for logical thought, reflection, explanation, and justification, (5) productive disposition- habitual inclination to see mathematics as sensible, useful, and worthwhile, coupled with a belief in diligence and one's own efficacy" (NRC, 2001, p.5).

These five strands of mathematical proficiency expanded and reinforced the Process Standards (problem solving, reasoning and proof, communication, connections, and representations) developed and released by NCTM in 1989 in the Curriculum and Evaluation Standards for School Mathematics and revised in 2000 in the Principles and Standards for School Mathematics. Building on these ideas from the NRC and NCTM, the Council of Chief State School Officers commissioned the Common Core State Standards Initiative, which developed eight Standards for Mathematical Practice. These Practices were created to provide clarity about what mathematics students needed to do order to become mathematically proficient. These Practices are: (1) make sense of problems and persevere in solving them; (2) reason abstractly and quantitatively; (3) construct viable arguments and critique the reasoning of others; (4) model with 
mathematics; (5) use appropriate tools strategically; (6) attend to precision; (7) look for and make use of structure; and (8) look for and express regularity in repeated reasoning.

The fifth Standard for Mathematical Practice, use appropriate tools strategically, highlights the importance of using technological tools such as calculators, computer software, and manipulatives, both concrete and virtual, to represent mathematical concepts. The reciprocal connection between technology, not only as a way of teaching mathematics, but also as a mode of representing mathematical situations is an indication of the potential technology offers in teaching and learning mathematics in the $21^{\text {st }}$ century.

For example in their 2008 report, Foundations for Success: The Final Report of the National Mathematics Advisory Panel, the U.S. Department of Education (DOE) noted that while the nature and strength of significant effects of technology are not consistent, the use of instructional technology has had overall benefits and that instructional technology used with specific populations (e.g., struggling learners) to meet specific goals had a positive impact. One recommendation from this report was that researchers continue to study the effects of instructional technology on student learning, especially with regard to struggling learners.

\section{Research on Attitude in Mathematics Education}

Researchers have found that a student's attitude toward mathematics can influence their performance in mathematics as well as their motivation to achieve. Published empirical studies used part or all of the TIMSS 2007 mathematics attitude items to measure different variables related to attitude (Chiu, 2007; Eklöf, 2007; 
Hammouri, 2004; Wigfield \& Eccles, 2002). Using confirmatory factor analysis, researchers developed the TIMSS (2007) Attitude Questionnaire measures attitude by focusing on three constructs: (1) Self-Confidence in Learning Mathematics; (2) Positive Affect Towards Mathematics; and (3) Valuing Mathematics (Choi, Bush, Hunter, \& Truitt, 2011; Martin \& Preuschoff, 2008; Olson et al., 2008). Self-confidence in learning mathematics is defined by students' attitudes about their ability to "do math". Students' "valuing mathematics" is measured by how important mathematics is to them. Positive affect towards mathematics is defined as students' feelings about mathematics. According to researchers these three constructs (self confidence, valuing, and positive affect) contribute to students' overall attitude towards mathematics (Chiu, 2007; Choi et al., 2011; Eklöf, 2007; Hammouri, 2004; Wigfield \& Eccles, 2002).

Motivation, however, is different than attitude. Middleton and Spanias (1999) define motivation as:

"Reasons individuals have for behaving in a given manner in a given situation. They exist as part of one's goal structures and one's beliefs about what is important, and they determine whether or not one will engage in a given pursuit," (p. 66).

Based on this definition, motivation is related to persons' attitudes about the importance of the pursuit, which, in turn, can be influenced by their confidence in their abilities to achieve the pursuit. The sections below provide a closer look at how the attitude construct described is connected to appropriately challenging mathematical tasks, students' attribution of effort to achievement in mathematics, and how attitude effects academic achievement in mathematics. 


\section{Attitude and Task Selection}

According to a review of research by Middleton and Spanias (1999), students' negative attitudes toward mathematics can be explained by lack of teacher support and a negative classroom environment. They suggest that (1) attitude is learned, (2) students generally learn to dislike mathematics, and (3) this dislike becomes an integral part of their mathematical self-concepts. Attitudes are pliable and teachers have the power to mold and change student attitudes.

Their synthesis also revealed that, for students to become more motivated to achieve, they must have opportunities for success. When students experience success in mathematics, their confidence in mathematics improves (J. Middleton \& Spanias, 1999) and their overall attitude toward mathematics then improves (Choi et al., 2011; Martin \& Preuschoff, 2008; Olson et al., 2008). Success in mathematics can reinforce positive feelings about students' abilities to do mathematics making them more willing to engage in more mathematics because they expect to be successful.

When students are interested, they will not only engage more, but their feelings about mathematics tend to improve, demonstrated by their enjoyment in tasks with which they are successful. Marsh, Trautwein, Köller, and Baumert's 2005 longitudinal study of over 600 seventh-graders showed that positive experiences with, interest in, and valuing of a task contributed to positive feelings toward the task. Just as confidence contributes to attitude, a student's positive feelings about mathematics also contribute to more positive attitudes, thus improving motivation. On the other hand, students show a decline in motivation when they feel they cannot be successful with a task (Dickinson \& Butt, 
1989).

If students realize that their successes are meaningful and result both from their abilities and from a high degree of effort, they are likely to believe that they can do mathematics if they try (Relich, 1984). This belief places great importance on the tasks that the teacher chooses because the amount of value the person assigns those tasks in which they are successful plays a significant role in how success with that task impacts the person's attitude. In order to best improve attitudes, tasks should offer the appropriate level of challenge for each student (Brophy, 1998).

\section{Effort and Achievement}

Researchers note that students in earlier grades typically have more positive attitudes towards mathematics than students in middle grades (Eccles, Wigfield, \& Schiefele, 1998; Wigfield et al., 1992; Wigfield \& Tonks, 2002). Wigfield and Tonks's (2002) Development of Achievement summarized research findings on the development of children's beliefs about ability, success, and achievement related to mathematics and how those beliefs changed over time. They reported that some students begin to differentiate ability for different content domains as early as kindergarten and by sixth grade, many students begin to perceive mathematics as a subject area only accessible to "smart" students. This finding has severe implications for students who struggle in mathematics. Over time, they attribute their lack of success to lack of ability and their attitudes toward mathematics declines. Students who experience failure in mathematics tend to greatly dislike mathematics (Eccles et al., 1998; Hammouri, 2004; Kloosterman, 1988; J. Middleton \& Spanias, 1999; Wigfield \& Tonks, 2002). 
Negative attitudes toward mathematics are problematic, not only because of emotional consequences, but also because of the potential for poor academic achievement. Variables that contribute to attitude toward mathematics such as a student's self confidence in learning mathematics and valuing of mathematics are positively correlated with academic achievement (Chen \& Stevenson, 1995; Green, Nelson, Martin, \& Marsh, 2006; Guay, Marsh, \& Boivin, 2003; Marsh, Trautwein, Köller, \& Baumert, 2005). For example, in a study of more than 3000 Jordanian eighth graders who took the TIMSS 1999 Attitude Questionnaire, mathematics attitude $(r=$ $0.21, p<0.05)$, confidence $(r=.34, p<0.05)$, and perceived importance of mathematics $(r=0.24, p<0.05)$ were shown to be significant predictors of mathematics achievement (Hammouri, 2004). Mathematics attitude, confidence, and perceived importance of mathematics were positively correlated with mathematics achievement, and these variables share a significant amount of variance with motivational variables.

Attitude toward mathematics has significant effects on the emotional and academic success of students, and this finding is true across grade levels. It becomes increasingly important for students who already have a poor image of their mathematical abilities. More importantly, teachers have the ability to influence students' attitudes by providing opportunities for success with meaningful and challenging tasks. Teachers can also influence attitudes by creating learning environments that honor student effort and ideas over perceived innate ability (Saphier, Haley-Speca, \& Gower, 2008).

Understandably, teachers have great power in influencing academic achievement because with each of these ideas in place, one can infer from research that student 
attitudes can improve, which in turn improves academic achievement (Chen \& Stevenson, 1995; Dickinson \& Butt, 1989; Eccles et al., 1998; Hammouri, 2004; Kloosterman, 1988; J. Middleton \& Spanias, 1999; Midgley, Feldlaufer, \& Eccles, 1989; Norwich, 2007; Wigfield \& Tonks, 2002). This finding has important implications for working with struggling learners because it suggests teachers have power in improving struggling learners attitudes towards mathematics, thereby improving struggling learners' achievement in mathematics. The next sections explore in more detail the specific needs struggling learners have and what research reports to be effective for improving their academic achievement.

\section{Struggling Students and Mathematics Intervention}

As noted earlier, the NCTM, NRC, and the CCSSI identified content and mathematical processes that result in mathematical proficiency. However, less is known about how to reach these goals, especially for struggling learners. Students who struggle with mathematics are not only students with learning disabilities, and students may not always struggle with the same mathematics topics or require the same level of intervention. This section provides an overview of research on mathematics intervention for struggling learners. It addresses both non-instructional and instructional interventions and the proposed effects of these interventions in mathematics education.

\section{Non-instructional Interventions}

Non-instructional interventions include strategies that support students, but are not directly related how the bulk of instruction is delivered. For example, a teacher may 
choose to use peer assisted tutors as a strategy for re-enforcing a skill or concept with the innitial instruction on that skill or concept delivered by the teacher. A synthesis of research on interventions for low-achieving mathematics students by Baker, Gersten, and Lee (2002) outlines four factors in successful intervention: a) providing student performance data to students and teachers; b) using peers as tutors; c) providing specific reports of student progress and needs to parents; and d) explicit instruction of mathematics concepts and procedures. Factors a) and b) are "non-instructional," whereas b) and d) are instructional.

One key to improved academic performance with struggling students is having students and teachers actively participate in analyzing student performance and setting goals. Fuchs, Fuchs, Hamlett, Phillips, and Bentz (1994) found that students of teachers who received weekly student performance data from computerized tests achieved more than students of teachers who monitored student progress using their own techniques. Furthermore, students of teachers who received specific recommendations for instruction showed greater academic achievement. The researchers concluded that when teachers and students are provided with computer-generated performance data and specific recommendations, mathematics intervention is more successful (Fuchs et al., 1994; Fuchs et al., 1997).

On the other hand, success with goal setting based on student data may be limited to teacher analysis and may not be beneficial for students with intellectual disabilities. Gersten and others (2009) found that students with intellectual disabilities displayed little 
benefit from goal setting based on their own performance data, which was probably due to the abstract nature of goal setting and long-term attainment.

Peer assisted learning is another factor in successful mathematics intervention. Baker, Gersten, and Lee (2002) reviewed six studies where struggling students interacted with peers in a structured way to learn mathematics concepts and practice skills. They noted that one advantage to peer tutoring is that struggling learners tended to have many questions and needed individual support while working problems. Peer tutors provided struggling students support, can answer questions, and encourage the struggling learner, freeing the teacher to monitor whole group progress and work individually with students. The studies reviewed found that peer tutoring had positive effects on struggling learners' computation skills, but results were not as conclusive with regards to struggling learners' conceptual understanding. In contrast, in a more recent meta-analysis, peer tutoring showed little positive effect on mathematics achievement of students with intellectual disabilities (Gersten et al., 2009). These mixed results may be due to the fact that peer tutoring works differently in different conditions, but not all conditions. For example, if teachers did not have structures in place to support peer tutoring, students may not have used the time productively.

In summary, findings indicate that effective non-instructional interventions include teacher-use of student performance data, the use of peer-tutors and, to a lesser extent, student goal setting and parent involvement. The use of student performance data has implications for this study because technologies make data collection and analysis more efficient. 


\section{Instructional Related Interventions}

Most interventions are embedded in instruction, and the type of intervention used with struggling learners matters. Baker and others (2002) found seven studies that examined the use of explicit instruction, contextualized instruction and practice, or a combination of explicit and contextualized instruction. Explicit instruction is an approach in which the teacher is very intentional and structured in helping students learn concepts, rules, and problem-solving strategies. Explicit instruction usually includes methods that assist students with a particular strategy and provide extensive use of visual representations (Ketterlin-Geller, Chard, \& Fien, 2008). Contextualized instruction focuses more on real-world applications and more open-ended problem solving.

According to the analysis by Baker and others (2002), explicit instruction proved to be most effective in raising student achievement with an effect size of 0.58 , meaning that the relationship between explicit instruction and higher student achievement was positive and strong. Contextualized instruction yielded an effect size of 0.01 , virtually zero, but possible language barriers raised questions about how to interpret the results. For example, studies on contextualized instruction focused heavily on real-life problems, and students with language difficulty or low reading levels might not have been able to overcome these barriers to succeed in mathematics.

Contextual problems that focused on conceptual understanding through visual representations yielded positive results in student's conceptual understanding, but low achievement on computation. Researchers noted significant time must be allowed for the conceptual understanding to develop into strong computational performance (Bottge \& 
Hasselbring, 1993; Woodward, Baxter, \& Robinson, 1999). In fact, in their review of research connecting teaching practices to student learning, Hiebert and Grouws (2007) found that teaching promoting conceptual development also leads to increased procedural fluency. They also found that students who mastered skills after conceptual development were better able to adapt their skills to solve new kinds of problems. In other words, conceptual understanding allowed them to be flexible in their thinking about how and why procedures worked which lead to procedural mastery.

Other researchers have found no statistical differences between intervention groups who received an explicit approach versus a discussion-oriented, contextualized approach (Ketterlin-Geller et al., 2008; Kroesbergen \& Van Luit, 2005). These findings suggest that the use of explicit and contextualized instruction may depend more on the specific students and their instructional needs (Ketterlin-Geller et al., 2008).

Additionally, small improvements in academic achievement were found when students received explicit instruction on problem-solving strategies before working more complex problems (Bottge \& Hasselbring, 1993; Fuchs, Powell, Seethaler, Cirino, et al., 2010), suggesting that low-achieving students need a solid foundation in mathematics and clear strategies before success can be realized with contextual problem-solving. As research suggests, contextualized instruction is still a "complex puzzle" (Baker et al., 2002, p. 66), and more research combining the best aspects of contextualized instruction and explicit instruction is needed.

Other researchers have expanded the work of Baker, Gersten, and Lee. In 2007, Maccini, Mulcahy, and Wilson completed a review of 23 articles published from 1995 to 
2006. Their conclusion built on the key components identified in Baker, Gersten, and Lee's (2002) meta analysis, and added that effective intervention should include strategies that help students acquire and generalize mathematics concepts and skills (Scarlato \& Burr, 2002), graduated instructional sequencing to move students to abstract thinking (Maccini \& Ruhl, 2000), and teach for understanding (Y. P. Xin, Jitendra, \& Deatline-Buchman, 2005). However these findings focused mostly on intellectually disabled students, and little research on struggling learners who may not have an intellectual disability existed.

Another gap in the research on intervention is the role that technology plays in helping struggling learners. In one study conducted by Woodward, Baxter \& Robinson, (1999) technology was used as explicit instruction. This study examined the effects of conceptual versus technology-enhanced procedural instruction in intervening with eighth and ninth graders. The technology used for explicit instruction was a series of video lessons where students watched a tutorial that explicitly explained procedures then completed a set practice problems. The use of this relatively new instructional medium may have impacted student achievement in the explicit instruction group making explicit instruction look more appealing than contextualized instruction. While other studies examined the use of computer technology to teach struggling learners (reviewed in a later section), this study was the only one that used technology for the purpose of explicit instruction. Consequently, this area of research seems to require more study especially since computer technology is frequently used as a replacement for instruction (explicit instruction) with struggling students. 


\section{Learning and Achievement}

Building mathematical proficiency in struggling learners is a complex process that requires attention to how children learn mathematics in general and difficulties struggling learners face. Instructional delivery should be explicit in scaffolding procedures while providing a strong conceptual base for students to make connections and contextualize their understanding. In 2008, Fuchs and others synthesized current research on interventions with struggling mathematics students and developed seven principles of effective practice. These seven principles not only summarized the work of previous researchers but also provided a framework for providing instruction for struggling learners. The seven principles include: ( 1 and 2 ) explicit instruction with a strong conceptual base; (3) instructional design to minimize learning challenge; (4) opportunity for drill and practice; (5) cumulative review; (6) motivators to helps students regulate their attention and behavior; and (7) ongoing progress monitoring.

The third principle is particularly complex and should not be interpreted as making mathematics easy for students but rather providing opportunities for students to easily make connections and bridge understanding. To do this, Rivera and Bryant (1992) suggested that struggling students should move through four phases of instruction: acquisition, fluency, generalization, and application. The phases discussed previously on mathematics proficiency and effective mathematics intervention are apparent in Rivera and Bryant's framework with: 1) the acquisition phase closely resembling explicit instruction; requiring modeling, guided practice and frequent feedback, and additional practice; and 2) the generalization, and application phase resembling a more 
contextualized approach (Rivera \& Bryant, 1992).

Based on Fuchs and others (2008) and Rivera and Bryant's (1992) frameworks, and the expectation that technology be integrated to enhance mathematics instruction (CCSSI, 2010), this study seeks to examine the role technology can play in enhancing the seven principles, enabling students to move through the developmental process Rivera and Bryant described to achieve proficiency.

Technology has the potential to address elements of both frameworks. Technology can offer explicit instruction connecting concepts to skills through enhanced representations, providing a transition from acquisition to application. Using diagnostic software, technology can minimize unnecessary learning challenges by tailoring instruction to the learner. Technology can provide skill practice with built-in error feedback and cumulative review and ongoing progress monitoring. Evidence also exists that technology may impact student attitudes, motivating them to stay on task. The next section discusses the role technology can play in enhancing mathematical representations to teach procedural fluency and mathematics concepts. Later sections will discuss how technology can potentially positively impact student attitude towards mathematics and achievement.

\section{Technology in Mathematics Education}

Research on technology use in mathematics learning abounds, beginning in the early seventies through today. Over 250 studies connecting technology use and mathematics learning were initially identified. Because this study seeks to examine the effects of CAI on low performing mathematics students, studies were excluded if they 
discussed calculators, document cameras, or software that did not directly teach mathematics content such as digital movie programs and interactive whiteboards. Studies that examined the use of CAI, virtual manipulatives and applets, animated tutoring, microworlds, and procedural response and how they relate to student mathematics achievement, student attitudes towards mathematics, and mathematics instruction are reported in this section.

When computers were first developed in the 1960's, researchers marveled at the possibilities. The researchers asked questions about the role technology could play in education: "Can computers actually teach students?" "Can computers do it better than humans?" (Kaput, 1985; McCollister, Burts, Wright, \& Hildreth, 1986; Palmer, 1973). Research over the last 40 years concluded that while technology has enhanced the way we teach mathematics, it has not replaced the expertise of an effective teacher (Bitter \& Hatfield, 1998; Cooperstein \& Kocevar-Weidinger, 2004; Driscoll, 2002; Guerrero, Walker, \& Dugdale, 2004; Kaput \& Pattison-Gordon, 1987; Ozel, Yetkiner, \& Capraro, 2008; Wenglinsky \& Educational Testing Service, 1998).

However, in an ever-expanding, technology-rich world, mathematics educators must recognize technology as an essential tool for learning and teaching mathematics. Technology has become an integral part of mathematical problem solving both in the classroom and workplace; teachers must tap into this medium not only to enhance instruction but also prepare students for the future. 


\section{Technology as an Enhanced Representation of Mathematics}

Research in mathematics education reveals that for students to have a deep understanding of mathematics, they must not only understand computational processes but also the underlying concepts that lead to different approaches and alternative strategies to solve problems (NRC, 2001). Mastery of mathematics is demonstrated by an individual's ability to understand, connect, and represent a concept through multiple representations: symbols, pictures, language, context, and concrete examples (NCTM, 2000). Cognitive research on the development of fluency in mathematics indicates that students who have difficulty performing and understanding computations are the same students who have difficulty moving between representations (Lesh, Post, \& Behr, 1987). As Heibert and Grouws (2007) discussed, emphasis on conceptual understanding leads to improved procedural fluency. Across numerous studies, technology has been found to help students mentally develop abstract concepts and ideas, move through multiple representations more quickly and efficiently to solidify mathematics understanding (Heid \& Blume, 2008; Kaput, 1985, 1986; Kaput \& Pattison-Gordon, 1987; Nguyen, Hsieh, \& Allen, 2006; Zbiek et al., 2007).

Just as mathematics instruction can be classified as procedural or conceptual, instructional technologies can also be categorized in the same way. Technologies that focus on mathematical actions and procedures were classified as procedural. Whereas, technologies that focus on understanding concepts, communicating, making mathematical connections, and reasoning were classified as conceptual. For this study, computer-based programs that focused on procedural fluency and computation were classified as 
procedural while applets and virtual manipulatives used by students in representing mathematical concepts and generalizations were classified as conceptual.

Virtual manipulatives and interactive applets give students new ways to express their understanding of abstract concepts and enable students to move through multiple representations more quickly and develop a strong conceptual base. The use of technology, as compared to concrete manipulatives, motivates many students to stay on task, which allows them to concentrate on conceptual knowledge because they are not focused solely on computation or organizing and managing concrete manipulatives, (Reimer \& Moyer, 2005). Virtual applets allow students a clean, organized, easy-toaccess space for working through concepts. Additionally, virtual manipulatives and applets are accessible at home and in other classrooms where concrete manipulatives may not be. Many engaged in research and teaching with technology argue that the use of virtual manipulatives (i.e., tools) can greatly enhance mathematics learning; virtual tools help students build a concrete understanding for abstract concepts and develop strong foundations for conceptual growth (Bruner, 1969; Kaput \& Pattison-Gordon, 1987; Reimer \& Moyer, 2005).

Technology and conceptual understanding. The majority of research on technology and conceptual understanding focuses on virtual manipulatives and use of applets. Two studies focused on general conceptual understanding (rather than a specific topic). Clements and Sarama (2000) found that virtual manipulatives help elementary students transition from relying on hand-held objects to more abstract thought-processes. As discussed in previous sections, this transition is a key component for influencing 
academic success with struggling mathematics students (Rivera \& Bryant, 1992). Taylor, Pountney and Malabar (2007) examined the effects of computer animation on undergraduate students to see if it helped students visualize what happens during a mathematics process. In other words, did computer animation aid students in reaching a more abstract conceptual understanding of mathematics? Undergraduate students reported finding the animation more useful than the static version of the concept. The researchers concluded "mathematics can be perceived as being a difficult subject to learn due to the conceptual leaps required to understand particular topics," (p.1) and argued that computer animation, such as virtual manipulatives, can aid students in obtaining sufficient imagination of abstract ideas. Many other studies have focused on conceptual understanding of particular content, each of these is reviewed below, sorted by content area.

Virtual rational number representations. Reimer and Moyer (2005) found that the use of virtual manipulatives produced statistically significant improvements in students' conceptual knowledge of fractions. In their study, 19 third-grade students were initially exposed to fraction concepts with concrete fraction manipulatives and later taught using virtual versions. Students took a pre-test for conceptual understanding after the first series of lessons using concrete manipulatives, and then took a post-test after using the virtual versions. The class pretest average $(60 \%)$ rose to $69 \%$ on the posttest, which was significantly higher $(M=11.0, S D=3.61)$ than on the pretest $(M=9.58, S=4.53)$, $t(18)=2.05, p<0.05$. It was also reported that the virtual manipulatives: (a) helped students in this class learn more about fractions by providing immediate and specific feedback; (b) 
were easier and faster to use than paper-and-pencil methods, (c) enhanced student enjoyment while learning mathematics.

The results of this study, however, should be interpreted with caution due to weak design. First, there was no control group used to measure effects against so it is unsure if the virtual manipulatives affected achievement or if students performed better simply due to more time with the content. Second, the researcher used teacher-made tests to measure conceptual and procedural performance and reported no evidence of reliability or validity of scores. Finally, no analysis was done on subgroups in the class. As the researchers pointed out, little research exists on the effects of virtual manipulatives and while this study contributes to the body of research, a need for research on this topic remains, specifically related to the effects on subgroups such as students with difficulty in mathematics.

One advantage of virtual manipulatives and computer programs is the greater number of patterns available and the creative ability a student needs to express or interpret those patterns using virtual mathematics programs. Olive and Lobato (2008) reviewed five projects that integrated technology into instruction on elementary and middle school students' learning of fraction concepts. Their analysis led to several significant findings with regards to technology's role in teaching and learning rational numbers. First, use of technology can aid students in the progression from whole number to rational number reasoning because virtual manipulatives enabled students to construct and demonstrate actions, such as disembedding. These actions cannot be conducted with static pictures or concrete manipulatives. Second, technology integration can lead to the 
construction of richer fraction representations than those typical of instruction without technology. Third, use of technology can provide insights into what students understand related to rational numbers. For example, Steffe's fraction construct and learning trajectories were informed by an analysis of student's interactions with a fraction applet (Olive \& Lobato, 2008; Steffe, 2004). The virtual applet enabled Steffe to observe discrete traits evident in a child's progression from whole number to fractional reasoning as they used a virtual fraction bar, traits that were not observable when students used concrete manipulatives or pictures. In one case, the child was able to explain and demonstrate the process of disembedding, or "imaginatively pulling out a fraction from the whole while keeping the whole intact and unaltered," (McCloskey \& Norton, 2009, p. 46). Without the use of virtual manipulatives, teachers would not have seen students perform this skill.

The research synthesis of Olive and Lobato (2008) on teaching rational number concepts using technology revealed limitations and challenges in using technology to support conceptual development. First, applets place more demand on the teacher than intended and sometimes lead to the development of inappropriate strategies when students are not well monitored. Computer applets and related feedback can be too structured or too frequent and thereby limit problem solving. They explain that the purpose of virtual representations is to support the construction of knowledge and foster active student participation and interactions with virtual manipulatives must allow this to occur. 
Virtual geometry representations. Geometry is perhaps the most obvious area for integrating technology because of its visual nature. Moyer and Bolyard (2002) describe the benefits of using virtual manipulatives to move students through Van Hiele's (1997) five levels of geometric thinking. Computer tools for geometry typically have fewer constraints than those used for whole number and rational number development, due to their resemblance to physical tools, (Van de Walle, Karp, \& Bay-Williams, 2010). Two advantages are the ability to construct geometric figures with precision and ease and that the use of computer environments aid students in connecting symbolic and visual representations. In fact one of the first mathematics computer applets was one in which students directed movements on a screen to draw figures and create paths. These simple programs enhanced geometry for elementary students (Clements \& Sarama, 1995; Clements, Sarama, Yelland, \& Glass, 2008, p. 142). As time passed more dynamic geometry software was created, and applets contained features that could record student work and even play back construction of shapes. According to Clements, Sarama, and Glass' (2008) synthesis of research on technology used in teaching geometry, these features helped students bridge the action of constructing geometric figures to the symbolism that described geometry figures. Additionally, this play-back feature acted as a form of feedback for the student and error analysis for the teacher, providing a window to student's mathematical thinking (Clements et al., 2008). Just as with rational numbers, virtual manipulatives can provide access to students' geometric thoughts, and help students create representations for ideas that may be difficult to construct with paper and pencil. 
Virtual algebra representations. Algebra can present significant barriers for students during their mathematical development because it involves abstract concepts that are often difficult to connect to concrete representations. Just as with number and geometry, researchers have found that computer-based technology can help students in understanding algebraic concepts and mastering algebraic procedures.

Studies showed that using CAI for supplemental algebra instruction with middle and high school students had positive effects on achievement and attitude (Bassoppo-Moyo, 2010; Hegedus \& Kaput, 2004; Nicaud, Bitta, Chaachoua, Inamdar, \& Maffei, 2006; Tatar et al., 2008). Specifically, Bassoppo-Moyo, (2010) examined the effect of CAI, used as a supplement to traditional classroom instruction, on students' understanding of selected algebra concepts. The high school students in this study received supplementary instruction on factoring, radicals and simple quadratics expressions delivered via CAI. Through a mixed methods design, Bassoppo-Moyo (2010) revealed students' attitudes and achievement levels were significantly and positively impacted. Specifically, they reported significant differences between pre and posttests $F=3.00, p<0.05$ and concluded that the CAI positively affected achievement. After conducting student interviews and administering student questionnaires, they reported over $87 \%$ of the students reported liking mathematics and they intended to study it in future. Bassoppo-Moyo (2010) results were similar to Hegedus and Kaput (2004) and Nicaud and others (2006) who reported high levels of engagement as students interacted with software to improve algebraic reasoning.

Based on an extensive review of literature, Heid and Edwards (2001) reported that 
computer use for teaching algebra concepts facilitated student access to algebra representations for even the most complex situations and allowed students to "see" more exact answers. In addition, they argue that computers offered "specific opportunities for the development of symbolic understanding, affording students with the opportunity and motivation:

- to see that different symbolic expressions provide different information (a notion illustrated in the section that follows);

- to outsource routine work to the CAS so that they can focus on more conceptual ideas, on the "bigger picture," or on more general ideas;

- to reason with confidence about symbolic results (possibly reducing students' anxiety over "making mistakes");

- to develop their own symbolic procedures;

- to bridge the gap between concrete examples and abstract generalization;

- to interpret information gained through one representation in an equivalent one (to see the symbolic in the graphic, to see the graphic in the symbolic, to visualize a contextual situation symbolically);

- to develop generalized rules for problem solving; and

- to examine symbolic patterns (more concretely)" (Heid \& Edwards, 2001, p. 129). Even young children can begin to understand algebra concepts when using virtual pattern blocks and applets that represent a balance (Clements \& Sarama, 2000; Van de Walle et al., 2010). 
In summary, technology can enhance representations across content strands and serve as a useful instructional tool for developing conceptual understanding. A void in this research is a focus on subgroups of learners (e.g., low performing students, gifted students) and the impact of technology on their conceptual understanding. Ainsworth, O'Malley, \& Wood (1998) found that a computer program COPPERS could contribute to student's development of multiple solutions for multiplication problems and translated into better performance for lower-performing students. In Pierce, Ball and Stacey's (2009) reported that while using CAI can aid students in connecting symbolic and graphical representations, teachers believed using the programs mostly benefited their high ability students. Given the literature that reports gaps in conceptual understanding of struggling learners, more research is needed to identify the way in which technology can support the conceptual understanding of struggling learners.

Technology and procedural knowledge. The line classifying procedural and conceptual technologies is not always clear or straightforward. In their synthesis of research on technology in mathematics education, Zbiek, Heid, and Blume (2009) argued that the manner in which technology is used plays a large role in how it is classified. They also noted a benefit to using technology is that students can move more quickly through representations and build deeper conceptual understanding because they are not hampered by tedious computations. However, others use that same point to argue that the use of technologies to teach mathematics undermines procedural fluency (Guerrero et al., 2004). Specifically, Heid and Blume (2008) noted that the use of spreadsheets or computer applets that treat functions as objects can "both limit and expand opportunities 
for conceptualizing algebra," (p. 93). Since technology has made learning mathematics easier, (e.g., solving equations) researchers suggest that mathematics curricula must also shift to focus on skills needed in the $21^{\text {st }}$ century (e.g., to shift from equation solving to mathematical modeling) (Heid \& Blume, 2008; Zbiek et al., 2007).

In the 1970 s, computerized drill and practice games became popular for learning basic number facts and, while research showed positive student and teacher attitudes toward the programs, few student achievement gains were found (Palmor, 1973). Studies in the seventies and eighties were largely comparison studies that focused on whether use of CAI had an impact on basic computation skills (Emihovich \& Miller, 1988; Howell, Sidorenko, \& Jurica, 1987; McDermott \& Watkins, 1983; Mevarech, 1985; Palmor, 1973). The technology available then was significantly different in these studies than it is today.

Even in 2010, the results of research on CAI in basic computation skills tended to be inconsistent and inconclusive in terms of improved academic achievement (Christmann \& Badgett, 1997; Fletcher-Flinn \& Gravatt, 1995; Jenks \& Springer, 2005; Lin, Podell, \& Tournaki-Rein, 1994; Mintz, 2000; Podell \& et al., 1992; Rasanen et al., 2009; Seo \& Bryant, 2009; Slavin \& Lake, 2008; Tienken \& Maher, 2008; Tsung-Yen \& Wei-Fan, 2009; Tucker, 2009). However, research on types of technology that enhanced procedural understanding reported that symbolically driven programs can positively impact procedural fluency when used in conjunction with other conceptually-based practices (Baker et al., 2002; Slavin et al., 2009). 
One benefit of using technology for procedural understanding is the instant feedback a computer applet can provide for students and teachers. Feedback during multi-step procedures can help prevent misconceptions or incorrectly learn procedures, (Nguyen et al., 2006; Suh, 2010). Additionally, reports of errors made during computation processes provide teachers with diagnostic information about specific algorithm steps in which students need support (Gerber, Semmel, \& Semmel, 1994). As noted above, struggling students perform better when teachers and students use diagnostic information to inform instruction (Fuchs et al., 1994; Fuchs et al., 1997).

Another benefit of using CAI for mathematics instruction is the vast number of tasks available instantaneously for practice and providing the opportunity for students to test the generalizability of algorithms across many different types of problems. Clements and Battista (2001) suggested that structured computational activities allow students to facilitate symbolic descriptive answers. Additionally, Zbiek, Heid, and Blume (2007) argued that symbolic technological programs enhance student understanding of calculations when the program is used after extensive conceptual understanding has been developed.

Students also recognize the benefit of a clear and organized symbolic environment in developing their computational stills. Nguyen, Hsieh, and Allen (2006) found that students felt the use of web-based skills practice applets made learning more fun because lessons were easy to read, more colorful, and highlighted with tables and charts providing an instantaneous link to multiple representations. 
Technology provides a medium for representing mathematics and can aid in the development of both conceptual and procedural knowledge. Research on conceptual understanding suggests that virtual manipulatives and animation can aid students in moving from concrete to abstract thinking, helping them to connect dynamic, visual representations to symbols and context (Heid \& Blume, 2008; Reimer \& Moyer, 2005). Similarly, research on procedural mastery indicates that computer-assisted skill practice can aid students in making generalizations about algorithms, and help students develop procedural fluency by providing instant feedback and practice on targeted weaknesses (Clements et al., 2001; Nguyen et al., 2006; Suh, 2010). Across these studies, findings were often mixed, which is an indication that the way in which technology is used may determine whether it is effective. It is important, then, to consider how technology is used in instruction.

\section{Effective Integration of Technology in Mathematics Instruction}

Technology can play a role in enhancing mathematical thinking, student and teacher discourse, and higher-order thinking by providing the tools for exploration and discovery (Bitter \& Hatfield, 1998). Research has revealed that using computers for higher-order thinking has a positive effect on achievement, but using computers for just drill and practice, a lower-order skill, has a negative effect on academic achievement (Wenglinsky \& Educational Testing Service, 1998). This suggests that technology itself positively affects academic achievement, but it depends upon how the technology is used. This section will explore the different instructional approaches in using technology to improve student achievement. 
Instructional technology is defined as mechanical, technical, or electronic tools that may be used to improve the learning environments in mathematics classrooms (Johnson, 2005). This definition of technology emphasizes technology as a tool and resource, which suggests that the way technology is implemented in a learning environment can improve learning outcomes. A common thread in the research presented above is that when technology is integrated in problem-solving environments and used to make meaning in mathematics, student improved achievement is realized.

As technology first became widely available in the 1980's, Becker and others (1990) conducted a large, two-year nationwide study with the intention of providing a detailed credible look into the effects of computer use in the mathematics classroom. The study explored mathematics instruction in grades five through eight in more than ninety classrooms. They found that mathematics teachers were less likely than English teachers and elementary teachers to use computers on a regular basis to support student learning. Both elementary teachers and mathematics teachers who used computers were most likely to use them for skill remediation through games. Bitters and Hatfield (1998) reported that computers were often an add-on used when time permitted. It was not consistently used to support a meaningful approach to learning. These studies, though somewhat dated, indicated that much inconsistency in how computers were used in mathematics classrooms was evident.

More recently, research has focused on connecting the quantity of computer-use to student achievement. For example, Middleton and Murray (1999) conducted a study of 107 teachers and scores from over 2000 of their fourth- and fifth-grade students and 
found that teachers' quantity of technology use impacted mathematics achievement with a positive correlation between increased use and student achievement. This study, however, did not distinguish between the type of technology (computers, video tutorials, or presentation software) used related to the higher mathematics achievement scores or whether the teachers used technology for skill or concept development (or both).

Increased quantity of use does not always impact student achievement. Papanastasiou and Ferdig (2006) found that quantity or overall comfort did not contribute to increased student achievement. Instead they reported only word processing had significant effects on student's mathematics achievement. Other instructional activities such as spreadsheet creation and the use of educational software had positive effects, but these effects were not statistically significant ( $p=0.02$ and 0.08 respectively). This study used data from the 2000 Program for International Student Assessment (PISA). Scores from 35 randomly selected students indicated that students who reported being very comfortable with computer use did not necessarily exhibit high mathematics achievement. They suggested this finding was due to the nature of computer use. For example, students who used the computer to draw, paint, use art programs or play games performed better. Papanastasiou and Ferdig concluded, "the passive or mechanical use of the computer alone does not highly correlate with increased academic growth" (p.369). Research on the comparison of CAI and traditional paper-and-pencil has suggested that the connection between computer use and achievement is weak, especially when used for just skill practice (procedures) (Guerrero et al., 2004; Lin et al., 1994; Tienken \& Maher, 2008; Tienken \& Wilson, 2007). Guerrero and others (2004) argued 
that the use of technology to teach mathematics can undermine student's computational skills. When technology is used well in middle grades mathematics, it can have positive effects on students' attitudes towards learning and conceptual understanding. Evidently, the proper use of technological resources remains the key to improved student achievement.

In 2008, Tienken and Maher reported a study on eighth-grade students who practiced skills using paper and pencil and those who practiced skills using CAI. In measures of the 121 students, the CAI group showed minimal gains over the paper-and-pencil group. However, in a previous study, Tienken and Wilson (2007) measured the use of technology for active learning. Active learning was defined as: a) when learners construct their own meaning; b) new learning builds on prior knowledge; c) learning is enhanced by social interaction; and c) meaningful learning develops through "authentic tasks" (Cooperstein \& Kocevar-Weidinger). In this study the authors found that the CAI group performed significantly better than the control group. Both studies examined the effects of using technology to teach skills but the instructional approach was different. In Tienken and Maher's (2008) study, students participated in computerized drill and practice, and in Tienken and Wilson's (2007) study students used computerized drill and practice then used presentation software to present their learning to the class. The latter was more of a constructivist approach. These findings have implications for technology use and demonstrate that the mere integration of $\mathrm{CAI}$ in instruction does not necessarily improve learning. However, when technology is used for active learning in combination 
with skills practice, it can have positive effects on student achievement (Tienken \& Maher, 2008; Tienken \& Wilson, 2007).

The effects of using technology for active learning were found with both third- and ninth-graders in studies by Xin (1996) and Scheiter, Gerjets, and Schuh (2010). In both cases, students engaged in mathematics problem solving enhanced by computer animation. Students who learned to solve problems in the computer-enhanced environment performed better on similar and unrelated problems.

Just as knowing how to integrate technology effectively into instruction is important, Handal, Handal, and Herrington (2006) noted the importance of selecting appropriate CAI materials. After reviewing over 500 mathematics education websites, they proposed that: a) online mathematics resources should be written at the appropriate reading level; b) graphics should be organized, uncluttered, and not distracting; c) the applet should contain a feedback component so students know when they have made errors; d) and directions should be clear and easy to understand. Not surprisingly, the researchers also noted that online resources created by professional organizations typically offered the best instructional design.

Overall, the literature suggests that the amount of time students use a computer does not matter as much as the types of activities students engage in while on a computer. When activities focus exclusively on mathematical skills or using computer games as a reward, there seems to be little impact on achievement. Instead, the use of technology for active learning seems to positively affect achievement. In order to integrate technology into mathematics teaching and learning effectively, teachers should create a technology- 
based learning environment that provides students with opportunities to experience the process of mathematical investigations through the efficient use of technology. Teachers should also be mindful of the technology they choose and of the purpose they want technology to play in instruction. In some cases technology can be used to enhance a topic that students might find uninteresting, help them be successful with procedures, or better understand a concept. When this happens, some would suggest that students' attitudes towards mathematics become more positive (Presland \& Wishart, 2004; Reed et al., 2010; Reimer \& Moyer, 2005; Tienken \& Wilson, 2007; Van Eck, 2006). The next section will discuss the impact of technology on mathematics attitude and some of the complexities regarding this research topic.

\section{Impact of Technology Use on Attitude Toward Mathematics}

As discussed previously, mathematics attitude can be measured by breaking it down into three constructs: 1) self-confidence in learning mathematics; (2) positive affect toward mathematics; and (3) valuing mathematics (Choi et al., 2011; Martin \& Preuschoff, 2008; Olson et al., 2008). In some cases, the complexity of measuring attitude has made determining the effects of technology on mathematics attitude difficult. Some researchers provided evidence that supports technology's positive effects on mathematics attitude (Bassoppo-Moyo, 2010), while others were skeptical of its impact (Kaput \& Thompson, 1994). Some studies only sought correlations between attitudes and computer use, not directly measuring the impact of computer use on attitude toward mathematics. Furthermore, when the effects of computer use on attitude was measured, attitude measurement was frequently identified by one feature of the construct, such as 
confidence or a student's feelings towards technology, and less associated with valid attitude measurement tools. This section provides examples of the research on the effects of technology on mathematics attitudes related to the areas outlined above.

Attitude vs. motivation. Attitude is difficult to measure because the underlying construct is difficult to identify and, while not synonymous with motivation, it is frequently associated with motivation. As discussed in the section Research on Attitude in Mathematics Education, the values that a student holds about mathematics, influenced by their confidence, impacts their willingness (motivation) to pursue mathematical tasks. The following study conducted at the secondary level provides a good example of the complex relationship. Galbraith and Haines (1998) studied 156 college students and found a strong correlation between confidence and motivation within both mathematics ( $r=0.47)$ and computer domains $(r=0.61)$. The study also revealed strong correlations between the computer/mathematics interaction and both computer confidence $(r=0.68)$ and computer motivation $(r=0.68)$, suggesting that when mathematics was taught using the computer, this interaction lead to high computer confidence and motivation. However, no significant relationships were found related to computer/mathematics interaction, and mathematics motivation and confidence, $r=0.13$, and $r=.35$ respectively. In other words, the use of computers to teach mathematics has little or no relationship with students' motivation or confidence in mathematics. Based on this study, one cannot conclude that computer use in mathematics is strongly associated with mathematics motivation or confidence. 
Computer-based applets may improve student attitudes because they are able to control students' learning pace and activities. According to Van Eck (2006), learner control is an important factor in promoting responsibility for learning and meta-cognition. Therefore, the more control students have over their learning the more motivated they are to achieve and the more positive their attitude is toward learning (Van Eck, 2006). SuccessMaker, a type of CAI that uses answer-pattern-response, does not offer much learner control but has been shown to improve attitudes (Presland \& Wishart, 2004). This finding may be because answer-pattern-response software adjusts tutorials at the students' level, making students feel confident with the tasks presented. Presland and Wichart (2004) reported that SuccessMaker could be linked to improved motivation and self-esteem after students participated in approximately 16 to 32 minutes of supplement mathematics instruction per week.

However, motivation is not the same as attitude and, although evidence exists connecting motivation to attitude, these studies do not clearly distinguish between attitude and motivation (Green et al., 2006; Hammouri, 2004; Norwich, 2007).

Affect toward technology. One element of attitude is affect. Researchers describe a student's feeling towards something as affect (Eklöf, 2007; Kadijevich, 2006; Martin \& Preuschoff, 2008). Studies have shown that students enjoy learning mathematics through computer-based software (Nguyen et al., 2006; Reimer \& Moyer, 2005; Tienken \& Maher, 2008), but these studies did not report using an instrument with validity that distinguished between affect towards technology and confidence or valuing of mathematics or technology. Instead they measured affect using adapted questionnaires 
and reports of student interviews. For example, Reimer and Moyer (2002) adapted a questionnaire to include questions about third-graders' feelings (affect) towards using virtual manipulatives in studying fractions, and then reported positive attitudes. It is difficult to determine if the instrument measured anything other than students' affect toward the technology. Another example is Bassoppo-Moyo's (2010) study discussed in previous sections. The researcher reported CAI had a positive impact on eleventh and twelfth graders' algebra achievement and attitudes towards mathematics; however, the researcher developed the instrument to measure whether or not students liked mathematics and enjoyed CAI. Again, the score reliability and the construct validity were not reported, making it difficult to determine if the specific impact of the technology was just on students' feelings towards mathematics, technology, or both.

Measures for attitude. Measures of attitude related to the use of technology in instruction tended to include surveys or interviews of students and were analyzed qualitatively. For example, in Reimer and Moyer's study, student interviews revealed that a majority of the class reported having a positive experience during lessons where they used virtual manipulatives. Student statements, such as, "If you make a mistake the computer tells you", and "If I get it wrong, I can fix the problem because it [the virtual manipulative applet] tells me" (p.18) were coded as positive experiences and indicating a positive attitude. The researchers reported that students believed they were able to be more successful in learning fractions with the virtual manipulatives, thus building confidence in those students' mathematics abilities and improving their general attitudes towards mathematics. 
Reports of students believing CAI supported their attitudes toward mathematics are common (Bassoppo-Moyo, 2010; Nguyen et al., 2006; Souter, 2002). These studies described student as enjoying algebra class more, striving for better achievement, liking instant scores and adapted feedback provided by computer programs, and showing more engagement in web-based assessment practice. However, none of these studies reported measuring student attitudes towards mathematics and technology before treatment. It could be that students had positive attitudes towards mathematics before the treatment. While accounts of student interviews helped personalize the effects of technology on student attitude, they did not clearly distinguish between the effects the technology had on the student's attitude towards mathematics and how that might have changed after using CAI.

Struggling learners' attitude towards mathematics and technology. The research on attitudes related to technology use is limited, and only one study addressed the needs of struggling learners. Reed, Drijvers, and Kirschner (2010) conducted a study on 565 seventh- and eighth-grade students who used CAI. The researchers used the instrument Mathematics and Technology Attitude Scale, developed by Galbraith and Haines, to measure student attitudes toward technology (Galbraith \& Haines, 1998). The researchers reported this instrument as measuring a four-factor construct for attitude toward mathematics and technology including: "(1) $M A T H$-general attitude towards mathematics; (2) TOOLS- attitude towards using computers for mathematics; (3) PURINV-purposeful and investigative behaviors; and (4) REFCOM-reflective and communicative behaviors," (Reed et al., 2010, p. 5). Reliability coefficients were 
reported and all but PURINV were above 0.70 , so this section was excluded from the analysis.

Using this instrument, researchers found that, for seventh and eighth graders, more positive attitudes towards mathematics yielded improved student conceptual understanding in both high-ability and low-ability groups. However, the study revealed a difference between how high- and low-ability students reacted to CAI. They found highability students demonstrated higher test scores as their attitude towards mathematics increased, but lower test scores as their attitudes towards using mathematics computer tools increased. On the other hand, low-ability students showed a positive correlation between attitudes towards mathematics and attitude towards using computer tools for learning mathematics. In other words, when low-ability students used a computer-based mathematics tool, as their attitudes toward that program improved, their attitude toward mathematics improved.

Current research on the effects of technology on attitude is difficult to interpret. Of the studies reviewed, few used attitude measurement instruments that proved to provide reliable or valid measures of attitude. Several reported on one factor of the attitude construct and were unclear in distinguishing between motivation and attitude. While one study revealed low performing students benefited from using a computer program they felt positively about (Reed et al., 2010), future research about the effects of CAI on mathematics attitude would contribute to current research. 


\section{Computer Assisted Instruction (CAI) and its Effects on Achievement}

Research on the effects of technology on academic achievement is vast. Because this study focuses on the use of technology with struggling middle school learners, it is important to contextualize these findings in terms of the students studied. Therefore, this section is organized according to student contextual factors. Specifically, one group of studies focused on comprehensive student achievement, with no analysis of subgroups. A second group of studies analyzed CAI use with students with intellectual disabilities or identified as struggling students. Each section describes studies that measured student's mathematics achievement after interacting with CAI. The final section reviews studies on one specific type of CAI, SuccessMaker, which is the CAI used in this study.

CAI and comprehensive students. The effects of technology on student outcomes have been studied for over 30 years, and the cumulative results from metaanalyses show CAI has a small positive impact on student achievement. Kulik and Kulik (1991) reported combined effect sizes of 0.24 for studies from 1966 to $1974,0.36$ for studies from 1974 to 1984 , and 0.30 for studies from 1974 to 1985 . Waxman, Connell, and Gray (2002) determined the combined effect size of 13 quantitative research syntheses conducted between 1975 and 1987, to be 0.42 indicating positive effects of CAI on student achievement. Continuing their efforts to understand the impact of technology on achievement, they examined 20 additional studies conducted from 1997 to 2002 , and found a similar mean effect size $0.30(p<0.05)$. However, these results should be interpreted cautiously because of the vast differences in the ways that CAI was used, 
the type of students in each study, and the instructional delivery methods with which CAI was compared.

CAI versus teacher-lead instruction. As stated in previous sections, the way technology is integrated into a learning environment impacts student achievement. However, when examining the effects of CAI on mathematics achievement of the general student population, researchers have focused less on how CAI was integrated and how specific student groups responded to $\mathrm{CAI}$ and more on comparing CAI to instruction given by a teacher. However research on this topic is inconclusive and provides a mix of results. First, the effects of CAI seemed to be related to the year published. Second, studies that took place over longer periods of time seemed to reveal that CAI was at least equal to teacher-led instruction. Third, larger-scale meta-analyses tended to reveal more favorable effects of CAI. Finally no studies distinguished among the types of teacherlead instruction (explicit or contextualized) that were used.

In 1995, Fletcher-Flinn and Gravatt reviewed studies using CAI teach mathematics. All studies were conducted between 1987 and 1992, and student participants spanned kindergarten through college level. They reported the mean effect size for CAI to be moderate $(0.24)$. The effect size seemed to increase as the year published increased, suggesting that improved technology might have lead to improved results. Pearce and Norwich's (1986) and Olusi's (2008) studies provided examples of this increase. In 1986 Piece and Norwich found all students mastered more (multiplication) facts under teacher-lead instruction, while Olusi's 2008 study reported that students who participated in CAI obtained a significantly higher mean achievement 
scores than students who participated in traditional instruction.

In studies that took place over longer periods of time, such as a year, and when measures were taken to control for other variables such as teacher personality, the impact of CAI had less to do with instructional medium and more to do with the quality of instruction provided by CAI materials (Fletcher-Flinn \& Gravatt, 1995). For example, McDermott and Watkins' (1983) conducted a year-long comparison study and found no differences in $\mathrm{CAI}$ and teacher-led instruction. Interestingly, Fletcher-Flinn and Gravatt (1995) found that the variation of the impact of the CAI seemed to be stable across teachers, but vary with different CAI. These results have implications for curriculum selection, including careful attention to which CAI might be used.

Large-scale meta-analyses revealed that CAI may improve student achievement (Christmann \& Badgett, 1997; Slavin \& Lake, 2008; Slavin et al., 2009). A recent review of elementary programs showed a mean effect size of 0.19 for the use of CAI on mathematics achievement, which was higher than the mean effect size calculated for the effects of mathematics textbook curricula $(0.10)$ on mathematics achievement (Slavin and Slavin, 2008). In this review, textbook curricula were defined as instructional materials that were in a paper book format and CAI as instruction delivered through student interaction with the computer. A number of studies that used randomized-quasi or randomized experimental designs had higher mean effect sizes $(n=37$, mean effect size $=$ 0.29), indicating that in a more rigorous experimental setting CAI still proved to be effective at improving achievement. 
In their review of middle and high school mathematics programs, Slavin and Slavin (2009) found similar results for CAI's effects on middle and high school student achievement. Specifically, they examined CAI core (weighted mean effect size $=0.09$ in 17 studies) and supplemental (weighted mean effect size $=0.19$ in 18 studies) programs, showing that supplemental CAI had a greater effect on achievement than CAI as a core curriculum. Unlike the results of their elementary review, however, Slavin and Slavin found that studies that used randomized-quasi or randomized experimental designs showed little or no effect for CAI on achievement.

\section{The effects of CAI on students with intellectual disabilities or identified as}

struggling. As noted in the section addressing struggling learners, the nation's push to make all students proficient in mathematics has lead researchers to enlist a variety of instructional resources in the hope of improving student achievement. CAI has been a key instructional tool used with students who have identified intellectual disabilities and those identified more broadly as struggling. There were differences in how and why CAI were used with these different subgroups, but the effects were similar.

Students with intellectual disabilities. CAI was frequently used to enhance instruction for students with intellectual disabilities by helping students move from a more concrete stage of mathematical thinking to one that was more abstract. Kroesbergen and Van Luit (2003) reviewed five studies focus on determining if CAI increased students' ability to move from concrete to abstract. Three of these studies used CAI in learning arithmetic for students with intellectual disabilities and two focused on CAI used in problem solving. The first of the three studies examined the effects CAI drill and 
practice versus paper-pencil practice and found no significant difference between the two interventions, $(d=-0.44)$. The second study found children receiving CAI scored higher on arithmetic achievement than those who worked with a teacher, $(\mathrm{d}=0.54)$. The third study examined the use of CAI on learning disabled students' multiplication facts and found that a CAI time-delay program was effective in teaching multiplication facts, $(d=$ 2.18). Their meta-analysis also reviewed two studies that examined the effects of CAI in a problem-solving format on student achievement and found positive results with both studies, effect sizes of 0.89 and 1.26 (Kroesbergen \& Luit, 2003). These results revealed that the use of CAI for whole-number computation through problem solving was more effective than drill-and-practice for basic fact mastery when used with students who had intellectual disabilities.

CAI has been frequently used across grade levels to assist students with mastering multiplication facts. For example, Howell, Sidorenko, and Jurica (1987) found that the use of CAI with ninth graders who had learning disabilities did not provide lasting benefits unless combined with teacher-directed instruction. Similarly, both Irish (2002) and Wilson and Majstere (1996) found that learning disabled students improved their accuracy on basic multiplication facts when using CAI, but Irish (2002) found students who just used paper-and-pencil performed better and Wilson and Majstere (1996) found that students in teacher-led groups performed better. In other words, the non-CAI group outperformed the CAI group, though all groups improved in their multiplication facts.

In contrast, other researchers found that the drill-and-practice CAI software promoted simple counting methods rather more abstract strategies for arithmetic 
(Christensen \& Gerber, 1990; Hasselbring \& et al., 1988; Pellegrino \& Goldman, 1987). As discussed earlier, students who struggle in mathematics tended to have difficulty moving from a concrete strategy such as counting on their fingers to a more abstract strategy. For example, when a struggling student is given an addition problem such as 17 plus 6 they may count-up using their fingers to keep track of the sum. This is a counting strategy. However, a more abstract strategy would be to decompose 17 to 10 and 7 to add more quickly. CAI that promotes counting strategies over more abstract thinking might be less productive for a struggling learner. This finding is relevant to students with intellectual disabilities since they frequently struggle with mathematics.

Hasselbring, Lott, and Zydney (2005) identified the following seven characteristics as essential for effective drill-and-practice software for students with intellectual disabilities: (1) identification of fluent and non-fluent facts; (2) restricted presentation of non-fluent information; (3) student generation of problem/answer pairs; (4) use of "challenge times"; (5) space presentation of non-fluent information; (6) the appropriate use of drill-and-practice; and (7) computer monitoring of student performance (Hasselbring et al., 2005). These characteristics fit within the framework for building procedural fluency identified by other mathematics researchers and key components for success when working more broadly with struggling learners (Baker et al., 2002; Fuchs et al., 2008; Gersten et al., 2009; Rivera \& Bryant, 1992).

CAI has also shown positive effects when the CAI displays a combination of conceptual and procedural strategies for solving problems. In 2010, Fuchs and others conducted four studies that used CAI in different ways to remediate number 
combiinations. The CAI was used for: 1) drill and practice, 2) conceptual instruction on decomposing numbers, 3) instruction on counting strategies, and 4) instruction on counting strategies with and without deliberate practice. The researchers found that students were more successful whith number combinations when the CAI showed both symbolic drill-like problems and a number line for conceptual understanding, (Fuchs, Powell, Seethaler, Fuchs, et al., 2010). This finding is consistent with other research on effective mathematics instruction, which noted that a strong conceptual base aided in procedural fluency (Hiebert, 2003; NCTM, 2000; NRC, 2001).

Students identified as struggling. Struggling students have difficulty in mathematics, but the difficulty is not related to an identified learning disorder. The term "struggling learner" can include students with intellectual dissabilities and can include all students who are peforming below grade level. As noted in previous chapters, explicit or direct instruction can help struggling students learn mathematics (Baker et al., 2002; Ketterlin-Geller et al., 2008). This conclusion suggests that the use of CAI as explicit instruction for struggling learners is worth examining. In addition, research has suggested CAI can be used as a supplement to teachers' core mathematics instruction for these students to address gaps in understanding and solidify concepts.

Seven years of research and over 400 students yielded positive achievement results for students who used a CAI program FASTT (Fluency and Automaticity through Systematic Teaching with Technology) for about 10 minutes a day for approximately 100 sessions. Hasselbring, Lott, and Zydney (2005) argued that their study revealed that students having difficulty in mathematics can benefit from drill-and-practice CAI when 
the technology employed the seven characteristics listed previously. Slavin and Slavin (2009) also found benefits when CAI was used as a supplement for struggling students labeled. They found that the mean effect size for CAI used as a supplement was higher that the mean effect size for CAI used as core instruction $(\mathrm{ES}=+0.19$ in 18 studies versus $\mathrm{ES}=+0.09$ in 17 studies). Overall, this research indicated that CAI used as a supplement can positively impact struggling learners' achievement.

One problem with the convenience and ease of using CAI to work with struggling learners is that schools will rely too much on CAI to "fix" struggling students.

Researchers have argued that computers are not a cure-all for struggling learners, but on the other hand they can serve as a viable tool for improving achievement, in particular for students who struggle (Fuchs et al., 1994; Fuchs et al., 1997; Ku et al., 2007; Slavin \& Lake, 2008; Slavin et al., 2009).

Additionally, for CAI to work well, students must have some knowledge base on which to build. In a study of 53 kindergartners, students who had higher pre-test scores in number recognition improved with CAI; however students with lower pre-test scores in number recognition performed better with teacher instruction. McCollister, Burts, Wright, and Hildreth (1986) noted that students in the latter category were less likely to trust the computer when it provided correct answers (McCollister et al., 1986). The results of this study suggested that for CAI to be effective, students must first have a knowledge base on which they can rely to determine the correctness of answers produced by the CAI. For students who may not have this knowledge base, teacher-facilitated instruction can assist in building student confidence. 
When working with struggling learners, teachers sometimes found it difficult to diagnose their mathematics deficiencies, which may vary greatly from student to student. Personalized CAI programs, or CAI that use answer-pattern responses to customize learning for students, can be helpful to differentiate and provide personalized instruction. $\mathrm{Ku}$, Harter, Liu, Thompson and Cheng (2007) found that personalized CAI versus nonpersonalized CAI had positive effects on low-achieving students' mathematics performance. In their 2007 study, 104 middle school students were administered a pretest to demonstrate mathematics knowledge. Students were then randomly assigned to personalized CAI, in which the computer program used names of people and places familiar to the student, and non-personalized CAI. The results, consistent with nontechnology oriented research on students with intellectual disabilities, suggested that students responded to instruction that was relevant to them and their achievement increased.

CAI in the 2010s. Researchers focusing on CAI argued that findings of the 1980s and 1990s were irrelevant today in our technologically enhanced world (Rasanen, Salminen, Wilson, Aunio, and Dehaene, 2009; Jenks \& Springer,2005). In fact, effect sizes for studies measuring the effects of CAI on achievement have improved as the published year increased (Fletcher-Flinn \& Gravatt, 1995). For example, in 1985, Fuson and Brinko's study found no difference between drill-and-practice CAI and flashcards when elementary students were learning basic facts. However, at the time, the CAI interface only displayed the numeric equation with a question mark in place of the answer, and this interface greatly resembled the flash-cards used in the study. Today's 
CAI has interactive tutorials, with virtual manipulatives built into the programs, and target student misconceptions based on sophisticated answer-pattern-response systems.

CAI has changed dramatically since researchers first began to study the impacts of these learning environments. For example, a 1990 study that investigated the effects of embedding drill and practice in a video game revealed that the game was distracting to some students (Christensen \& Gerber, 1990). More recently however, Tsung-Yen and Chen (2009) found that a more visually stimulating interface improved student achievement. In their study, third graders participated in a more traditional CAI interface with text-based instructions and few graphics then with a 3-dimensional video-game-like interface. The results revealed students who participated in the video game interface performed better at both lower-level cognitive test such as matching and higher-cognitive test such as application (Tsung-Yen \& Wei-Fan, 2009). As these studies suggest, improvements in CAI interfaces and video games have led to software that is less distracting and has more potential for monitoring and supporting student learning; however, more research is needed to determine if these effects hold true for struggling students.

CAI as a diagnostic teaching tool. Another key feature of newer CAI is the use of answer-pattern-response to diagnose student learning and to target the needs of specific students. Answer-pattern-response adjusts the difficulty level of questions or instruction based on student's previous responses. One particular program is SuccessMaker, Math Concepts and Skills 2 (Pearson Digital Learning, 2005b). This program uses answer-pattern-response decision-making algorithms to continually assess 
student performance and provide individualized instruction (Pearson Digital Learning, 2005a). According to research presented in a previous section, students, especially those struggling in mathematics, benefit from this type of personalized CAI (Fuchs et al., 1994; Fuchs et al., 1997; Ku et al., 2007; Slavin \& Lake, 2008; Slavin et al., 2009). Although, this type of CAI is designed to improve mathematics achievement, studies that examined the effects of SuccessMaker on achievement scores show minimal positive correlation, and results, while positive, have not yielded statistically significant results.

Most studies that explored the use of SuccessMaker and its effect on student achievement focused on the amount of time students spent on the program. For example, Kirk (2003) found students who received a supplemental CAI (SuccessMaker Math Concepts, and Skills) for an average of approximately 13 hours a school year, scored 21 to 30 scale points higher each year for three consecutive years than the national average on the Terra Nova CTBS assessment $5^{\text {th }}$ edition. Additionally, the gains demonstrated by the sample were more than the average expected gain; however, these findings were not reported to be statistically significant. Manning (2004) also found a positive correlation between Florida state mathematics achievement scores and time spent on the SuccessMaker program, but this study did not control for specific student characteristics such as previous mathematics ability. While students who spent more than 30 hours on the program revealed statistically higher scores on their state assessment, it is possible that those students spending more time were already higher achieving and enjoyed mathematics more.

Additional research on SuccessMaker also revealed flaws in methodology, 
rendering the results less convincing. For example, Gee (2008) focused on time spent on the program, but her results were not measured against a control group. This strategy is problematic because the time students spent on the program was not controlled. In addition, as she noted in her summary, it was unclear if implementation was consistent across all classrooms and all ability groups. As in the previous example, higher achieving groups of students might have spent more time on the program.

In some cases, however, time spent on the program was not reported. Mathis (2010) examined the effects of the SuccessMaker program on 500 students classified into different sub-groups based on race, socio-economic status, and disability. The study yielded two statistically significant results: a significant difference in mathematics achievement between Caucasian and African American students and a significant difference between students with disability compared to students without disabilities. None of the results indicated a significant effect of SuccessMaker on mathematics achievement. While these results could imply SuccessMaker had no effect on mathematics achievement it is difficult to determine from these studies because student growth over time was not measured. Additionally, no data were reported in terms of the fidelity of use of SuccessMaker. In fact, Mathis (2010) found that teachers did not implement the program as it was designed in some cases, and students spent only 60 minutes a week on the program.

Only one study used a pre/post test design to measure student learning as it related to SuccessMaker. The study examined the effects of SuccessMaker on mathematics achievement of fourth- and fifth-grade students in thirteen schools located in the Etowah 
County (Alabama) School District (Mintz, 2000). Specifically, it examined the program's effects on critical thinking skills as revealed on the Stanford Achievement Test 9 and found that students who used SuccessMaker showed lower critical thinking scores as compared to students who did not use the program. Because the study used a pre/post test design, more confidence can be placed in the finding that SuccessMaker had no impact on critical thinking. However, as Mintz (2000) noted, the assessment used in her study was a grade level assessment so students may have had significant gains but still not have demonstrated the skills necessary to show statistically significant improvement on the state's grade level assessment. This study leaves unanswered questions about SuccessMaker's ability to improve struggling students' performance.

Current research on SuccessMaker CAI is also inconclusive. While some studies found students who used SuccessMaker made gains in student achievement, questions about their methodology weaken their arguments. No studies used a control group, and only one controlled for the achievement level of students using the program. Furthermore, the amount of time students spent on the program varied greatly from study to study, and some studies did not follow program recommendations for implementation. Also, none of the studies reviewed measured fidelity of implementation and only one study addressed how SuccessMaker was implemented. This review of research suggests SuccessMaker could be a viable tool for working with struggling learners, but it needs to be implemented using effective practices for working with struggling learners and recommendations for effective mathematics technology integration. 


\section{Summary}

The review of literature provided in this chapter highlights key areas of interest in working with struggling learners and how technology may impact their achievement. The review began with a broad look at mathematics education, defining what it means to be mathematically proficient and how attitudes can impact a student success in mathematics. The section on Attitude in Mathematics Education emphasized the teachers' role in improving student attitude by providing opportunities for success with meaningful and challenging tasks.

Shifting from a broad look at mathematics education, struggling learners and their needs related to mathematics instruction was addressed. A theoretical framework was described for providing effective mathematics intervention for struggling students. This framework included seven principles for providing mathematics intervention fused with four phases of instruction that Rivera and Bryant (1992) suggested that students must move through in order to achieve procedural fluency and the ability to flexibly apply understanding to solve mathematics problems. The seven principles included: ( 1 and 2) explicit instruction with a strong conceptual base; (3) instructional design to minimize learning challenge; (4) opportunity for drill and practice; (5) cumulative review; (6) motivators to helps students regulate their attention and behavior; and (7) ongoing progress monitoring. Woven into these seven principles were four phases of instruction: acquisition, fluency, generalization, and application. The acquisition phase closely resembled explicit instruction requiring modeling, guided practice and frequent feedback, 
and additional practice, while the generalization and application phase resembled a more contextualized approach (Fuchs et al., 2008; Rivera \& Bryant, 1992).

Next, the chapter focused on the role technology that plays in mathematics education and how it can: (1) provide explicit instruction connecting concepts to skills through enhanced representations; (2) provide skill practice with built-in error feedback, cumulative review, and ongoing progress monitoring; (4) impact student attitudes, motivating them to stay on task; (5) minimize unnecessary learning challenges by tailoring instruction to the learner; and (6) when intentionally used to provide students with opportunities to experience the process of mathematical investigations, it can positively affect mathematics achievement (Baker et al., 2002; Fletcher-Flinn \& Gravatt, 1995; Heid \& Blume, 2008; Slavin et al., 2009; Zbiek et al., 2007).

The literature reviewed in this chapter provided a basis for the argument that CAI has a role to play in providing mathematics intervention for struggling learners. This study seeks to examine this role by measuring the effects CAI has on mathematics attitude and achievement when used alone compared to when it is combined with teacherfacilitated explicit instruction. 


\section{CHAPTER III: METHODOLOGY}

\section{Purpose and Research Questions}

The purpose of this study was to examine the effects of various instructional methods on students, mathematics achievement and attitudes toward mathematics. The instructional strategies examined in this study were computer-assisted instruction (CAI), explicit instruction using a structured curriculum (SC), and the combination of CAI and SC. The researcher hypothesized that the combination of CAI and SC would have positive effects on students' mathematics achievement and attitudes towards mathematics.

Previous chapters have identified CAI as an intervention used to improve procedural fluency in struggling mathematics students (Fletcher-Flinn \& Gravatt, 1995; Hasselbring et al., 2005; Slavin et al., 2009). But theory suggests that effective mathematics instruction should be a balance of both conceptual understanding and procedural fluency, and CAI is most effective when combined with a conceptually oriented, inquiry-based curriculum (Hiebert \& Grouws, 2007; NRC, 2001; Slavin et al., 2009). Fuchs and others (2008) suggests that mathematics interventions should meet the following seven principles: ( 1 and 2$)$ contain instructional explicitness with a strong conceptual base; (3) be designed to minimize learning challenges; (4 ) offer opportunity 
for drill and practice; (5) provide cumulative review; (6) contain motivators to help students regulate their attention and behavior to work hard; and (7) offer progress monitoring. Also, interventions should honor the developmental process that struggling students undergo to achieve mastery of a topic: (1) acquisition; (2) fluency; (3) generalization; and (4) application (Rivera \& Bryant, 1992).

Both $\mathrm{CAI}$ and $\mathrm{SC}$ were used in this study as instructional strategies for the acquisition and development of procedural fluency and for developing conceptual understanding in order to promote generalization and application. The CAI and SC programs both met the development framework of Rivera and Bryant (1992). They also both provided explicit instruction with connections to concepts (principles one and two), recommended by researchers as an effective strategy for working with struggling learners (Baker et al., 2002; Gersten et al., 2009). In addition to the explicit instruction, both the $\mathrm{CAI}$ and $\mathrm{SC}$ offered systems that met the other five principles, but a combination of the two was expected to enhance some principles.

The CAI used in this study was intended to enhance instruction by offering additional drill and practice and cumulative review (principles four and five). The CAI also used answer-pattern-response to customize the learning experience and minimize learning challenges (principle three) as recommended by research (Fuchs et al., 2008; Rivera \& Bryant, 1992). Furthermore, the CAI used in this study provided ongoing progress monitoring (principle six), which informed the teacher on topics to address during instruction using the SC. Meanwhile, the SC used in this study was intended to enhance principles one and two by providing conceptually based lessons on procedures. 
While both the CAI and SC were intended to improve student achievement, the expectation was that combining $\mathrm{CAI}$ and $\mathrm{SC}$ would have positive effects on students' mathematics achievement scores and attitudes towards mathematics.

The research questions for this study were:

1. Is there a significant effect of instructional type on mathematics achievement?

2. Is there a significant effect of instructional type on mathematics attitude?

3. What is the factor structure of attitude scale scores obtained from the mathematics attitude survey?

This chapter provides a detailed account of the research design of this study, including a description of the population, sample, participant selection procedures, major variables, instruments, data analysis procedures, and limitations.

\section{Research Design}

A three-group pre/post-test design was used in this study. Academic achievement and attitude toward mathematics served as the dependent variables. The study consisted of three treatment groups: Structured Curriculum Group (NR sC), Computer-Assisted Instruction Group (NR $\mathrm{CAI}$ ), and Computer-Assisted Instruction with Structured Curriculum Instruction Group (NR $\mathrm{CAI}$ with $\mathrm{SC})$. The structured curriculum group received instruction using a structured curriculum (NR $\mathrm{SC}$ ) without computer-assisted instruction (CAI). Structured curriculum is defined in this study as lessons from a formal program curriculum. The group labeled $\mathrm{NR}_{\mathrm{CAl}}$ received computer-assisted instruction but did not use structured curriculum (SC). For example, while students were using the CAI, they sometimes had questions about the mathematics content presented by the CAI. The 
teacher did not use a formal curriculum to address student misconceptions. Instead, the teacher relied on his or her own pedagogical content knowledge to assist students and provide instruction on the topics of concern. Occasionally, the teacher would plan a small-group lesson to address a common misconception, but the teacher designed these lessons without the use of a formal curriculum. The third group, (NR $\mathrm{CAl}$ with SC) received computer-assisted instruction to build procedural fluency with explicit instruction using a structured curriculum to enhance conceptual understanding.

Due to scheduling restrictions, the three treatment groups met at various times throughout the school day and on different days of the week. These differences will be discussed more in a later section.

Classes lasted 55 minutes and the interventions took place over a 8-week period. Mathematics achievement and attitude were measured at the beginning and end of the 8week period. All student participants received treatment as a supplement to their core mathematics program, Connected Mathematics Project 2.

\section{Population}

The target population included middle school students who demonstrated deficiencies in middle school mathematics content or who struggled with mathematics. The sample was drawn from students who attend a middle school in a public school district in Kentucky. The school district had a total student population of 98,000 in 136 schools, 24 of which were middle schools. Middle schools in this school district served students in grades $6-8$, ages ranging from 11 to 14 . At the time of the study, approximately $58 \%$ of students received free-or-reduced lunch. 
In June 2001, the Kentucky Board of Education adopted new performance standards that defined categories for student performance in mathematics. The performance categories were labeled novice, apprentice, proficient, and distinguished (Kentucky Department of Education, 2007), and the state measured school performance based on the number of students who scored proficient or distinguished on the state standardized tests.

According to the Kentucky Department of Education (2001), novice students were those who rarely demonstrated understanding of grade-level skills, concepts, and relationships in number/computation, geometry/measurement, probability/statistics, and algebraic ideas. Additionally, novice students rarely demonstrated understanding of problems, as demonstrated by incomplete or incorrect solutions. Students identified as struggling in this study scored at the novice level on Kentucky's state assessment. In contrast, students classified as proficient were students who demonstrated understanding of grade-level skills, concepts, and relationships in the domains listed above. Proficient students also demonstrated a general understanding of problems and problem solving as a process, providing complete solutions most of the time, with possible minor computational errors (Kentucky Department of Education, 2001). In 2010, 21\% of students in the school district scored novice on the mathematics portion of the Kentucky Core Content Test (KCCT), compared to $13 \%$ at the state level. On the same test, $50 \%$ of middle school students in the school district scored at the proficient level, compared to $61 \%$ at the state level. 
Participants in this study were students who attended Baxter Middle School. This middle school had a population of 717 students, with $66 \%$ classified as having free-orreduced-price lunches. In 2010,30\% of students at Baxter scored novice on the KCCT, and $26 \%$ scored proficient, well below the percentage of students who scored proficient at the district and state levels. Furthermore, $62 \%$ of students with disabilities and $39 \%$ of African Americans scored novice (Kentucky Department of Education, 2010).

Due to six years of inadequate performance on KCCT, Baxter Middle School was classified as Restructuring. Schools with this status must notify parents and offer them a choice of whether to send their student to that school. Additionally, such schools were required to determine a corrective action plan to reduce the number of novice students and increase the number of proficient students. Within their corrective action plan, the middle school initiated an intervention program to provide support and remediation to struggling students. As part of this intervention program, Baxter Middle School staff began each school year by identifying students who struggle with mathematics, which was determined by students' mathematics achievement scores. From there, students identified as struggling were enrolled in a supplemental intervention class, where they receive instruction on the skills and concepts they had not mastered. All students in intervention still attended their daily mathematics class, where they engaged in gradelevel instruction; meanwhile, their intervention class focused on student-demonstrated areas of deficiencies from previous grade levels. Students who participated in mathematics intervention were potential participants in this study.

In an effort to remain instructionally focused and provide a strong mathematical 
base for students, the middle school's administrators decided that intervention instruction would focus on the Number and Operations strand. Students in Baxter's intervention program were those who demonstrated gaps in fundamental mathematics skills, including number concepts, operational meaning, whole number place value development, and whole number computation, measured by Measures in Academic Progress (MAP), a mathematics assessment tool that aligns with Kentucky's state test (Dahlin, 2008).

\section{Sample}

Student Selection and Group Assignment. The sample of students for this research study represented sixth-, seventh-, and eighth-grade students. Each grade level had at least one group of each type of treatment: one SC group, one CAI group, and one CAI with SC groups.

Classes were comprised of students in the same grade level. Preliminary student selection based on baseline mathematics achievement scores obtained using the MAP computerized test took place in September 2011. Students who scored 203 or less on MAP were selected as potential participants. According to Dahlin (2008), a MAP score of 203 or less is comparable to scoring novice on the KCCT. Following the identification of potential participants, parental approval was obtained, and those students who did not have parental approval were eliminated from the study. All selected students received mathematics intervention instruction in addition to their regular mathematics curriculum. Two groups of sixth graders received structured curriculum without CAI, two groups of sixth graders received CAI only, and two groups of sixth graders received CAI with SC. Similarly, two groups of seventh graders received structured curriculum without CAI, 
two groups of seventh graders received CAI only, and one group of seventh graders received CAI with SC. Finally, one group of eighth graders received structured curriculum without CAI, one group of eighth graders received CAI only, and one group of eighth graders received CAI with SC.

Figure 1

Diagram of Grade-level Groups

\begin{tabular}{l|c|c|c} 
& $\mathbf{6}^{\text {th }}$ Grade & $\mathbf{7}^{\text {th }}$ Grade & $\mathbf{8}^{\text {th }}$ Grade \\
\hline NR $_{\text {Control }}$ & 2 groups & 2 groups & 1 group \\
NR $_{\text {CAI }}$ & 2 groups & 2 groups & 1 group \\
NR $_{\text {CAI with SC }}$ & 2 groups & 1 group & 1 group
\end{tabular}

Teacher Selection and Training. Teachers were selected by the principal and assigned to the groups based on their schedule. They received detailed instructions for administering treatments and were asked to complete logs of their interactions with students. Teachers who taught the structured curriculum attended professional development workshops, where they learned how to plan instruction, execute lessons, and assess student learning using Do the Math curriculum. Teachers who taught the CAI group received training on the SuccessMaker program, which included both technical and instructional components. The technical components included an overview of the program, simple troubleshooting, and instructions on how to manage and print reports as well as interpret reports. The instructional component included training on how to address student misconceptions and questions while students were working on the computer and how to group and conduct small-group instruction based on the reports. 


\section{Major Variables}

Instructional type served as the independent variable with three levels: computerassisted instruction (NR $\mathrm{NAI}_{\mathrm{CI}}$ ), structured curriculum $\left(\mathrm{NR}_{\mathrm{SC}}\right)$, and $\mathrm{CAI}$ with structured curriculum (NR $\mathrm{CAI}$ with $\mathrm{SC})$. Mathematics achievement and attitude toward mathematics scores served as the dependent variables. The following are the operational definitions of each.

Computer-assisted instruction (CAI). Computer-assisted instruction (CAI) is defined for this study as instruction using computer software designed to diagnose procedural skill deficiencies and provide tutorials to improve deficient skills. The curriculum SuccessMaker Enterprise by Pearson was used for this study. SuccessMaker is a computer-based mathematics intervention curriculum for grades $2-8$. It is a supplement to core instruction and aids students in practicing mathematics skills, using virtual models and representations to build procedural fluency.

As stated above, intervention instruction focused on Number and Operations, which included the following topics in the SuccessMaker program: place value in baseten, whole number operations (addition, subtraction, multiplication, and division), fraction concepts (i.e., equivalency and fraction representations), fraction operations (addition and subtraction with like and unlike denominators, multiplication, and division), decimal concepts (i.e., equivalency and decimal representations), decimal operations (addition and subtraction with like and unlike denominators, multiplication, and division), and the concept of percent skills (i.e., percent of a whole number). 
The program operates on a Windows or Macintosh operating system and uses the Novell network server. SuccessMaker is programmed to align directly with Kentucky grade-level content. Furthermore, SuccessMaker addresses the NCTM process standards of problem solving, multiple representations, and making connections. SuccessMaker provides concept-based instruction on mathematical procedures and provides practice with simple problem solving. The program is designed to deliver individualized lessons to each student. Each topic is represented through a variety of representations and models. Text presented on the screen is read orally to the student, and complex concepts are presented through scaffolded questioning, which breaks down a mathematics concept or procedure into a series of simple questions. This scaffolding makes it possible for students to work independently while the teacher answers questions or delivers smallgroup instruction to other students. Student performance on SuccessMaker is reported using a grade equivalency score that ranges from 0.0 to 12.0 (Pearson Digital Learning, 2005a, 2005b; Thrall \& Tingey, 2003).

Structured curriculum (SC). For this study, structured curriculum was defined as instruction using hands-on problem solving, in which the teacher intentionally guided students in constructing their understanding of concepts and procedures and provided explicit connections among them. The curriculum used in this study consisted of lessons from Burns' (2011) Do the Math Now. This program is a 12-module intervention curriculum designed to focus on Number and Operations; therefore, the instructional topics were identical to those addressed above. 
Mathematics achievement. Student mathematics achievement for this study was measured by Measures in Academic Performance (MAP), a computerized diagnostic assessment created by Northwest Evaluation Association (NWEA). It is computer-based and uses answer-pattern responses to assess mathematics achievement levels.

Performance is reported using the Rasch unit score, or RIT score. RIT scores are reported using an equal-interval scale that estimates student achievement based on individual item difficulty. The equal-interval score used by NWEA ensures that the difference between scores is the same regardless of grade level and the student's ranking on the RIT scale. Student scores are also reported as a range to allow room for error in measuring a student's mathematics achievement. RIT score ranges for the Number and Operations strand include: below 161,161-170, 171-180, 181-190, 191-200, 201-210, 211-220, 221-230, 231-240, 241-250, 251-260 and above 260. RIT scales are aligned to grade-level equivalency scores and show a strong positive correlation with SuccessMaker scores $(r=0.86)$, (Pearson, 2006). Additionally, RIT scales have been aligned with KCCT performance scores and can be used as a predictor of performance on Kentucky's state assessment (NWEA, 2009).

Mathematics attitude. Attitude toward mathematics is defined in this study as a mean response to TIMSS Attitude Survey. The survey consists of 12 items measuring student attitudes toward mathematics. The first set of items in the TIMSS 2007 assessment includes: I usually do well in mathematics; I would like to take more mathematics in school; Mathematics is more difficult for me than for many of my classmates; I enjoy learning mathematics; Mathematics is not one of my strengths; I 
learn things quickly in mathematics; Mathematics is boring; and I like mathematics. The eight items reflect perceived confidence and affective reaction to mathematics (like or dislike), three of these items are reverse scaled. The second set of items includes: I think learning mathematics will help me in my daily life; I need mathematics to learn other school subjects; I need to do well in mathematics to get into the university of my choice; and I need to do well in mathematics to get the job I want. This set of items largely reflects students' perceived utility of mathematics. The questionnaire uses Likertresponse format ranging from one ("agree a lot") to four ("disagree a lot").

\section{Instruments}

\section{Measures in Academic Progress}

Measures in Academic Progress (MAP) was chosen to measure students' academic achievement for several reasons. First, research indicates that MAP scores are highly reliable (NWEA, 2004, 2009). Second, the design and purpose of this instrument assure content validity. Third, MAP uses a computerized answer-pattern response system to customize the assessment for each student. This format ensures that each student receives a test appropriate for his or her ability level, making the test easy to administer and appealing to students. Finally, MAP offers diagnostic data broken down by strands in mathematics. These strands enabled the researcher to target the Number and Operations strand and identify common concepts and skills in which students demonstrated deficiencies. 
Reliability. The test developer reported two types of reliability scores from the MAP: test-retest and parallel forms. NWEA $(2004,2009)$ reported administering a first test and then administering a parallel test 7 to 12 months later. According to the test developer, this combination of test-retest and parallel forms was made possible because of MAP's computerized, answer-pattern response system in which students were administered test items based on their performance on previous items. Essentially, each time a student takes the MAP test, a parallel form is created. NWEA (2004) reported reliability coefficients for the sixth, seventh, and eighth grades over several years, and the reported coefficients are all above 0.90 , which is considered very good (Shavelson, 1996; Stevens, 2009; Urbina, 2004). Additionally, a study conducted in Kentucky reported reliability coefficients of 0.87 for sixth grade $(n=2834), .88$ for seventh grade $(n=2407)$, and 0.88 for eighth grade ( $n=1891)$ (NWEA, 2009). Although these coefficients are slightly lower than 0.90, they are considered good (Shavelson, 1996; Stevens, 2009; Urbina, 2004).

Validity. NWEA ensures content validity of MAP by "carefully mapping existing content standards from a district or a state into a test blueprint" (NWEA, 2004, p. 3). Additionally, "every effort is made within a goal area or strand to select items with a uniform distribution of difficulties" (NWEA, 2004, p. 3). NWEA also measures concurrent validity, which requires that test scores be correlated with external criteria that will be used in decision-making. To measure concurrent validity, NWEA administered two test forms designed to measure the same content. Scores on these parallel forms were examined and correlated. A higher correlation implies stronger evidence of 
concurrent validity. Concurrent validity for MAP was reported as $0.75(\mathrm{n}=2451), 0.82$ $(n=1974)$, and $0.80(n=2235)$, respectively, for sixth, seventh, and eighth grades when compared to Kentucky's state accountability test in spring 2006. Also, predictive validity was reported as $0.63(n=2451), 0.66(n=1974)$, and $0.66(n=2235)$, respectively, for the sixth, seventh, and eighth grades when measured with Kentucky's state accountability test in spring 2006 (NWEA, 2009). Overall, the reported correlations were high and suggest adequate levels of both content validity and predictive validity of the scores from MAP. In addition to MAP's high reliability and validity coefficients, other factors influenced the decision to use this instrument in the study. First, MAP was specifically designed with the following goals:

1. Challenge students across all test items;

2. Take a minimal amount of instructional time relative to the amount of information it provides;

3. Provide an accurate and reliable account of a student's achievement;

4. Include content the student should have had an opportunity to learn;

5. Provide information about a student's change in achievement level;

6. Provide results immediately while maintaining a high level of integrity in the reported results (NWEA, 2009).

The design and purpose of MAP are specifically aligned with the goals and theoretical framework of this study. Middle school students need engaging and challenging work to maintain focus (L. Taylor, 1993; Vygotsky, 1978). Additionally, most middle schools are required to maintain a large number of instructional minutes. 
MAP's accurate and efficient testing procedures make it a good fit for a study with middle school students. Finally, the easy-to-use reports helped maintain consistency when examining student growth and identifying concepts that was taught during the study.

\section{TIMSS Student Questionnaire}

The TIMSS (2007) Student Questionnaire has two components (see Appendix A). The first component consists of items measuring attitude toward mathematics. The second component includes questions relating to computer skills and home computer environments.

Attitude toward mathematics. The TIMSS (2007) Attitude Questionnaire was chosen due to its construct validity, simple design and layout, and ease of use. The survey was designed to measure students' attitudes toward mathematics, using twelve items categorized into three domains: Self-Confidence in Learning Mathematics (SCLM), Positive Affect Towards Mathematics (PATM), and Valuing Mathematics (VM) (Choi et al., 2011; Martin \& Preuschoff, 2008; Olson et al., 2008). This questionnaire was chosen because of its ability to measure attitudes based on this three-factor structure.

Validity. The survey includes 12 questions: Math is more difficult for me; Math is not one of my strengths; I usually do well in math; I learn things quickly in math; Math is boring; I enjoy learning mathematics; I like math; I would like to take more math; I need math to get into college; I need math to get the job I want; I need math to learn other subjects; Math will help me in my daily life. 
According to Martin and Preuschoff (2008), the 12 items in this questionnaire measure a 3-factor construct for mathematics attitude. Although it is unclear whether the authors used an exploratory factor analysis or all 12 items in the confirmatory factor analysis, their final model shows only 11 indicator items of the three latent variables: positive affect toward mathematics (three items), self-confidence in learning mathematics (four items), and valuing mathematics (four items).

Other studies have found similar factor structures when using part or all of the items. Eklöf (2007) used data from 4,256 Swedish eighth-grade students who participated in TIMSS 2003 and found that 12 items could be divided into two variables: mathematics self-concept and valuing of mathematics. Chiu (2007) used 11 items from TIMSS 2003 instead of 12 when studying 87,913 students from 19 countries. Like Eklöf, Chiu first divided the 11 questions into two variables (confidence and valuing), but analysis revealed that a three-factor construct (confidence, utility, and interest) was more appropriate. Hammouri (2004) used 11 of the 12 items to measure self-perception of mathematics importance, mathematics confidence, and attitudes toward mathematics, while Meelissen and Luyten (2008) used the survey to study Dutch fourth-graders on self-confidence in mathematics and liking mathematics. Kadijevich (2006) used only eight of the items to measure self-confidence in learning mathematics and liking mathematics. Although researchers may have used only part of the items, it is comforting to note the similarities in constructs.

Furthermore, a more recent study conducted in 2011 by Choi, Bush, Hunter, and Truitt (2011) confirmed a three-factor construct using all 12 items from the questionnaire. 
Their study examined scores of 7,593 eighth-grade students in the United States who participated in the TIMSS 2007 assessment. They reported factor correlations of 0.08 , 0.21 , and 0.32 and confirmed the three-factor solution, which accounted for about $66 \%$ of the total variance after rotation, with communalities ranging from 0.52 to 0.80 . Choi and others (2011) named these factors positive affect toward mathematics (four items), selfconfidence in learning mathematics (four items), and valuing mathematics (four items) as had Martin and Preuschoff (2008).

Reliability. The scores from this survey have been reported to be reliable. The Cronbach's alpha reliability coefficient for this survey was reported to be $\alpha=0.81$ internationally and $\alpha=0.86$ for the United States (Martin \& Preuschoff, 2008). Additionally, a more current study reported Cronbach's alphas $0.86,0.74$, and 0.84 , respectively, for a three-factor construct (Choi et al., 2011). Each of these reported values is deemed sufficient for research purposes by Henson and Roberts (2006).

Computer comfort level. Computer comfort level was measured using three items: I feel very comfortable working on the computer, I have good computer skills, and I enjoy using computers. Additional items were included to gain insight into major findings of this study, which was heavily focused on technical aspects of mathematics instruction. The additional three items were Do you have a computer at home? Do you have Internet connection? and How often do you use the computer? Although the adapted items were not field tested, content experts were consulted on the face validity of items. 
Demographic variables. In addition to the variables measured above, the researcher obtained demographic information on student participants through school records. These variables included gender, age, race, free or reduced lunch status, and intellectual disabilities.

\section{Treatment and Data Collection Procedures}

\section{Treatment Groups}

As outlined above, students were placed into one of three treatment groups. The goal of the study was to examine the effect of SC, CAI, and the combination of CAI with SC on mathematics achievement and attitude. Treatment procedures for these three groups are described in this section, and the diagram below provides a visual description of pre-test observation $\left(\mathrm{O}_{1}\right)$, treatment $(\mathrm{X})$, and post-test observation $\left(\mathrm{O}_{2}\right)$. All groups underwent treatment during the same 8 -week period in fall 2011, but treatments did not take place at the same time during the school day or on the same days.

The CAI with SC group and met five days a week; the control and CAI groups met every other day. However, due to the length of lessons in the SC and CAI sessions, the difference in total class periods did not matter. Class periods lasted 55 minutes a day and the SC lessons were 20 minutes long so it was expected that the SC groups would cover approximately two lessons per day. Similarly, students in the NR ${ }_{\text {CAl }}$ group had time to complete two sessions of CAI each class period. Meanwhile students in the NR CAI with SC completed one SC lesson a day and one CIA session, making treatment equal across all 
groups. The chart below shows the estimated number of SC lessons and CAI sessions students were expected to complete.

Table 1

Diagram of Intervention Instructional Classes and Estimated Number of SC Lessons and Time Students Used CAI

\begin{tabular}{|c|c|c|c|c|c|}
\hline Teacher & Grade & $\begin{array}{c}\text { Number } \\
\text { of } \\
\text { Students }\end{array}$ & Treatment & $\begin{array}{c}\text { Number of } \\
\text { SC Lessons } \\
\text { (Lessons } \\
\text { Last.20 } \\
\text { minutes) }\end{array}$ & $\begin{array}{c}\text { Number of } \\
\text { CAI Sessions } \\
\text { (Sessions Last } \\
\text { 20 minutes) }\end{array}$ \\
\hline Teacher 1 & 6 & 9 & CAI & - & 40 \\
\hline Teacher 1 & 6 & 4 & CAI & - & 40 \\
\hline Teacher 2 & 6 & 8 & CAI with SC & 20 & 20 \\
\hline Teacher 2 & 6 & 10 & CAI with SC & 20 & 20 \\
\hline Teacher 3 & 6 & 5 & SC & 40 & - \\
\hline Teacher 4 & 6 & 16 & SC & 40 & - \\
\hline Teacher 1 & 7 & 6 & CAI & - & 40 \\
\hline Teacher 1 & 7 & 7 & CAI & - & 40 \\
\hline Teacher 2 & 7 & 4 & CAI with SC & 20 & 20 \\
\hline Teacher 5 & 7 & 8 & SC & 40 & - \\
\hline Teacher 6 & 7 & 8 & SC & 40 & - \\
\hline Teacher 1 & 8 & 7 & CAI & - & 40 \\
\hline Teacher 2 & 8 & 9 & CAI with SC & 20 & 20 \\
\hline Teacher 7 & 8 & 12 & SC & 40 & - \\
\hline
\end{tabular}

Students in all three groups were administered the mathematics achievement pretest and attitude survey at the beginning of the 8 -week period and again at the end of the 8-weeks. 
Figure 2

Design Diagram

\begin{tabular}{llll} 
NR $_{\text {SC }}$ & $\mathrm{O}_{1}$ & $\mathrm{X}$ & $\mathrm{O}_{2}$ \\
\hline $\mathrm{NR}_{\text {CAI }}$ & $\mathrm{O}_{1}$ & $\mathrm{X}$ & $\mathrm{O}_{2}$ \\
\hline $\mathrm{NR}_{\text {CAI with SC }}$ & $\mathrm{O}_{1}$ & $\mathrm{X}$ & $\mathbf{O}_{2}$
\end{tabular}

Operations concepts and skills identified by their MAP results. Teachers in the control group used lessons from Do the Math (M. Burns, 2011), and these lessons were identical to those taught to the treatment group. Lessons were designed to build conceptual understanding through small-group instruction, explicit instruction, and hands-on experience. The control group did not use SuccessMaker during the 18-week treatment.

CAI group (NR CAI). The CAI treatment group participated in SuccessMaker, which comprised most of their instruction. The program developer suggests that students spend a minimum of 20 minutes per day on SuccessMaker. Students spent approximately $75 \%$ of their instructional time on SuccessMaker and approximately $25 \%$ of their time working with a teacher on skills and concepts that supported the students' work on SuccessMaker. The program developer does not provide a structured model for teacherdelivered instruction to support student use of the program. However, detailed reports provide a picture of the concepts and skills students need assistance with, and the teacher was directed to use these reports to guide unstructured lessons for students. 
The teacher was directed to monitor students while they worked on SuccessMaker and to provide students with help if they asked for it, but Do the Math structured curriculum was not used. Instead, the teacher used student diagnostic reports provided by SuccessMaker to determine instructional focus. Then the teacher conducted one-on-one or small-group lessons with students based on the topics identified by SuccessMaker but did not use a structured curriculum for those lessons. Rather, the teacher informally addressed student misconceptions using explicit instruction, and then the students practiced the procedures using worksheets generated by SuccessMaker. Even though the teacher provided some instruction, the students received most instruction via CAI.

CAI with SC group (NR CAI with SC). The CAI with SC (NR CAI with SC) treatment group received instruction via SuccessMaker $50 \%$ of the time and small-group lessons from Do the Math (M. Burns, 2011) 50\% of the time. Although these lessons were identical to those provided to the control group, one difference was that the teacher in the treatment group was instructed to use the diagnostic data on student performance provided by SuccessMaker to make connections between the small-group lessons and the mathematics skills and concepts students were studying on the computer.

Each week, the teacher used the diagnostic reports produced by SuccessMaker to identify students' areas of weakness. Then, the teacher aligned these areas of difficulty with the lessons planned for the week. During the lesson, the teacher addressed student misconceptions by making explicit connections to concepts that would help students understand the procedures they were struggling with on SuccessMaker. The researcher provided examples of how to make these connections using research-based mathematics 
interventions (M. K. Burns, Codding, Boice, \& Lukito, 2010; Fuchs et al., 2008; Fuchs, Powell, Seethaler, Fuchs, et al., 2010; Gersten et al., 2009; Ketterlin-Geller et al., 2008; Kroesbergen \& Van Luit, 2005; Maccini, Mulcahy, \& Wilson, 2007; Rivera \& Bryant, 1992).

\section{Fidelity of Implementation}

CAI. The fidelity of implementation of SuccessMaker was monitored weekly using the CAI Observation Tool (see Appendix) created by the researcher. To reduce bias, the school's resource teacher and the researcher conducted observations. Also, as recommended by the program developer, the researcher compiled data from the SuccessMaker reports to measure fidelity of implementation. The SuccessMaker reports provided a detailed account of student attendance, number of sessions completed, and overall student performance.

To describe the type of interactions the teacher had with students, the teacher completed the CAI Student-Teacher Interaction Log (see Appendix A) created by the researcher. When teachers completed the log, they were asked to categorize the type of interaction they had with a student as behavioral, technical, conceptual, or procedural, which helped the researcher to determine the level of interaction the teacher had with the students and the type of instruction provided. Directions on how to complete the logs were a component of the training all teachers received prior to treatment.

Interactions categorized as behavioral included those in which the teacher addressed students' behavior, such as redirecting a student who was off-task. Interactions categorized as technical included those in which the teacher provided assistance with the 
computer hardware or software, such as a teacher reminding a student of his or her password. Interactions categorized as conceptual were those in which the teacher taught a mathematical concept. Examples included: (a) explaining the meaning of operations, (b) explaining the relationships between operations (c) explaining the meaning of mathematics vocabulary (d) helping students form generalizations about mathematics concepts or procedures, and (e) helping students connect and interpret different representations of mathematics. Interactions categorized as procedural were those in which the teacher taught mathematics procedures. Examples included assisting a student with the traditional algorithms for addition, subtraction, multiplication, or division.

Structured Curriculum (SC). The fidelity of implementation of SC was monitored weekly using the Structured Curriculum Observation Tool (see Appendix A), which was created by the researcher. Data were gathered to ensure that the teacher followed the guidelines for instruction provided by the Do the Math program developers. It included items on the lesson process, instructional strategies, the use of explicit instruction, and gradual release. The program defines gradual release as lessons where the teacher models a procedure, students work in pairs to practices, and then students work individually on the procedure. To eliminate bias, the school's resource teacher, and the researcher conducted observations. The researcher compiled data to measure fidelity of implementation.

\section{Testing Procedures}

Students were administered MAP and TIMSS (2007) Student Questionnaire with both attitude and computer comfort-level components at the beginning of the study in 
September 2011. At the end of the 8-week period students were administered MAP and TIMSS (2007) Student Questionnaire with both attitude and computer comfort-level components again.

The MAP test took approximately one hour, and, on average, students responded to 50 items. These factors vary by student, because the test was customized for each student based on his or her responses. A virtual calculator was made available where appropriate. Students were allowed to use scratch paper, and the proctor was allowed to pronounce a word for a student, but no other accommodations, such as teacher paraphrasing or reading, were allowed. Students' scores were compiled by NWEA and made available via the Internet within a week after testing. Reports provided by NWEA are extensive and offer detailed descriptions of concepts and skills not yet mastered in the score range for each student.

\section{Data Analyses}

\section{ANCOVA and MANCOVA}

To answer research question one (Is there a significant instructional type effect on mathematics achievement?), the means of the mathematics performance of the three groups of students were tested using one-way analysis of covariance (ANCOVA). For this analysis, the researcher used the pretest score on the MAP and computer comfort level as the covariates. To address research question two (Is there a significant instructional type effect on mathematics attitude?), three means from the three dimensions of the attitude measure were tested using one-way multivariate analysis of 
covariance (MANCOVA). For this analysis, the pretest scores were used as the covariates. Covariates were used in this study to reduce the variability in the dependent variable by removing any variance predicted by the covariate. This practice reduces error and is especially helpful in improving accuracy and reducing systemic bias in nonrandomized studies such as this by helping to make a fairer comparison between treatment groups.

After means were tested and post hoc analysis was performed, strength of association or effect size was calculated using partial eta squared, $\eta^{2}$. This measure shows the strength of association between the type of instruction and mathematics achievement and was evaluated using Cohen's effect size scale (1988).

Assumptions. The following assumptions must be upheld when using ANCOVA or MANCOVA: (a) Independence, (b) Normality, (c) Homogeneity of regression (slopes) (d) Homogeneity of variance, (e) Parallelism of the regression planes, and (f) Error-free measurement of the covariate. In this study, the independence assumption was upheld because the scores in the three groups were independent from each other. The assumption for normality was upheld because the scores within each treatment population were normally distributed. This assumption was tested using a histogram diagram of scores for each group. Homogeneity of variance is the assumption that the variance in each group is equal. This assumption was tested using the Box's Test of Equality of Covariance Matrices statistical test and, as long as differences between groups were minimal, this assumption was met. Levene's Test of Equality of Error Variances ensures that the error variance of the dependent variable is equal across groups, and, as long as 
differences between groups were minimal, this assumption was met (Stevens, 2009). Furthermore, scatter plots of regression lines were analyzed to ensure a linear relationship between covariates and dependent variables and parallelism of the regression planes.

\section{Factor Analysis}

In addition to the MANCOVA used to address research question two (Is there a significant instructional type effect on mathematics attitude?), principle component factor analysis was conducted to identify the factor structure of the scores from the attitude measure. Henson and Roberts (2006) noted that exploratory factor analysis is used to identify a factor structure for a set of variables. Exploratory factor analysis was used because this study sought to examine the factor structure of attitudes related to struggling students. Although the factor structure of scores from TIMSS (2007) Student Questionnaire had previously been examined by several researchers, the samples in those studies represented a large body of general student population in the United States. It is not known whether the factor structure of the scores from struggling students would be similar to the ones that have been reported.

\section{Limitations}

The limitations of this study include: (a) the fact that the study was not quasiexperimental; (b) fidelity of program implementation; (c) student characteristics, specifically computer comfort level, socio-economic-status and literacy levels; and (d) the measure of long-term effects of treatment. Although efforts were made to control for these confounding variables, limitations to this study were still present. 
The manipulation of treatment and random assignment are cardinal aspects of a quasi-experimental design. Treatment was manipulated in this study, and scheduling conflicts restricted the use of random assignment. The lack of random assignment in this study limited an examination of the cause-and-effect relationship between treatment and mathematics achievement and attitude scores.

Due to the nature of Baxter Middle School's schedule, it was not possible to randomly assign teachers to different treatment groups. In an effort to control for and explain possible teacher effects, teachers attended training on the type of instruction they were to deliver. Additionally, the principal, resource teacher, and researcher monitored fidelity of implementation with classroom observations to ensure that instruction was consistent across all treatments and met guidelines set by program developers. To explain differences in student-teacher interactions, teachers were asked to keep a log indicating the type of interactions he or she had with each student. The log indicated whether the teacher assisted the student with a behavioral, technical, conceptual, or procedural question and identified the type of assistance the teacher gave. This log was especially helpful in describing the interactions in the NR $\mathrm{CAI}_{\mathrm{I}}$, as a structured curriculum was not used to address student misconceptions. However, differences in teacher dispositions and their relationships with the student subjects still presented the potential to be a confounding factor in this study.

Computer comfort level presented a limitation because both MAP and one of the treatments took place via the computer. To control for this confounding effect, comfort level was measured using items on the TIMSS (2007) Student Questionnaire. 
Another limitation was that students' literacy and socioeconomic levels varied and were not necessarily representative of the population. Although the pretest served as a means of control for these variables by identifying a starting place for each student's growth or lack or growth, these factors could still influence the long-term effects of treatment.

Finally, the long-term effects of treatment were not measured, so it is difficult to determine whether the effects of treatment would be evident one to two years after treatment. The length of treatment was comparable to that of most studies of this nature as revealed in the literature but may not have longevity beyond three months.

\section{Summary}

This chapter provided a detailed account of the research design for this study. The goal was to determine the effects of instructional type on mathematics achievement and attitudes. This chapter outlined the study with respect to its research questions and hypothesis that the combination of $\mathrm{CAI}$ and $\mathrm{SC}$ will have a positive impact on mathematics achievement and attitude. It included a description of population, sample, procedures for participant selection, major variables, instruments, data analysis procedures for testing and treatment, and potential limitations to the study. In addition, it showed how each of these components contributes to the overall goals. 


\section{CHAPTER IV: RESULTS}

\section{Purpose and Research Questions}

The purpose of this study was to determine the effect instructional type had on struggling students' performance in mathematics and on their attitudes toward mathematics. Computer-assisted instruction (CAI), teacher-facilitated explicit instruction using a structured curriculum (SC), and the combination of CAI and SC were specific instructional strategies of interest. The research questions used to guide this study were:

1. Is there a significant effect of instructional type on mathematics achievement?

2. Is there a significant effect of instructional type on mathematics attitude?

3. What is the factor structure of attitude scale scores obtained from the mathematics attitude survey?

\section{Fidelity of Implementation}

In this study, fidelity of implementation was measured in three ways. First the school's mathematics resource teacher and the researcher each conducted observations using observation rubrics created by the researcher. The purpose of these observations was to determine the amount of the time students spent with the instructional strategies, how many students were on-task, the instruction topic, the pace at which the teacher covered the materials, and any extenuating circumstances such as behavior problems, or 
other class interruptions. Second, fidelity of implementation was measured by reports generated by the CAI program which summarized (1) the amount of time students spent on the program, (2) the number of sessions they completed, and (3) the percent of skills students mastered. Third, fidelity of implementation was measured by records kept by the CAI teachers documenting the types of interactions they had with students. The three groups in this study used two programs. The non-random CAI (NR CAI) group used SuccessMaker for their instruction. The non-random CAI with SC group (NR CAI with SC) used SuccessMaker and Do the Math Now while the non-random SC group (NR $\mathrm{sC}$ ) used Do the Math Now. Observations were used to monitor both CAI and SC while the program reports and teacher logs were only used with the CAI teachers.

\section{Computer Assisted Instruction (CAI)}

The CAI used in this study was a program called SuccessMaker. SuccessMaker is a computer program that uses answer-pattern response to craft individualized lessons for each student. The two treatment groups that use SuccessMaker were the CAI only (NR

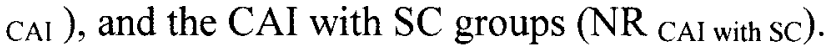

Frequency of CAI Sessions. As recommended by the program developer, the researcher compiled data from the SuccessMaker reports to measure fidelity of implementation. The SuccessMaker program generates a detailed report on each student's progress on SuccessMaker. These reports provided a detailed account of amount of time each student spent on the program, the number of sessions completed, and the percent of skills mastered. The program designers suggest students use SuccessMaker for a minimum of 20 minutes a day, five days a week. Every 20 minutes 
students spend on the program is considered a session, so the program designers recommend students participate in at least five sessions of SuccessMaker per week. The researcher examined both the total time students spent on the program and the number of sessions because students who are not monitored may not have completed a session as instructed. Based on the length of the study, the researcher expected students to spend approximately 800 minutes on SuccessMaker, completing approximately 40 sessions. Neither group met this expectation, as indicated in Table 2.

Table 2

Summary of Student Progress on CAI

\begin{tabular}{|c|c|c|}
\hline & NR CAI & NR CAI with SC \\
\hline Number of Students & 35 & 27 \\
\hline Maximum time on CAI (min) & 752 & 1090 \\
\hline Minimum time on CAI (min) & 87 & 181 \\
\hline Mean time on CAI (min) & 301.11 & 530.96 \\
\hline Standard Deviation (SD) & 176.76 & 204.07 \\
\hline Maximum CAI Sessions * & 38 & 55 \\
\hline Minimum CAI Sessions* & 4 & 9 \\
\hline Mean CAI Sessions* & 15.10 & 26.56 \\
\hline Standard Deviation (SD) & 8.83 & 10.23 \\
\hline Mean \% of Skills Mastered & 78.91 & 70.56 \\
\hline Standard Deviation (SD) & 7.15 & 4.40 \\
\hline
\end{tabular}

* 1 CAI session $=$ approximately 20 minutes

Overall, students in the NR $\mathrm{NAI}_{\text {with }} \mathrm{SC}$ group ( $\left.M=530.96, S D=204.07\right)$ spent more time on the computer-assisted instruction than those in the $\mathrm{NR}_{\mathrm{CAl}}$ group ( $M=301.11$, $S D=176.76)$. This finding is also confirmed by the mean number of CAI sessions for

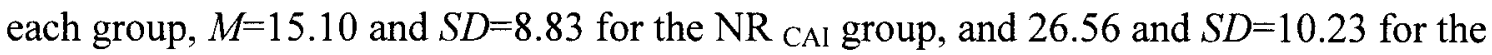


$\mathrm{NR}_{\mathrm{CAI}}$ and SC group. While the $\mathrm{NR}_{\mathrm{CAl}}$ group completed fewer sessions, their mean for percent of skills mastered $(M=78.91, S D=7.15)$ was eight percent higher than the mean for the NR CAI with SC group $(M=70.56, S D=4.40)$.

Examination of the standard deviations for the Mean time on CAI and Mean CAI Sessions calls to questions fidelity of implementation of the CAI for all student subjects related to the frequency of use with CAI. The standard deviations for both Mean time on CAI and Mean CAI Sessions were very large, suggesting a wide spread of values for these two variables. For example, the standard deviation for Mean time on CAI for the

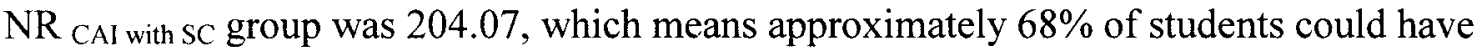
spent between 326.89 and 735.03 minutes using the CAI. Similarly, $68 \%$ of students in the $\mathrm{NR}_{\text {CAI }}$ group could have spent between 124.35 and 477.87 minutes using the CAI. This wide range of CAI use could have contributed to lower mathematics achievement scores than what might be possible had students spent more time on the CAI.

Percent of Skills Mastered. Another measure that indicates fidelity of implementation is the mean for percent of skills mastered. The SuccessMaker program calculates the percent of skills each student has mastered to show how many skills a student has mastered out of the total number of skills they encounter during their sessions. While the NR $\mathrm{CAI}_{\text {g }}$ group completed fewer sessions, their mean for percent of skills mastered $(M=78.91, S D=7.15)$ was eight percent higher than the mean for the NR CAl with sc group $(M=70.56, S D=4.40)$. The difference in these means is unexpected because the $\mathrm{NR}_{\text {CAI }}$ group spent less time using the CAI than the NR CAI with SC group. However, the difference may be due to the design of the SuccessMaker program. 
SuccessMaker begins instruction for a student at their current level of understanding and gradually increases difficulty as students master foundational skills and concepts. It is possible that the students in the NR CAI with SC group encountered more difficult content because they participated in more CAI sessions; therefore their percentage of mastery was not as high as the $\mathrm{NR}$ CAI group who encountered easier content.

Enactment of the Curriculum. Fidelity of implementation of SuccessMaker was monitored weekly using the CAI Observation Tool (see Appendix) created by the researcher. A total of 14 observations were conducted. Below is a table summarizing these observations. The observation form was designed to capture information on the amount of time students spent on SuccessMaker and the number and type of interactions the teacher had with students. Interactions were classified as behavioral, technical, conceptual, or procedural. Interactions categorized as behavioral included those in which the teacher addressed students' behaviors, such as redirecting a student who was off-task. Interactions categorized as technical included those in which the teacher provided assistance with the computer hardware or software, such as a teacher reminding a student of his or her password. Interactions categorized as conceptual were those in which the teacher instructed on a mathematical concept, such as the part to whole relationship in fractions, and procedural were interactions where the teacher instructed students on procedures for calculating solutions such as telling students a list of steps for solving equations. Observations were organized by treatment group, CAI only (NR CAI), and CAI with SC (NR $\mathrm{CAI}$ with SC). 
Table 3

Summary of CAI Observations

\begin{tabular}{|c|c|c|c|c|}
\hline $\begin{array}{c}\text { Observation } \\
\text { Date }\end{array}$ & $\begin{array}{c}\text { Approximat } \\
\text { e Time on } \\
\text { SuccessMak } \\
\text { er per } \\
\text { Student } \\
\end{array}$ & $\begin{array}{c}\text { Treatment } \\
\text { Group }\end{array}$ & $\begin{array}{l}\text { Number of } \\
\text { Student } \\
\text { interactions }\end{array}$ & $\begin{array}{c}\text { Type of Student- } \\
\text { Teacher Interactions }\end{array}$ \\
\hline $10 / 17$ & 20 minutes & $N_{\text {CAI }}$ & 15 or more & $\begin{array}{l}\text { All behavioral. Re- } \\
\text { directing students. }\end{array}$ \\
\hline $10 / 17$ & 20 minutes & $\mathrm{NR}_{\text {CAI }}$ & 7 & $\begin{array}{l}1 \text { conversation about a } \\
\text { topic other than those } \\
\text { listed. } 4 \text { behavioral. } 1 \\
\text { procedural on } \\
\text { memorizing } \\
\text { multiplication facts. }\end{array}$ \\
\hline $10 / 17$ & 20 minutes & $\mathrm{NR}_{\text {CAI with SC }}$ & 3 & 3 behavioral. \\
\hline $10 / 17$ & 20 minutes & $\mathrm{NR}_{\text {CAl with SC }}$ & 1 & $\begin{array}{l}\text { I technical explaining } \\
\text { how to draw a line } \\
\text { using the program. }\end{array}$ \\
\hline $11 / 3$ & 15 minutes & $\mathrm{NR}_{\mathrm{CAI}}$ & 10 & $\begin{array}{l}1 \text { procedural interaction } \\
\text { about how to find } \\
\text { factors of a number. } 9 \\
\text { behavioral. }\end{array}$ \\
\hline $11 / 3$ & 20 minutes & $\mathrm{NR}_{\mathrm{CAI}}$ & 5 & $\begin{array}{l}1 \text { technical assisting a } \\
\text { student using the } \\
\text { program. } 4 \text { behavioral. }\end{array}$ \\
\hline $11 / 3$ & 20 minutes & $\mathrm{NR}_{\text {CAI }}$ & 12 & $\begin{array}{l}2 \text { other topics. } 7 \\
\text { behavioral. } 2 \text { procedural } \\
\text { interactions about how } \\
\text { simplify a fraction. }\end{array}$ \\
\hline $11 / 3$ & 20 minutes & $\mathrm{NR}_{\mathrm{CAl}}$ with SC & 3 & $\begin{array}{l}1 \text { behavioral. } 2 \\
\text { procedural on how to } \\
\text { count money. }\end{array}$ \\
\hline $11 / 3$ & 20 minutes & $N_{\text {CAI with SC }}$ & 1 & 1 behavioral. \\
\hline $11 / 3$ & 20 minutes & $\mathrm{NR}_{\text {CAI with SC }}$ & 0 & \\
\hline $11 / 9$ & 20 minutes & $\mathrm{NR}_{\text {CAI with SC }}$ & 23 & $\begin{array}{l}\text { Procedural interactions } \\
\text { on addition with } \\
\text { regrouping and } \\
\text { measurement of time. }\end{array}$ \\
\hline $11 / 17$ & 20 minutes & $\mathrm{NR}_{\mathrm{CAI}}$ & 3 & 3 behavioral. \\
\hline $11 / 17$ & 20 minutes & $\mathrm{NR}_{\text {CAI }}$ & 2 & $\begin{array}{l}1 \text { technical. } 1 \\
\text { behavioral. }\end{array}$ \\
\hline $12 / 5$ & 15 minutes & $\mathrm{NR}_{\mathrm{CAI}}$ & 16 & Mostly behavioral. \\
\hline
\end{tabular}


During observations the resource teacher and researcher reported approximately 64 student-teacher interactions involving student behavior. In contrast, they reported 30 interactions where the teacher explained a mathematics procedure to a student, three that were technical in nature, and two that were on other topics not described on the observation form. The results of these 14 observations suggest behavior problems may have posed a barrier to ensuring fidelity of implementation.

In addition to classroom observations conducted by the researcher and mathematics resource teacher, both the $\mathrm{NR}_{\mathrm{CAI}}$ and $\mathrm{NR}_{\mathrm{CAI}}$ with SC group teachers were asked to complete a CAI Student-Teacher Interaction Log (see Appendix) created by the researcher. In this log, teachers were asked to categorize the type of interaction they had with a student as behavioral, technical, conceptual, or procedural, which helped the researcher to determine the level of interaction the teacher had with the students and the type of instruction provided. Of the two teachers who used the CAI program, only the NR

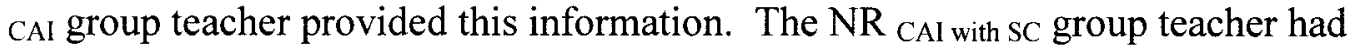
extenuating personal circumstances, which kept her from being able to complete the log. Another caveat was that the log provided by the teacher for the NR $\mathrm{NAI}_{\text {g }}$ group only included data for four of the eight weeks in which the study took place. The table below provides a summary of the reported types of interactions the teacher for the NR $\mathrm{CAI}$ group reported having with students while they were participating in CAI. 
Table 4

Percent of Type of Interactions Reported by CAI Teacher

\begin{tabular}{|c|c|c|}
\hline $\begin{array}{c}\text { Type of } \\
\text { Interaction }\end{array}$ & $\begin{array}{c}\text { Percent of } \\
\text { Interactions }\end{array}$ & $\begin{array}{c}\text { Total Time in } \\
\text { Minutes }\end{array}$ \\
\hline Behavioral & $47.50 \%$ & 214 \\
\hline Technical & $12.50 \%$ & 56 \\
\hline Conceptual & $10.00 \%$ & 4 \\
\hline Procedural & $30.00 \%$ & 45 \\
\hline
\end{tabular}

Based on the summary of data provided, the $\mathrm{NR}_{\text {CAI }}$ teacher reported mostly interacting with students regarding their behavior (47.50\%) for an approximate total of 215 instructional minutes, or 4.28 instructional periods. The teacher classified $12.50 \%$ of their interactions as technical, which represented a total of 56 minutes, approximately 1.12 instructional period. This suggests that approximately 5.40 instructional periods were spent on behavior and technical problems.

The teacher also categorized $30.00 \%$ of their instruction as procedural, lasting a total of 45 minutes, or approximately one instructional period. Meanwhile, the teacher reported that only $10.00 \%$ of their interactions were categorized as conceptual; the $10.00 \%$ reported represented a total of only four minutes of instruction.

Overall, fidelity of implementation with the SuccessMaker program may have impacted the results of this study. Based on observation and reporting data, student behavior seemed to keep many students from completing the recommended time on the SuccessMaker program. The implications of these results will be discussed more in the next chapter. 


\section{Structured Curriculum (SC)}

The SC used in this study was a program called Do the Math Now. Do the Math Now is a 12-module intervention curriculum designed to focus on Number and Operations. Lessons from this program were designed to last 20 minutes each and are scripted for teachers. Teachers in this study were expected to follow the scripted lesson, which included teacher-lead whole-class explicit instruction, partner, and individual student work. The treatment groups that used Do the Math Now were NR SC groups.

Frequency of Lessons. One potential breach of fidelity was that SC groups did not complete as many lessons as the researcher anticipated. The researcher anticipated groups would complete 40 lessons; however, the average was 23 lessons. While the number of lessons was far less than the researcher anticipated, each group completed roughly the same number of lessons so this lack of lessons did not pose a breach in fidelity of implementation.

Enactment of the Curriculum. The fidelity of implementation of SC was monitored weekly using the Structured Curriculum Observation Tool (see Appendix), which was created by the researcher based on the recommendations in the SC teacher guide on how to use the materials. The following categories included: Approximate Length of Lesson, Fraction of Students Participating in the Lesson, Lesson Topic, and Notes. The notes category was used to document any deviations from the scripted lesson plan. Data were gathered to ensure that the teacher followed the guidelines for instruction provided by the Do the Math Now program developers. 
Table 5

Summary of SC Observations

\begin{tabular}{|c|c|c|c|c|}
\hline $\begin{array}{c}\text { Observation } \\
\text { Date }\end{array}$ & $\begin{array}{l}\text { Treatment } \\
\text { Group }\end{array}$ & $\begin{array}{l}\text { Approximate } \\
\text { Length of } \\
\text { Lesson }\end{array}$ & $\begin{array}{c}\text { Fraction of } \\
\text { Students } \\
\text { Participating } \\
\text { in Lesson } \\
\end{array}$ & Lesson Topic \\
\hline $10 / 17$ & $\mathrm{NRC}_{\mathrm{SC}}$ & 25 minutes & $12 / 12$ & $\begin{array}{c}\text { Multiplication } \\
\text { sentences "groups } \\
\text { of". }\end{array}$ \\
\hline $11 / 17$ & $\begin{array}{c}\text { NRC ClA with } \\
\text { SC }\end{array}$ & 20 minutes & $3 / 3$ & Basic fact inventory. \\
\hline $11 / 3$ & $\mathrm{NRC}_{\mathrm{SC}}$ & 50 minutes & $15 / 15$ & $\begin{array}{c}\text { Progress monitoring } \\
\text { and review. }\end{array}$ \\
\hline $11 / 9$ & $\mathrm{NRC}_{\mathrm{SC}}$ & 50 minutes & $13 / 13$ & $\begin{array}{c}\text { Reviewing a } \\
\text { progress monitoring } \\
10 \text { students } \\
\text { regrouped based on } \\
\text { errors. Other } \\
\text { students playing } \\
\text { multiplication } \\
\text { games. } \\
\end{array}$ \\
\hline $11 / 14$ & $\mathrm{NRC}_{\mathrm{SC}}$ & 50 minutes & $14 / 15$ & $\begin{array}{c}\text { Introduction and } \\
\text { initial practice with } \\
\text { splitting strategy. }\end{array}$ \\
\hline $11 / 17$ & $\mathrm{NRC}_{\mathrm{SC}}$ & 30 minutes & $4 / 5$ & $\begin{array}{c}\text { Recognizing } \\
\text { multiples. }\end{array}$ \\
\hline $11 / 17$ & $\mathrm{NRC}_{\mathrm{SC}}$ & 50 minutes & $9 / 9$ & $\begin{array}{c}\text { Splitting strategy } \\
\text { with } 12 \text { 's. }\end{array}$ \\
\hline $11 / 17$ & $\begin{array}{c}\text { NRC ClA with } \\
\text { SC }\end{array}$ & 20 minutes & $4 / 4$ & Splitting strategy. \\
\hline $12 / 5$ & $\mathrm{NRC}_{\mathrm{SC}}$ & 45 minutes & $11 / 16$ & $\begin{array}{l}\text { Introduction to } \\
\text { splitting strategy. }\end{array}$ \\
\hline $12 / 9$ & $\mathrm{NRC}_{\mathrm{SC}}$ & 50 minutes & $9 / 9$ & $\begin{array}{c}\text { Splitting strategy } \\
\text { with multiplication. }\end{array}$ \\
\hline $12 / 14$ & $\mathrm{NRC}_{\mathrm{SC}}$ & 25 minutes & $10 / 12$ & $\begin{array}{l}\text { Peer tutors teaching } \\
\text { the class "tack on a } \\
\text { zero" strategy for } \\
\text { multiplying by } 10 .\end{array}$ \\
\hline
\end{tabular}


Fidelity of implementation was upheld by six of the seven teachers, based on the observation results. Overall, most teachers adhered to the guidelines set out by the program developers. One teacher, however, used peer tutoring during which student peer tutors taught Do the Math Now lessons to the class of struggling students. The program was not designed to support this practice. While peer tutors somewhat followed the scripted lesson, their inexperience at teaching mathematics and lack of training may have impacted student learning. The researcher was not informed about how many times the teacher used this strategy and was unable to determine the effect this instructional change may have had on the results.

Fidelity of implementation with the Do the Math program was less of a concern than the fidelity of the SuccessMaker program, but still may have impacted the results of this study. While student behavior did not seem to pose a problem, one teacher did deviate from the scripted lessons. The implications of these results will be discussed more in the next chapter.

\section{Sample}

A total of 155 students participated in Baxter Middle School's mathematics intervention program during the time period ranging from September 2011-December 2011. However, 45 students were removed from the study for various reasons; 17 students were removed from the study because they transferred to another school and 24 students did not complete the first attitude survey and were thus removed from the study. Three students did not have a score for the mathematics achievement pre-test, so their data could not be analyzed. And, one student was removed from the study because he 
was transferred to a new class for behavior problems. A total of 110 students MAP scores and survey results were collected and analyzed.

\section{Descriptive Statistics}

The sample consisted of 57 females (51.8\%) and 53 males (48.2\%). There were a total of 51 sixth graders $(46.4 \%), 33$ seventh graders $(30 \%)$, and 26 eighth graders (23.6\%). All 110 students in the study were classified as struggling based on their mathematics achievement pre-test scores and of these, 31 students $(28.2 \%)$ were classified as having an intellectual disability, meaning they had been tested and qualified for special education services.

Students participated in one of three types of instruction, computer assisted instruction ( $\mathrm{NR}_{\mathrm{CAl}}$ ), structured curriculum ( $\mathrm{NR}_{\mathrm{SC}}$ ), or computer assisted instruction with structured curriculum ( $\mathrm{NR}_{\mathrm{CAl}}$ with SC). The chart below shows a breakdown of the students who received each type of instruction.

Table 6

Summary of Number of Students by Instructional Type

\begin{tabular}{|c|c|c|c|c|c|c|c|}
\hline \multirow{2}{*}{$\begin{array}{c}\text { Instructional } \\
\text { Type }\end{array}$} & \multirow{2}{*}{$\begin{array}{c}\text { Total } \\
\text { Number } \\
\text { of } \\
\text { Students } \\
\end{array}$} & \multicolumn{2}{|c|}{$\begin{array}{c}\text { Number } \\
\text { Male/Female }\end{array}$} & \multicolumn{3}{|c|}{$\begin{array}{c}\text { Number by } \\
\text { Grade }\end{array}$} & \multirow{2}{*}{$\begin{array}{l}\text { Number with } \\
\text { Intellectual } \\
\text { Disabilities }\end{array}$} \\
\hline & & Male & lle & $6^{\text {th }}$ & $7^{\text {th }}$ & $8^{\text {th }}$ & \\
\hline $\mathrm{NF}$ & 35 & 18 & 17 & 3 & 13 & 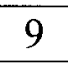 & 11 \\
\hline $\mathrm{NR}_{\mathrm{SC}}$ & 48 & 24 & 24 & 20 & 16 & 12 & 8 \\
\hline $\mathrm{NR}_{\text {CAl with SC }}$ & 27 & 11 & 16 & 18 & 4 & 5 & 12 \\
\hline
\end{tabular}




\section{Means and Standard Deviations for Major Variables}

Students were surveyed at the beginning of the study to determine their comfort level with using a computer. For these items, the observed Cronbach's alpha reliability coefficient was $\alpha=0.62$. This statistic measures the internal consistency of items, or how strongly they are related to each other. The more variance these items share, the more likely it is they measure the same latent variable, in this case computer comfort. This value is considered undesirable according to DeVellis (2003), meaning these items do not share a great amount of variance. However, since computer comfort was not a major variable and simply used to describe the sample's comfort level with computers, the researcher continued to report values related to computer comfort.

Out of the 110 students surveyed, 91 students $(82.7 \%)$ reported having a computer at home and 92 students $(83.6 \%)$ reported having Internet connections. In response to the question I am very comfortable working on the computer, $2.8 \%$ "disagreed a lot", $5.6 \%$ "disagreed a little", 30.8\% "agreed a little", and 60.7\% "agreed a lot". Furthermore, most students "agreed a lot" (44.8\%) when asked the question I have good computer skills, with $42.9 \%$ "agreeing a little", $11.4 \%$ disagreeing a little", and only $1 \%$ "disagreed a lot". The table below shows the results organized by treatment group. 
Table 7

Mean Responses to Computer Comfort-level by Instructional Type

\begin{tabular}{|l|c|c|c|}
\hline \multicolumn{1}{|c|}{ Instructional Type } & NR CAI & NR SC & NR CAI with SC \\
\hline $\begin{array}{l}\text { Mean Response to: Do you } \\
\text { have a computer at home? }\end{array}$ & 1.15 & 1.15 & 1.08 \\
\hline $\begin{array}{l}\text { Mean Response to: Do you } \\
\text { have Internet connection at } \\
\text { home? * }\end{array}$ & 1.14 & 1.08 & 1.13 \\
\hline $\begin{array}{l}\text { Mean Response to: I am } \\
\text { very comfortable working on } \\
\text { the computer?** }\end{array}$ & 3.54 & 3.49 & 3.44 \\
\hline $\begin{array}{l}\text { Mean Response to: I have } \\
\text { good computer skills?** }\end{array}$ & 3.38 & 3.29 & 3.27 \\
\hline $\begin{array}{l}\text { Mean Response to: How } \\
\text { often do you use the } \\
\text { computer?** }\end{array}$ & 3.49 & 3.11 & 3.74 \\
\hline $\begin{array}{l}\text { Mean Computer Comfort } \\
\text { Level }\end{array}$ & 3.50 & 3.39 & 3.37 \\
\hline
\end{tabular}

*For these items $1=$ Yes, $2=\mathrm{No}$

**For these items 1=Disagree a lot, 2=Disagree a little, 3= Agree a little, 4= Agree a lot

These results suggest that the sample was comfortable and confident using the computer. The results also showed students used the computer frequently. When asked the question How often do you use the compute, most students $(59.8 \%)$ reported using the computer daily. Related to the same question, $27.1 \%$ reported using the computer " $1-3$ times a week", and only $5.6 \%$ and $7.5 \%$ reported using the computer "every two weeks" and "once a month", respectively.

To measure the effects of instructional type on mathematics achievement, students took a mathematics achievement pre-test and post-test; these variables were named MAPNUMSEP and MAPNUMDEC respectively. Additionally, to measure the 
effect of instructional type on attitudes toward mathematics, students were administered a pre- and post-survey, these variables were named PRESURVEY and POSTSURVEY respectively.

The overall mean for MAPNUMSEP was 194.39, with a standard deviation of $11.78(N=109)$. The overall mean for MAPNUMDEC was 201.60 with a standard deviation of $14.22(N=105)$. According to NWEA (2009), the difference between these means (7.21) is within the normal range of growth for students who take MAP.

The PRESURVEY mean was 2.81 with a standard deviation of $0.51(N=110)$. Similarly, the POSTSURVEY mean was 2.84 with a standard deviation of $0.50(N=110)$. According to the scale used on the attitude survey ( $1=$ Disagree a lot, $2=$ Disagree a little, $3=$ Agree a little, $4=$ Agree a lot), it could be interpreted that students in this study had a neutral attitude about mathematics but that it was slightly more positive than negative.

The researcher also examined means and standard deviations for the three attitude scales and instructional type. The table below summarizes those means: 
Table 8

Means and Standard Deviations by Instructional Type for Pre and Post Attitude Scale

Scores $\left(N R_{C A I} N=35, N R_{S C} N=47, N R_{C A I \text { with } S C} N=27\right)$

\begin{tabular}{|c|c|c|c|}
\hline Instructional Type & $\mathbf{N R}_{\text {CAI }}$ & $\mathbf{N R}_{\mathbf{s C}}$ & $\mathbf{N R}_{\text {CAl with SC }}$ \\
\hline \multicolumn{4}{|l|}{$\begin{array}{c}\text { Self Confidence in Learning } \\
\text { Mathematics (SCLM) }\end{array}$} \\
\hline Pre-survey Mean & 2.58 & 2.41 & 2.56 \\
\hline Standard Deviation & 0.67 & 0.66 & 0.72 \\
\hline Post-survey Mean & 2.59 & 2.47 & 2.57 \\
\hline Standard Deviation & 0.78 & 0.66 & 0.86 \\
\hline Difference & 0.01 & 0.06 & 0.01 \\
\hline \multicolumn{4}{|l|}{$\begin{array}{l}\text { Positive Affect Towards } \\
\text { Mathematics (PATM) }\end{array}$} \\
\hline Pre-survey Mean & 2.52 & 2.45 & 2.55 \\
\hline Standard Deviation & 0.74 & 0.85 & 0.98 \\
\hline Post-survey Mean & 2.45 & 2.48 & 2.67 \\
\hline Standard Deviation & 0.75 & 0.89 & 1.00 \\
\hline Difference & -0.07 & 0.03 & 0.12 \\
\hline \multicolumn{4}{|l|}{ Valuing of Mathematics (VM) } \\
\hline Pre-survey Mean & 3.48 & 3.47 & 3.37 \\
\hline Standard Deviation & 0.52 & 0.61 & 0.42 \\
\hline Post-survey Mean & 3.51 & 3.39 & 3.50 \\
\hline Standard Deviation & 0.41 & 0.57 & 0.53 \\
\hline Difference & 0.03 & -0.08 & 0.13 \\
\hline \multicolumn{4}{|l|}{ Overall Attitude } \\
\hline Pre-survey Mean & 2.86 & 2.81 & 2.76 \\
\hline Standard Deviation & 0.45 & 0.57 & 0.48 \\
\hline Post-survey Mean & 2.86 & 2.78 & 2.91 \\
\hline Standard Deviation & 0.47 & 0.50 & 0.56 \\
\hline Difference & 0.00 & -0.03 & 0.15 \\
\hline
\end{tabular}

Changes in attitude scale scores were minimal overall. For most scales the change ranged from 0 to 0.15 . The group that showed the most change in attitude scores was NR CAl with SC demonstrating mean differences of $0.12,0.13$ and 0.15 for PATM, VM, 
and overall attitude respectively. This group did not show much change in SCLM $(0.01)$. Based on observations conducted by the researcher and mathematics resource teacher, this finding may be due to the teacher's nurturing personality and the small group and one-on-one attention students received in this group.

The $\mathrm{NR}_{\text {CAI }}$ group had a decline in the PATM attitude scale, which meant students' attitudes moved toward disliking mathematics. Although small (-0.07), this finding could be attributed to students' poor attitudes towards the CAI program SuccessMaker. The NR $\mathrm{CAI}_{\text {I }}$ teachers reported that many students did not like using the program, and several of the teacher's recorded behavior interactions were reported as occurring because students refused to use the program.

Meanwhile, the NR sc group had a very small decline in students' overall attitudes toward mathematics and a slightly larger decline (-0.08) in students' valuing of mathematics (VM). This finding may be due to the nature of the structured curriculum used in this study. The program, Do the Math Now, focuses on building conceptual understanding of basic mathematics concepts such as multiplication and division. Do the Math Now uses a gradual release approach with heavy emphasis on connections between pictures, words, and symbols to represent mathematics. The program is not rich in reallife examples or context. Students may have seen little connection to mathematics in the real world and consequently, their valuing of the subject declined.

\section{Correlations Between Major Variables}

According to Shavelson (1996), "the correlation coefficient is a measure of strength of association between two variables," (p.153). In this case, the correlation 
coefficient describes how strongly the major variables and covariates are related to each other. The table below summarizes the correlations between major variables.

Table 9

Summary of Means, Standard Deviations, and Correlations for Mathematics Achievement (MAPNUMSEP and MAPNUMDEC), COMPUTER COMFORT LEVEL(PRECOMPUTERCOMFORT), and Mathematics Attitude (PRESURVEY and POSTSURVEY) $(N=110)$

\begin{tabular}{|l|r|r|c|c|c|c|c|}
\hline \multicolumn{1}{|c|}{ Measure } & $\boldsymbol{M}$ & $\boldsymbol{S D}$ & $\mathbf{1}$ & $\mathbf{2}$ & $\mathbf{3}$ & $\mathbf{4}$ & $\mathbf{5}$ \\
\hline 1. MAPNUMSEP & 192.39 & 11.77 & 1 & & & & \\
\hline 2. MAPNUMDEC & 201.60 & 14.22 & $0.58^{*}$ & 1 & & & \\
\hline 3. PREMEANCOMPUTERCOMFORT & 2.81 & 0.51 & -0.02 & 0.07 & 1 & & \\
\hline 4. PRESURVEY & 2.84 & 0.50 & 0.06 & -0.02 & 0.09 & 1 & \\
\hline 5. POSTSURVEY & 3.28 & 0.61 & 0.01 & -0.04 & 0.02 & $0.66^{*}$ & 1 \\
\hline
\end{tabular}

${ }^{*} p<0.01$

The correlation coefficient for the pre and post mathematics achievement test (MAPNUMSEP and MAPNUMDEC) was 0.58 . This suggests that MAPNUMSEP increased as MAPNUMDEC increased. Additionally, approximately $33 \%$ of the variance in post-mathematics achievement scores (MAPNUMDEC) was shared by premathematics achievement scores (MAPNUMSEP). These results showed a moderate correlation between MAPNUMSEP and MAPNUMDEC. The correlation between the pre- and post-attitude survey scores (PRESURVEY and POSTSURVEY) was also moderate $(r=0.66)$, with approximately $45 \%$ of the variance in the post-survey scores shared by the pre-survey scores. 
Other correlations, however, were not as high. In fact, the correlation between computer comfort level (COMPUTERCOMFORTLEVEL) and post-mathematics achievement scores was 0.07 , indicating virtually no relationship between these variables. Due to the minimal relationship between computer comfort level and mathematics achievement scores, the researcher eliminated computer comfort level as a covariate.

\section{Analysis of Research Questions One and Two}

To address research questions: 1) Is there a significant effect of instructional type on mathematics achievement, and 2) Is there a significant effect of instructional type on mathematics attitude, means were tested using one-way analysis of covariance (ANCOVA) and one-way multivariate analysis of covariance (MANCOVA). ANCOVA was used to answer research question one, while MANCOVA was used to answer research question two. As stated in a previous section, covariates were used in this study to reduce the variability in the dependent variable by removing any variance predicted by the covariate. This practice reduces error and is especially helpful in improving accuracy and reducing systemic bias in nonrandomized studies by helping to make a fairer comparison between treatment groups.

\section{ANCOVA Analysis}

To address research question one, means were tested using one-way analysis of covariance (ANCOVA). For this analysis, the pretest score on MAP was used as a covariate. The correlation coefficient for the pre and post mathematics achievement test (MAPNUMSEP and MAPNUMDEC) was 0.58 indicating a strong, positive relationship 
between the two variables. The obtained Pearson's Correlation for MAP post-test (MAPNUMDEC) and computer comfort level was 0.07 , indicating virtually no relationship between these variables. Therefore this variable was not used as a covariate.

ANCOVA Assumptions. The following assumptions must be upheld when using ANCOVA: (a) independence, (b) normality, (c) homogeneity of regression (slopes) (d) homogeneity of variance, (e) parallelism of the regression planes, and (f) error-free measurement of the covariate.

Independence and Normality. In this study, the independence assumption was upheld because the scores in the three groups were independent from each other. The assumption for normality was upheld because the scores within each treatment population were normally distributed. This assumption was tested using a histogram diagram of scores for each group. To view these histograms, see Figures 3-5 in appendix B.

Homogeneity of regression and variance. Homogeneity of regression (slopes) assumes no significant interaction between the covariate and the independent variable in the prediction of the dependent variable. According to the results, there was no significant interaction between the covariate and the independent variable, $F(2,99)=$ $0.472, p=0.625, p>0.05$. Therefore, this assumption was met.

Levene's Test of Equality of Error Variances ensures that the error variance of the dependent variable is equal across groups. According to the results, the differences between groups were minimal, $F(2,102)=0.280, p=0.756, p>0.05$; therefore this assumption was met. 
Parallelism of the regression planes. Scatter plots of regression lines were analyzed to ensure a linear relationship among covariates and dependent variables and parallelism of the regression planes. To view these scatterplots, see Figures 3-5 in appendix B.

The scatterplot indicated a strong linear relationship between MAP post-test scores (MAPNUMDEC) and the covariate Map pre-test scores (MAPNUMSEP).

\section{ANCOVA Results}

The table below shows means and standard deviations for the pre- and pos-t mathematics achievement test by instructional type.

Table 10

Means and Standard Deviations by Instructional Type for Pre and Post Mathematics Achievement Scores

\begin{tabular}{|c|c|c|c|}
\hline & NR $_{\text {CAI }}$ & NR $_{\text {SC }}$ & NR $_{\text {CAI with SC }}$ \\
\hline MAPNUMSEP & 203.43 & 192.75 & 185.52 \\
\hline $\begin{array}{c}\text { Standard Deviation } \\
\text { (SD) }\end{array}$ & 10.93 & 6.69 & 12.00 \\
\hline MAPNUMDEC & 208.66 & 201.51 & 191.88 \\
\hline $\begin{array}{c}\text { Standard Deviation } \\
\text { (SD) }\end{array}$ & 12.24 & 12.41 & 14.52 \\
\hline $\begin{array}{c}\text { Difference Between } \\
\text { Pre and Post-test }\end{array}$ & 5.23 & 8.76 & 6.36 \\
\hline
\end{tabular}

$\left(N R_{C A I} N=35, N R_{S C} N=47, N R_{C A I \text { with } S C} N=27\right)$

The table shows that while students in all three groups showed some improvement from pre- (MAPNUMSEP) to post-test (MAPNUMDEC), the change was minimal. According to the test publishers, this growth is within the normal range for students 
(NWEA, 2009). Normal range is growth a typical middle school mathematics student would achieve without additional time in an intervention classroom.

In addition to examining the weighted means, the researcher used ANCOVA to examine means once they had been adjusted for the effect of the covariates, in this case pre mathematics achievement scores (MAPNUMSEP). The estimated marginal means for $\mathrm{NR}_{\mathrm{CAl}}$ and NR $\mathrm{sc}$ were very similar, 203.28 with a standard error of 2.21 and 202.83 with a standard error of 1.74 respectively. Meanwhile, the adjusted mean for $\mathrm{NR}_{\mathrm{CAI}}$ with SC was slightly smaller; 197.04 with a standard error 2.51 . At first glance, the difference between these means was minimal which was confirmed by the ANCOVA analysis. The results of the analysis indicated no statistical difference in MAP post-test mean between the different instructional types, $F(2,101)=2.01, p=0.13, p>0.05$ (See Table 11). The test assessed the differences among adjusted means for the three groups (NR $\mathrm{CAI}$ $=203.28, \mathrm{NR}_{\mathrm{SC}}=202.83$, and NR $\mathrm{CAl}$ with SC $\left.=197.04\right)$ and found no statistically significance difference between them, meaning the instructional type did not have a significant effect on mathematics achievement. Therefore, no post-hoc analyses were conducted. Strength of association or effect size was calculated using partial eta squared, $\eta^{2}$. This measure shows the strength of association between the type of instruction and mathematics achievement and was evaluated using Cohen's effect size scale (1988). The strength of association between instructional type and mathematics achievement was only $4 \%$, which is extremely small according to Cohen's effect size scale (1988). This means instructional type accounted for only $4 \%$ of the variance in mathematics achievement and that these two variables are not strongly associated with each other. 
Table 11

Analysis of Covariance (ANCOVA) for Mathematics Achievement by Instructional Type $(N=102)$

\begin{tabular}{llllll}
\hline Source & $S S$ & $d f$ & $M S$ & $F$ & Sig. \\
\hline $\begin{array}{l}\text { MAP Mathematics } \\
\text { Achievement Pre-Test }\end{array}$ & 3531.84 & 1 & 3531.84 & 26.63 & 0.00 \\
Instructional Type & 554.98 & 2 & & & \\
Error & 13395.93 & 101 & 132.63 & & \\
Total & 21033.20 & 104 & & & \\
\hline
\end{tabular}

The results of the ANCOVA revealed no statistical difference in mathematics achievement score between students who participated in different instructional types. In other words, there is no statistically significant effect of instructional type on mathematics achievement.

\section{MANCOVA Analysis}

To address research question two (Is there a significant instructional type effect on mathematics attitude?), three means from the three dimensions of the attitude measure were tested using one-way multivariate analysis of covariance (MANCOVA). For this analysis, the pretest scores for MAP and overall attitude were used as the covariates. As stated in previous sections, the correlation coefficient for the pre and post mathematics achievement test (MAPNUMSEP and MAPNUMDEC) was .58 indicating a strong, positive relationship between the two variables. The correlation coefficient for pre- and 
post-attitude survey (PRESURVEY and POSTSURVEY) was $r=0.66$. This correlation was also considered strong with approximately $45 \%$ of the variance in the post-survey scores accounted for by the pre-survey scores. This correlation showed a strong and positive relationship between pre-and post-survey attitude scores. For example, having positive attitudes prior to the study was strongly correlated with positive attitudes at the end of the study.

MANCOVA Assumptions. The following assumptions must be upheld when using MANCOVA: (a) independence, (b) normality, (c) homogeneity of regression (slopes) (d) homogeneity of variance, (e) parallelism of the regression planes, and (f) error-free measurement of the covariate.

Independence and Normality. As stated in previous sections, the independence assumption was upheld because the scores in the three groups were independent from each other and the assumption for normality was upheld because the scores within each treatment population were normally distributed.

Homogeneity of regression and variance. Homogeneity of variance is the assumption that the variance in each group is equal. This assumption was tested using the Box's Test of Equality of Covariance Matrices statistical test. Since the sample sizes for each group were unequal, this analysis was conducted at the 0.001 alpha level rather than 0.05 level (Garson, 2011). According to the results, there was no significant interaction between the covariate and the independent variable, $F(30,21,695.00)=1.50$, $p=0.04, \mathrm{p}>0.001$. The researcher concluded this assumption was met. 
As stated above, Levene's Test of Equality of Error Variances ensures equal variance across groups and according to the results, the differences between groups were minimal for all five categories: 1) MAP post-test $(F(2,102)=0.31, p=0.73, \mathrm{p}>0.05), 2)$ Post mean for PATM $(F(2,102)=3.03, p=0.053, \mathrm{p}>0.05), 3)$ Post mean for $\operatorname{SCLM}(F(2$, 102) $=1.86, p=0.16, \mathrm{p}>0.05), 4)$ Post mean for $\operatorname{VM}(F(2,102)=2.35, p=0.10, \mathrm{p}>0.05)$, and 5) Post attitude survey mean $(F(2,102)=0.96, p=0.39, \mathrm{p}>0.05)$.

Parallelism of the regression planes. Scatter plots of regression lines were analyzed to ensure a linear relationship between covariates and dependent variables and parallelism of the regression planes. To view these scatter plots see Figures 6-7 in Appendix B.

\section{MANCOVA Results}

The researcher conducted Wilk's Lambda test of significance to determine if the changes were statistically significant. The results showed there was no statistically significant difference between pre- and post-test scores based on instructional type ( $F(10$, 192) $=0.97, p=0.47, p>0.05)$. The strength of association, partial eta squared $\left(\eta^{2}\right)$ between instructional type SCLM, PATM, and VM, and overall attitude was approximately $5 \%$ which is extremely small according to Cohen's effect size scale (1988). These results indicated no need for Post Hoc procedures.

In context, these results suggest that instructional type had no statistical effect on students' attitude towards mathematics. 


\section{Analysis of Research Question Three}

\section{Factor Analyses of Attitude Survey Scores}

The third research question (What is the factor structure of attitude scale scores obtained from the mathematics attitude survey?) focused on determining how the items in the attitude survey measured components of attitude towards mathematics. While it was determined that instructional type had no statistical effect on attitude, the researcher used factor analysis to examine any patterns in students responses to the attitude survey. These patterns provide insights to how the latent variable, attitude towards mathematics, is shaped by student's 1) Self-Confidence in Learning Mathematics (SCLM), 2) Positive Affect Towards Mathematics (PATM), and 3) Valuing Mathematics (VM).

For this analysis, Principle Component Factor analysis was conducted using an oblique rotation, which allowed the factors to be correlated with one another. The researcher used both Oblimin and Promax oblique rotations as recommended by Stevens (2009). After examination of results from both analyses, the researcher determined the results on the Promax rotation were most appropriate in explaining the factor structure for these data. Stevens (2009) supports this decision, since he claimed there is no such thing as a "best oblique rotation" and that judgment must be left to the researcher.

Pre-Survey. Prior to factor analyses of the pre-survey scores, the Kaiser-MeyerOlkin Measure of Sampling Adequacy statistic was examined to determine the proportion of variance in the variables that might be caused by underlying factors. This value $(0.75)$ was statistically significant $(p<0.05)$, indicating that a factor analysis would be useful with these data. Next, Bartlett's Test of Sphericity was performed. The results indicated 
that the variables were sufficiently correlated and therefore suitable for structure detection. Bartlett's Test of Sphericity yielded a p-value less than $0.05\left(\chi^{2}=355.56\right.$, $p=0.00$ ) again, indicating that a factor analysis would be useful.

Reliability. As discussed in previous sections, Cronbach's alpha reliability coefficient measures the internal consistence of items. The obtained Cronbach's alpha reliability coefficient for this survey was reported by Martin and Preuschoff (2008) to be $\alpha=0.81$ internationally and $\alpha=0.86$ for the United States. These values are considered very good according to DeVellis (2003). For this study, the observed Cronbach's alpha reliability coefficient was $\alpha=0.74$. This value, although slightly lower, was still considered "respectable" according to DeVellis (2003).

Factor Analysis. Principal component factor analysis with Oblimin and Kaiser Normalization Rotation methods were performed to examine the internal structure of the scores obtained from the current sample.

Initially, three factors with eigenvalues greater than 1 were extracted. This accounted for $58.17 \%$ of the total variance, each factor accounting for $28.71 \%, 46.67 \%$, and $58.17 \%$, respectively. The scree plot (see Figure 8 in Appendix B) further suggested three factors.

Following the oblique rotation, factor structure coefficients greater than 0.40 were retained. In this study all twelve of the items met this criteria suggesting that these items significantly contribute to the factor structure. Specifically, items I usually do well in mathematics (0.92), I learn things quickly in mathematics (0.83), I enjoy learning mathematics (0.70), and I like mathematics (0.60) contributed significantly to factor one. 
Meanwhile, I need mathematics to get the job I want (0.74), I need mathematics to learn other school subjects (0.70), I think learning mathematics will help me in my daily life (0.69), I need mathematics to get into the University of my choice (0.61), and I would like to take more mathematics in school (0.43) significantly contributed to the second factor. The items Mathematics is more difficult for me (0.74), Mathematics is not one of my strengths $(0.71)$ and Mathematics is boring (0.62) significantly contributed to the third factor. See the table below for pattern structure coefficients. 
Table 12

Pre-Survey: Pattern and Structure Coefficients, Communalities, Means, and Standard Deviations for 12 Items

\begin{tabular}{|c|c|c|c|c|c|c|}
\hline & Factor 1: & Factor 2: & Factor 3: & & & \\
\hline Item & $\mathrm{P}(\mathrm{S})$ & $\mathrm{P}(\mathrm{S})$ & $\mathrm{P}(\mathrm{S})$ & $h^{2}$ & $M$ & $S D$ \\
\hline $\begin{array}{l}\text { I usually do well in } \\
\text { mathematics }\end{array}$ & $0.92(0.77)$ & $-0.24(0.09)$ & $-0.21(0.03)$ & 0.68 & 2.76 & 0.97 \\
\hline $\begin{array}{l}\text { I learn things quickly } \\
\text { in mathematics }\end{array}$ & $0.84(0.72)$ & $-0.34(-0.02)$ & $-0.21(0.23)$ & 0.61 & 2.56 & 1.01 \\
\hline $\begin{array}{l}\text { I enjoy learning } \\
\text { mathematics }\end{array}$ & $0.70(0.83)$ & $0.25(0.53)$ & $0.13(0.36)$ & 0.76 & 2.65 & 1.05 \\
\hline I like mathematics & $0.60(0.77)$ & $0.21(0.47)$ & $0.30(0.50)$ & 0.71 & 2.49 & 1.14 \\
\hline $\begin{array}{l}\text { I need to do well in } \\
\text { mathematics to get the } \\
\text { job I want }\end{array}$ & $-0.25(.05)$ & $0.74(0.65)$ & $0.07(0.08)$ & 0.47 & 3.62 & 0.69 \\
\hline $\begin{array}{l}\text { I need mathematics to } \\
\text { learn other school } \\
\text { subjects }\end{array}$ & $-0.22(0.06)$ & $0.70(0.60)$ & $0.07(0.08)$ & 0.43 & 3.06 & 0.94 \\
\hline $\begin{array}{l}\text { I think learning } \\
\text { mathematics will help } \\
\text { me in my daily life }\end{array}$ & $0.14(0.31)$ & $0.69(0.71)$ & $-0.30(-0.18)$ & 0.59 & 3.58 & 0.67 \\
\hline $\begin{array}{l}\text { I need to do well in } \\
\text { mathematics to get } \\
\text { into the university of } \\
\text { my choice }\end{array}$ & $0.11(0.20)$ & $0.61(0.60)$ & $-0.50(-0.40)$ & 0.59 & 3.51 & 0.84 \\
\hline $\begin{array}{l}\text { I would like to take } \\
\text { more mathematics in } \\
\text { school }\end{array}$ & $0.35(0.56)$ & $0.43(0.58)$ & $0.17(0.32)$ & 0.50 & 2.40 & 1.02 \\
\hline $\begin{array}{l}\text { Mathematics is more } \\
\text { difficult for me than } \\
\text { for many of my } \\
\text { classmates }\end{array}$ & $0.07(0.23)$ & $-0.16(-0.05)$ & $0.74(0.74)$ & 0.57 & 2.42 & 1.04 \\
\hline $\begin{array}{l}\text { Mathematics is not } \\
\text { one of my strengths }\end{array}$ & $-0.03(0.13)$ & $-0.12(-0.05)$ & $0.71(0.69)$ & 0.49 & 2.22 & 1.15 \\
\hline Mathematics is boring & $-0.01(0.32)$ & $0.38(0.44)$ & $0.62(0.66)$ & 0.57 & 2.50 & 1.13 \\
\hline $\begin{array}{l}\text { Eigenvalue and \% of } \\
\text { Variance Post-rotation }\end{array}$ & \begin{tabular}{|l|}
3.45 \\
$28.71 \%$
\end{tabular} & $\begin{array}{l}2.16 \\
17.96 \%\end{array}$ & $\begin{array}{l}1.38 \\
11.50 \%\end{array}$ & & & \\
\hline
\end{tabular}

Note: $\mathrm{P}=$ pattern coefficients; $\mathrm{S}=$ structure coefficients; $h^{2}=$ communalities. 
The factor loadings showed a slightly different factor structure for struggling students compared to the structure suggested by other researchers who organized the twelve items into three categories: 1) Self-Confidence in Learning Mathematics (SCLM), 2) Positive Affect Towards Mathematics (PATM), and 3) Valuing Mathematics (VM) (Choi et al., 2011; Martin \& Preuschoff, 2008; Olson et al., 2008). Factor one consisted of the items I usually do well in mathematics (0.92), I learn things quickly in mathematics (0.84), I enjoy learning mathematics $(0.70)$, and I like mathematics $(0.60)$. The third factor contained the items Mathematics is more difficult for me than for many of my classmates (0.74), Mathematics is not one of my strengths (0.71), and Mathematics is boring (0.62). These factor loadings represent a different factor structure than that suggested by literature in that PATM and SCLM items are not distinctly separated. Furthermore, one item I would like to take more mathematics in school (0.43) loaded on factor two with the other VM items (I need to do well in mathematics to get the job I want (0.74), I need mathematics to learn other school subjects (0.71), I think learning mathematics will help me in my daily life (0.69), I need to do well in mathematics to get into the university of my choice ( 0.61$)$ loading together. This may be due to the way struggling students view mathematics compared to the way a student who is not struggling views mathematics. This topic and the connections to theory will be discussed more in the next chapter.

Post-Survey. As described in the previous section, the Kaiser-Meyer-Olkin Measure of Sampling Adequacy statistic was examined before factor analyses of the postsurvey scores. This value $(0.70)$ was statistically significant $(p<0.05)$, indicating that a 
factor analysis would be useful with these data. Next, Bartlett's Test of Sphericity $\left(\chi^{2}=409.40, p=0.00, \mathrm{p}<0.05\right)$ determined that the variables were suitable for structure detection.

Reliability. Similar the pre-survey analysis, Cronbach's alpha was used to measure internal consistency of items. For post-survey scores, the observed Cronbach's alpha reliability coefficient was $\alpha=0.75$. This value was also considered "respectable" according to DeVellis (2003).

Factor Analysis. Just as with the pre-survey scores, principal component factor analysis with Promax and Kaiser Normalization Rotation methods were performed to examine the internal structure of the scores obtained from the current sample.

Similar to the pre-survey analyses, three factors with eigenvalues greater than 1 were extracted and the three factors accounted for $57.64 \%$ of the total variance. Each factor accounted for $29.75 \%, 47.83 \%$, and $57,64 \%$, respectively. The scree plot (see Figure 9 in appendix B) confirmed the selection of three factors.

Factor structure coefficients greater than 0.40 were considered significant after the rotation. Again, all twelve items met this criteria suggesting that these items significantly contribute to the factor structure but compared to the pre-survey analyses the factor structure was slightly different. Specifically, items I like mathematics $(0.88), I$ enjoy learning mathematics (0.85), I would like to take more mathematics in school (0.74) Mathematics is boring (0.71) contributed significantly to factor 1. Additionally, Mathematics is more difficult for me than my classmates (0.86), Mathematics is not one of my strengths (0.73), I learn things quickly in mathematics (0.56), and I usually do well 
in mathematics (0.49) significantly contributed to the second factor. Lastly, I need mathematics to get into the university of my choice (0.80), I think learning mathematics will help me in my daily life (0.78), I need mathematics to get the job I want (0.64), and I need mathematics to learn other school subjects (0.46) significantly contributed to factor three. See the table below for pattern structure coefficients. 
Table 13

Post-Survey: Pattern and Structure Coefficients, Communalities, Means, and Standard Deviations for 12 Items

\begin{tabular}{|c|c|c|c|c|c|c|}
\hline & \begin{tabular}{|l|} 
Positive \\
Affect \\
Towards \\
Mathematics \\
(PATM)
\end{tabular} & $\begin{array}{l}\text { Self- } \\
\text { Confidence } \\
\text { in Learning } \\
\text { Mathematics } \\
\text { (SCLM) }\end{array}$ & $\begin{array}{l}\text { Valuing } \\
\text { Mathematics } \\
(\text { VM) }\end{array}$ & & & \\
\hline Item & $\mathrm{P}(\mathrm{S})$ & $\mathrm{P}(\mathrm{S})$ & $\mathrm{P}(\mathrm{S})$ & $h^{2}$ & $\bar{M}$ & $S D$ \\
\hline I like mathematics & $0.88(0.90)$ & $0.49(0.34)$ & $0.29(0.19)$ & 0.81 & 2.62 & 1.12 \\
\hline $\begin{array}{l}\text { I enjoy learning } \\
\text { mathematics }\end{array}$ & $0.85(0.88)$ & $0.04(0.34)$ & $0.09(0.25)$ & 0.78 & 2.72 & 1.02 \\
\hline $\begin{array}{l}\text { I would like to take more } \\
\text { mathematics in school }\end{array}$ & $0.74(0.64)$ & $-0.21(0.70)$ & $-0.10(0.07)$ & 0.46 & 2.47 & 1.06 \\
\hline Mathematics is boring & $0.71(0.74)$ & $0.08(0.33)$ & $0.03(0.16)$ & 0.55 & 2.45 & 1.12 \\
\hline $\begin{array}{l}\text { Mathematics is more } \\
\text { difficult for me than for } \\
\text { many of my classmates }\end{array}$ & $-0.23(0.10)$ & $0.86(0.77)$ & $0.04(-0.09)$ & 0.63 & 2.47 & 1.05 \\
\hline $\begin{array}{l}\text { Mathematics is not one } \\
\text { of my strengths }\end{array}$ & $0.26(0.29)$ & $0.73(0.75)$ & $-0.04(-0.11)$ & 0.56 & 2.28 & 1.12 \\
\hline $\begin{array}{l}\text { I learn things quickly in } \\
\text { mathematics }\end{array}$ & $0.33(0.54)$ & $0.56(0.68)$ & $0.04(0.04)$ & 0.56 & 2.71 & 1.01 \\
\hline $\begin{array}{l}\text { I usually do well in } \\
\text { mathematics }\end{array}$ & $0.35(0.50)$ & $0.49(0.63)$ & $-0.15(-0.13)$ & 0.51 & 2.82 & 0.88 \\
\hline $\begin{array}{l}\text { I need to do well in } \\
\text { mathematics to get into } \\
\text { the university of my } \\
\text { choice }\end{array}$ & $0.08(0.15)$ & $-0.20(-0.26)$ & $0.80(0.84)$ & 0.73 & 3.52 & 0.84 \\
\hline $\begin{array}{l}\text { I think learning } \\
\text { mathematics will help } \\
\text { me in my daily life }\end{array}$ & $-0.14(0.12)$ & $0.30(0.17)$ & $0.78(0.72)$ & 0.59 & 3.59 & 0.68 \\
\hline $\begin{array}{l}\text { I need to do well in } \\
\text { mathematics to get the } \\
\text { job I want }\end{array}$ & $-0.01(0.12)$ & $0.04(-0.06)$ & $0.64(0.63)$ & 0.40 & 3.64 & 0.56 \\
\hline $\begin{array}{l}\text { I need mathematics to } \\
\text { learn other school } \\
\text { subjects }\end{array}$ & $0.15(0.14)$ & $-0.26(-0.26)$ & $0.46(0.51)$ & 0.32 & 3.13 & 0.88 \\
\hline $\begin{array}{l}\text { Eigenvalue } \\
\text { and } \% \text { of Variance Post- } \\
\text { rotation }\end{array}$ & \begin{tabular}{|l|}
3.57 \\
$29.75 \%$
\end{tabular} & $\begin{array}{l}2.17 \\
18.08 \%\end{array}$ & $\begin{array}{l}1.18 \\
9.81 \%\end{array}$ & & & \\
\hline
\end{tabular}

Note: $\mathrm{P}=$ pattern coefficients; $\mathrm{S}=$ structure coefficients; $h^{2}=$ communalities. 
The results more closely resembled the three-factor structure supported by research (Choi et al., 2011; Martin \& Preuschoff, 2008; Olson et al., 2008). Therefore, the first factor consisting of the items: I like mathematics, I enjoy learning mathematics, I would like to take more mathematics in school, and Mathematics is boring were named Positive Affect Toward Mathematics (PATM). The second factor containing the items: 1) Mathematics is more difficult for me than for many of my classmates, 2) Mathematics is not one of my strengths, 3) I learn things quickly in mathematics, 4) I usually do well in mathematics were classified as Self-Confidence in Learning Mathematics (SCLM). The third factor was named Valuing Mathematics (VM) because it contained the items: 1) I need to do well in mathematics to get into the university of my choice, 2) I think learning mathematics will help me in my daily life, 3) I need to do well in mathematics to get the job I want, and 4) I need mathematics to learn other school subjects. The factor structure identified in by the post-survey scores differed from that identified by the pre-survey scores. The implications of these results will be discussed in the next chapter.

\section{Summary of Results}

As described in the introduction to this chapter, the purpose of this study was to examine the effects instructional type has on students' mathematics achievement scores and attitudes towards mathematics. The research questions used to guide this study are as follows:

1. Is there a significant instructional type effect on mathematics achievement?

2. Is there a significant instructional type effect on mathematics attitude? 
3. What is the factor structure of mathematics attitude scores of struggling learners?

First, an analysis of covariance (ANCOVA) was conducted to answer the first research question. Results of the ANCOVA revealed there was no statistically significant instructional type effect on mathematics achievement.

Second, a multivariant analysis of covariance was conducted to examine the effects of instructional type on the three domains of mathematics attitude: 1) Positive Affect Towards Mathematics (PATM), 2) Self-Confidence in Learning Mathematics (SCLM), and 3) Valuing Mathematics (VM). Again, the results of the MANCOVA showed no statistically significant instructional type effect on the three domains of mathematics attitude.

Lastly, Factor Analyses were conducted to answer the third research question. Factor analyses of pre-survey attitude scores revealed a factor structure different from the one presented in presented in research. The items I usually do well in mathematics, I learn things quickly in mathematics, I enjoy learning mathematics, and I like mathematics contributed significantly to factor one. The items, I need mathematics to get the job I want, I need mathematics to learn other school subjects, I think learning mathematics will help me in my daily life, I need mathematics to get into the University of my choice, and I would like to take more mathematics in school significantly contributed to the second factor. The items Mathematics is more difficult for me, Mathematics is not one of my strengths and Mathematics is boring significantly contributed to the third factor. In contrast, factor analyses of post attitude survey scores resulted in factor structures 
resembling that found in research and were thus named Positive Affect Towards

Mathematics (PATM), 2) Self-Confidence in Learning Mathematics (SCLM), and 3)

Valuing Mathematics (VM).

The next chapter will discuss the implications of these results in more detail and attempt to explain some of the differences. 


\section{CHAPTER V: DISCUSSION}

\section{Study Summary}

High-stakes testing and low performance in international comparison studies have forced U.S. schools and school districts to focus on students who struggle in mathematics. Many schools already are implementing mathematics intervention programs where students spend extra time learning mathematics concepts and skills with which they have struggled in the past. This study examined the effects of one mathematics intervention program.

\section{Purpose and Research Questions}

The purpose of this study was to examine the effects that different instructional programs might have on struggling students' mathematics achievement scores and attitudes towards mathematics. Specifically, the study sought to understand how Computer Assisted Instruction (CAI), Structured Curriculum (SC), or the combination of CAI and SC influenced students' mathematics achievement and attitudes toward mathematics. The study also sought to determine the factor structure for struggling students' attitudes towards mathematics. Three research questions were addressed to achieve the study's purpose:

1. Is there a significant effect of instructional type on mathematics achievement? 
2. Is there a significant effect of instructional type on mathematics attitude?

3. What is the factor structure of attitude scale scores obtained from the mathematics attitude survey?

\section{Summary of Research Design}

This study used a three-group pre/post-test design. The dependent variables were academic achievement and attitudes toward mathematics and the independent variable was instructional type. Instructional type consisted of three levels: Structured Curriculum Instruction $\left(\mathrm{NR}_{\mathrm{SC}}\right)$, Computer-Assisted Instruction (NR $\mathrm{NAI}_{\mathrm{C}}$, and Computer-Assisted Instruction with Structured Curriculum Instruction $\left(\mathrm{NR}_{\mathrm{CAl}}\right.$ with $\left.\mathrm{SC}\right)$. The $\left(\mathrm{NR}_{\mathrm{SC}}\right)$ group received instruction using a structured curriculum, Do the Math Now (M. Burns, 2011), without computer-assisted instruction (CAI). The $\mathrm{NR}_{\mathrm{CAI}}$ group received $\mathrm{CAI}$ but not structured curriculum (SC), and the group labeled $\mathrm{NR}_{\mathrm{CAl}}$ with SC received a combination of both SC and CAI. The CAI used in this study was a program called SuccessMaker, which used answer-pattern response to craft individualized lessons for each student at their ability level.

Mathematics achievement was measured using a diagnostic test called Measures in Academic Progress created by the Northwest Evaluation Association (NWEA). Attitude toward mathematics was measured using the TIMSS (2007) Student Questionnaire. This survey consisted of 12 items measuring students' attitudes toward mathematics.

Sample and Procedures. The sample included students at Baxter Middle School who were identified as struggling learners in mathematics. Baxter Middle School is a 
public school in Kentucky. Students were selected for this study if they scored a 203 (the score of an average fourth grader) or less on the MAP mathematics achievement test. They were administered the mathematics achievement test and the attitude survey at the beginning and end of an 8 -week treatment period. Pre- and post-test scores were analyzed to determine the effect of treatment on mathematics achievement and attitude toward mathematics. One-way analysis of covariance (ANCOVA) was used to measure the effects of instructional type on mathematics achievement with MAP pre-test scores used as a covariate in order to reduce error. One-way multivariate analysis of covariance (MANCOVA) was used to measure the effects of instructional type on attitude toward mathematics. For this analysis, pre-test survey scores were used as the covariate. Finally, factor analyses were conducted on pre- and post-survey scores to determine the factor structure for struggling students' attitudes toward mathematics.

\section{Discussion of Research Questions}

The results of this study with connections to existing research are discussed in the following section. Fidelity of implementation will be discussed first in an attempt to provide context for the discussion of research questions. From there, the subsection sections are organized by research questions. Each subsection offers a brief review of findings and connections to existing research. Next, implications of the results are discussed and limitations of this study are revisited. Finally, recommendations for future research, the significance of this study, and study conclusions are provided. 


\section{Fidelity of Implementation}

Fidelity of program implementation was measured through quantity of coverage, as well as nature of instruction. Although the researcher provided professional development on the intended curricula SuccessMaker and Do the Math Now, the results showed a wide range of implementation for these two programs.

First, a large range in the time students spent using the CAI was found. Some of the discrepancy may be attributed to the starting time, since one teacher was delayed in implementation due to the need for more training. However, adequate time to complete the 20-minute sessions per day across the eight week was evident, but only five computers in this classroom were available to be shared by all students in the group. Another significant factor was student off-task behaviors, which accounted for approximately 4.28 instructional periods in this classroom $\left(\mathrm{NR}_{\mathrm{CAI}}\right)$. Technical problems accounted for an additional 1.12 instructional periods. In total, the $\mathrm{NR}_{\mathrm{CAI}}$ group lost a minimum of 5.4 instructional periods out of the 20 days reported ( $27 \%$ of instructional time). The $\mathrm{NR}_{\mathrm{SC}}$ and $\mathrm{NR}_{\mathrm{CAl}}$ with SC group quantity of lessons was also less than anticipated, an average of 23 lessons compared to the anticipated 40 . Each group covered the approximately same amount of material; therefore, fidelity of implementation was less of a concern than the quantity of lessons covered by NR $\mathrm{SC}_{\mathrm{SC}}$ group.

Qualitatively, the interventions also lacked fidelity. CAI should be supported by teacher-led instruction based on student progress reports generated by the CAI which identify concepts and skills with which students struggle (Baker et al., 2002; Fuchs et al., 1994; Fuchs et al., 1997). Based on observations and teacher-reported data, very little 
instruction on concepts took place with the NR CAI groups--just four minutes overall during a 4-week period of time. This finding is very concerting for three reasons: 1) mathematics instruction should be a balance of procedures and concepts in order to help struggling learners make representational connections and develop an understanding (Lesh et al., 1987); 2) high-quality mathematics instruction is characterized by a combination of conceptual and procedural instruction (Hiebert \& Grouws, 2007; NCTM, 2000; NRC, 2001); and 3) the CCSSO Mathematics Content and Practices recommend that students be proficient in concepts and procedures (CCSSI, 2010). Based on the observations and teacher-reported data, little evidence of instruction targeting misconceptions was found; rather, instruction targeted procedures and processes.

One NR ${ }_{S C}$ teacher also struggled with fidelity and decided to employ 'peer tutors' as an instructional strategy. While the use of peer tutors is a recommended strategy by Baker, Gersten, and Lee (2002), the program Do the Math Now recommends teachers not deviate from the scripted lessons.

\section{Instructional Type and Mathematics Achievement}

Research question 1 addressed the effects of instructional type on students' attitudes toward mathematics: Was there a significant effect of instructional type on students' mathematics achievement? This study hypothesized that the combination of CAI with SC would have more positive effects on mathematics achievement than CAI or $\mathrm{SC}$ alone. Analysis revealed no significant difference in mathematics achievement scores among students who participated in different instructional types. 
Overall, mathematics achievement of students in all three groups improved, but the none of the gains were outside the normal range of growth (NWEA, 2009). The NR CAI group mean growth was 5.23 points, the $\mathrm{NR}_{\mathrm{SC}}$ group mean growth was 8.76 points

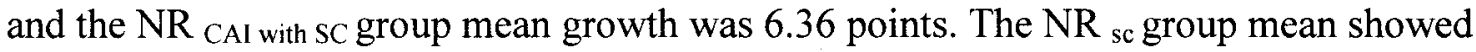
slightly more improvement than any other group. Although these results were not statistically significant, they favored the impact of teacher-led instruction.

These findings were consistent with studies published in earlier years that examined the comparison of CAI and teacher-lead instruction (Fletcher-Flinn \& Gravatt, 1995; Kulik \& Kulik, 1991; Waxman et al., 2002). The findings, however, are not consistent with more recent studies that found CAI with SC to be more effective than CAI and SC alone (Gee, 2008; Kirk, 2003; Manning, 2004; Slavin et al., 2009). The studies, however, used large groups of students without control groups and few identified subgroups such as struggling learners.

As discussed in previous sections, the researcher hypothesized that the $\mathrm{NR}_{\mathrm{CAI}}$ with sc group would perform best because CAI was meant to enhance the balance of procedural and conceptual instruction. Fuchs and other's (2008) framework for effective mathematics intervention provides a lens for examining the different components of mathematics intervention used by this group. Students received the bulk of their conceptual instruction from teacher-led lesson from Do the Math Now and the bulk of their drill and practice, cumulative review, and progress monitoring (principles four, five, and six) from the CAI. Student achievement scores did not provide evidence that the combination of $\mathrm{CAI}$ with $\mathrm{SC}$ was superior to $\mathrm{CAI}$ or $\mathrm{SC}$ alone. 
An explanation for students' minimal improvement in achievement may have been that the NR CAI with SC group teacher missed several days of school due to an injury. Also, the teacher for the NR CAI with SC group reported having some behavior problems in her class; however, this teacher was unable to complete the student-teacher interaction $\log$ and the researcher was not able to formally document the ratio of behavior interactions compared to instructional interactions.

A reason for smaller gains with the $\mathrm{NR}_{\mathrm{CAI}}$ with SC group may have been that these students had a lower mathematics achievement mean at the start of the intervention $(M=185.52)$. For CAI to work well, students must have some knowledge on which to build. McCollister and others (1986) found that lower performing kindergartners were less likely to trust CAI because they had less of a mathematics foundational understanding to rely on. The students in the NR $\mathrm{CAI}$ with SC group were lower performing and may have had less prerequisite understanding than students in the other groups.

Another unanswered question was "If the students who participated in the intervention would have shown gains even if they had not had the extra mathematics intervention class?" Minimal growth data suggested that students might not have benefited from any of the interventions. Teacher reports and data on student attitude suggested otherwise. Teachers for all three groups reported that the interventions helped their students and that they saw improvement in students' number sense and confidence in their students' ability to do mathematics. Unfortunately, these anecdotes did not provide conclusive evidence that the interventions were worthwhile. 


\section{Instructional Type and Attitude Toward Mathematics}

Research question two addressed the effects of instructional type on students' attitudes toward mathematics: Is there a significant effect of instructional type on mathematics attitude? Based on prior literature, the researcher hypothesized that students who received $\mathrm{CAI}$ or $\mathrm{CAI}$ with $\mathrm{SC}$ would have more improved attitudes than students who received SC only. The results of the analysis revealed no significant differences between pre- and post-attitude scores based on instructional type.

These results are not consistent with prior research. According to recent literature, students' attitudes are generally more positive about using CAI. For example, several studies found that students enjoyed using technology to learn mathematics, and some studies reported that students became smarter while using the technology (Nguyen et al., 2006; Reimer \& Moyer, 2005; Tienken \& Maher, 2008). However, these studies did not report using an instrument with validity that distinguished between affect towards technology and confidence or valuing of mathematics or technology. Instead they measured affect using adapted questionnaires and reports of student interviews. Bassoppo-Moyo (2010) reported using an instrument to measure attitude toward mathematics and concluded that CAI had a positive impact on eleventh and twelfth graders' algebra achievement and attitudes. Although Bassoppo-Moyo (2010) used an instrument to measure attitude, the instrument was developed by the researcher, and score reliability and construct validity were not reported' Therefore, it is difficult to determine if the specific impact of the technology was from students' feelings towards mathematics, the technology, or both. While the results of this study contradict the conclusions 
presented by previous researchers, it differed by seeking to examine attitude using a research-based measure for attitude.

As described in a previous section, this study used TIMSS (2007) student attitude survey. This survey measures attitude using three scales: 1) Self-Confidence in Learning Mathematics (SCLM); (2) Positive Affect Toward Mathematics (PATM); and (3) Valuing Mathematics (VM) (Choi et al., 2011; Martin \& Preuschoff, 2008; Olson et al., 2008). A student's attitude regarding their ability to "do math" is described as SelfConfidence in Learning Mathematics (SCLM). Meanwhile, Positive Affect Toward Mathematics (PATM) is defined as a student's feelings about mathematics, and their Valuing of Mathematics (VM) measures how important mathematics is to students.

The results of this study showed that students in the NR $\mathrm{CAI}$ with SC demonstrated slightly improved scores for PATM, VM, and overall attitude but virtually no change in scores for SCLM. These results, however, were not significant, and did not confirm the hypotheses that CAI combined with SC leads to improved attitudes in mathematics for struggling students.

One reason CAI had little effect on student attitude in this study may be the fact these students were struggling. Wigfield and Tonks (2002) suggested that students begin to differentiate ability for different content domains as early as kindergarten. By middle school, many students have already developed the belief that mathematics is accessible only to "smart" students. If a middle school student has this perception, they may have had this perception about themselves for as many as eight years. This issue calls into 
question whether eight weeks of intervention is long enough to dramatically change a struggling student's attitudes toward mathematics.

Also interesting is that the attitude scores from the NR $\mathrm{CAI}_{\text {group also contradicted }}$ recent research on attitude and the use of CAI. For example, the NR CAI group exhibited virtually no change in SCLM, VM, or their overall attitude scores but did have a decline in PATM. These results suggest that CAI has little or no effect on struggling students' attitudes toward mathematic and might even have a negative effect on their valuing of mathematics.

Contextual factors may also have impacted the results. For example, the teacher for the $\mathrm{NR}_{\mathrm{CAI}}$ reported that several behavior problems related to students who did not want to participate in the CAI. These reports contradict the results of Nguyen and others (2006) who found thqt students enjoyed using the CAI and were willing to spend more time on the CAI to gain understanding and strive for better achievement. One reason for this finding might be related to the NR $\mathrm{CAI}_{\text {AI }}$ teacher's enthusiasm for teaching mathematics using the CAI program. Observations revealed that the teacher did not convey enthusiasm for the CAI program. The teacher would frequently tell students they "just needed to complete the program" but did not explain the importance of the program or why it would benefit them. Also, before the study began, the teacher for the NR CAI group exhibited a lack of enthusiasm for teaching mathematics using the CAI software. A recent study examined the relationship between teacher and student enjoyment and found a link between the two, suggesting the effect of teacher enjoyment on student enjoyment was mediated by teacher enthusiasm (Frenzel, Goetz, Lüdtke Prrun, \& Sutton, 2009). The 
$\mathrm{NR}_{\text {CAI }}$ teacher's lack of enthusiasm for teaching mathematics could be related to the student results.

The teacher for the NR CAI group was not a certified teacher. While she was employed full-time, her job description was not that of a full-time certified teacher. Additionally, she was not trained in mathematics education. Most mathematics teacher preparation programs include coursework that addresses classroom and behavior management and encourages enthusiasm for ones subject matter.

\section{Factor Structure for Struggling Student's Attitudes Towards Mathematics}

Research question three examined the factor structure for struggling students' attitude scores. The results of analyses revealed a different factor structure for struggling students before the intervention than after the intervention. The factor structure for the pre-test for struggling students did not match the factor structure in recent research, while the factor structure in the post-test did match the literature base. See the table below for a summary of the pre- and post-test factor structures compared to the factor structure suggested by research. 
Table 14

Comparison of Pre and Post-Survey Factor Structures to the Literature-Suggested Factor Structure

\begin{tabular}{|c|c|c|c|}
\hline & $\begin{array}{l}\text { Literature- } \\
\text { Supported } \\
\text { Factor } \\
\text { Structure }\end{array}$ & $\begin{array}{c}\text { Factor } \\
\text { Structure of } \\
\text { Pre-Survey } \\
\text { Scores }\end{array}$ & $\begin{array}{c}\text { Factor } \\
\text { Structure of } \\
\text { Post-Survey } \\
\text { Scores }\end{array}$ \\
\hline Item & & & \\
\hline I like mathematics & \multirow{4}{*}{ PATM } & Factor 1 & \multirow{4}{*}{ PATM } \\
\hline I enjoy learning mathematics & & Factor 1 & \\
\hline $\begin{array}{l}\text { I would like to take more mathematics } \\
\text { in school }\end{array}$ & & Factor 2 & \\
\hline Mathematics is boring & & Factor 3 & \\
\hline $\begin{array}{l}\text { Mathematics is more difficult for me } \\
\text { than for many of my classmates }\end{array}$ & \multirow{4}{*}{ SCLM } & Factor 3 & \multirow{4}{*}{ SCLM } \\
\hline $\begin{array}{l}\text { Mathematics is not one of my } \\
\text { strengths }\end{array}$ & & Factor 3 & \\
\hline I learn things quickly in mathematics & & Factor 1 & \\
\hline I usually do well in mathematics & & Factor 1 & \\
\hline $\begin{array}{l}\text { Ineed to do well in mathematics to } \\
\text { get into the university of my choice }\end{array}$ & \multirow{4}{*}{$\mathbf{V M}$} & Factor 2 & \multirow{4}{*}{ VM } \\
\hline $\begin{array}{l}\text { I think learning mathematics will help } \\
\text { me in my daily life }\end{array}$ & & Factor 2 & \\
\hline $\begin{array}{l}\text { Ineed to do well in mathematics to } \\
\text { get the job I want }\end{array}$ & & Factor 2 & \\
\hline $\begin{array}{l}\text { I need mathematics to learn other } \\
\text { school subjects }\end{array}$ & & Factor 2 & \\
\hline
\end{tabular}

Note: Positive Affect Towards Mathematics =PATM, Self-Confidence in Learning Mathematics $=$ SCLM, Valuing Mathematics $=$ VM. 
The factor structure of struggling students before the intervention was most different in the areas of SCLM and PATM. This pattern suggested students confused their feelings toward mathematics and their self-confidence in mathematics--a finding that is consistent with research showing that students who have experienced failure tended to have little confidence in their ability to do mathematics (Dickinson \& Butt, 1989; J. Middleton \& Spanias, 1999) and in turn, tend to greatly dislike mathematics (Eccles et al., 1998; Hammouri, 2004; Kloosterman, 1988; J. Middleton \& Spanias, 1999; Wigfield \& Tonks, 2002). While students in this study confused their confidence in mathematics with their liking of mathematics, they still understood what it meant to value mathematics (VM) and how valuing relates to other school subjects, advanced education, and their future career.

Post-survey scores revealed a different factor structure, which more resembled current research (Chiu, 2007; Choi et al., 2011; Eklöf, 2007; Hammouri, 2004; Wigfield \& Eccles, 2002). The differences in factor structures for students before and after the intervention suggested that the mathematics intervention changed patterns in students' associations between their self-confidence and liking mathematics. After eight weeks of intervention, students' factor structure more closely resembled that of non-struggling students. This finding suggested shifts in attitude occurred due to the intervention, but those shifts were not apparent in students overall attitude scores and were not attributed to the instructional type but rather because students were receiving intervention. 


\section{Implications}

The results, briefly described above, and in detail in chapter four, have important implications for both practitioners and researchers.

\section{Mathematics Intervention Implementation}

One implication of this study is how mathematics interventions are implemented. While the results of this study may offer administrators and school leaders more flexibility in the instructional types they select for working with struggling mathematics students, what is more important is the fidelity of implementation of the instructional type selected, which can be controlled by teacher-selection and structures for monitoring fidelity.

Often the program used for intervention characterizes the intervention rather than paying more attention to instructional strategies used with struggling learners. Little attention is given to the fidelity of any particular program, and therefore the blame or credit for improving student learning is often "program-based". In fact, in her report on measuring curriculum implementation, Huntley (2009) commented on the importance of measuring levels of fidelity when examining the effectiveness of programs, teaching, or students.

As the findings of this study indicate, each of these programs was mildly helpful to students. However, reasons for only small achievement gains may have more to do with (1) the time (or lack thereof) on task, and (2) focus on conceptual understanding. As noted by observation and teacher reports, students were not engaged in the curriculum for more that $60 \%$ of the intervention time, and only $10 \%$ focused on conceptual 
understanding. These statistics highlight the importance of implementing a program with fidelity.

One way fidelity of implementation may be controlled is by teacher selection. The instructor for the $\mathrm{NR}_{\mathrm{CAI}}$ group was not certified and may not have been trained to manage instruction. But simply selecting a certified teacher may not be the solution. Teachers that show enthusiasm for the content, and instructional type, affect students' enthusiasm for the content and instructional type (Frenzel, Goetz, Lüdtke Prrun, \& Sutton, 2009). Careful selection of teachers who will work with struggling learners may impact student success more than the program selected.

Another way to ensure fidelity of implementation is through the structures designed to support high levels of implementation. Administrators or teacher leaders can support implementation by taking active roles in monitoring fidelity of implementation through observations, student interviews, and progress monitoring to ensure students and teachers are supported in their work (Brown, Pitvorec, Ditto, \& Randall, 2009; Fuchs et al., 2008).

Implementation should focus more on how time is used (e.g., lessons completed) rather than how much time is allotted to interventions (e.g., time during school day). In this study, it was projected that students would complete approximately 40 sessions of CAI, the equivalent of approximately 800 minutes of instruction. Both groups fell far short of this goal with an average of 15.10 sessions in the NR CAI group and 26.56 sessions in the NR CIA with SC group. Monitoring the accomplishments of the students, and adapting as needed (e.g., by adding computers in a classroom), can maximize the 
potential benefits of an intervention program.

Furthermore, teachers implementing intervention programs must pay attention to the fact that many students in an intervention lack motivation and are likely to exhibit off-task behaviors. Teachers should set up classroom structures to minimize time off task and maximize the learning experience (Saphier et al., 2008). Motivators should be used to add value to the content being taught (Fuchs et al., 2008), and these motivators do not need to be extrinsic rewards, but celebrations of student success with benchmark goals (Kohn, 1993/1999).

\section{Understanding the Struggling Learner}

Struggling learners may not act in ways predicted by the general population. Struggling learners initially confused their confidence in mathematics with their liking or disliking of mathematics. This finding has implications for the teachers working with struggling learners. For example, struggling learners' attitudes may impact their classroom behavior and motivation to pursue content that is challenging to them (J. Middleton \& Spanias, 1999). Teachers should be mindful of selecting tasks in which students can have success (Dickinson \& Butt, 1989). Also, students should be told why they receive additional instruction in mathematics and be included in goal setting and progress monitoring (Baker et al., 2002; Fuchs et al., 1994; Fuchs et al., 1997).

This study showed that attitudes did not improve significantly in any of the three intervention groups, which might be explained by the stigma some students associate with mathematics intervention. Students were assigned mathematics intervention in addition to their core class; therefore, not all of their peers in their core classes received 
intervention. This practice may have contributed to students having a negative perception of mathematics intervention.

Baker, Gersten, and Lee (2002) reported improvement in acheivement when students were involved goal setting. This finding is relevant to this study. In order for students to be involved in goal setting, students must be made aware of their performance related to mathematics acheivement in an honest yet positive way. For example, teachers and administrators might hold conferences with students about their progress and assist them with goal setting. In addition, Middleton and Spanias (1999) reported that students' negative attitudes toward mathematics can be explained by lack of teacher support. Therefore, teachers and/or administrators should exaplain the opportunities for learning that are available with mathematics intervention and show students examples of tasks in which they can be successful in order to provide support, gain buy-in, and improve motivation (Brophy, 1998; Dickinson \& Butt, 1989).

Another implication from this study relates to the selection of materials for struggling learners and the connections made to mathematics in the real world. This conclusion arose from the small decline in valuing mathematics within the NR $\mathrm{SC}$ group. This decline might be due to the nature of the SC materials, which offered few connections to real-life contexts. While the program itself offered few examples of mathematics in the real world, the instructor can make connections to real-life contexts, which may impact a students' valuing of mathematics. Additionally, student-teacher conferences, like the one recommended above, offer opportunities for teachers to help students find connections between mathematics and students' future aspirations. 


\section{Professional Development}

A major implication of this study was the need for teacher professional development on the specific needs of struggling learners and a focus on proper implementation of the intended curriculum.

This study revealed a potential difference in how struggling students viewed mathematics versus how the general population viewed mathematics. As discussed above, these differences impacted the ways in which teachers interacted with struggling students. Teachers should receive professional development to help them understand these potential differences and how they will impact classroom management, task selection, and instructional strategies.

Intervention in mathematics often elicits visions of flash cards and skill practice. The results of this study indicated that teachers also focused on procedures when considering what students had not mastered. Professional development must impress on the fact that conceptual understanding supports procedural fluency, and that the proficiency requires both (Hiebert \& Grouws, 2007; NCTM, 2000; NRC, 2001).

In this study, teachers using the CAI would have benefited from professional development connecting mathematical concepts with procedures in meaningful ways that supported and enhanced the work students do on the computer. The student progress reports generated by the CAI could have been used to help teachers determine gaps students had in their understanding and highlight areas in which the teacher could bolster instruction (Lesh et al., 1987). Furthermore, professional development on how to create classroom structures that both encourage learning and involve the student in the learning 
process (Baker et al., 2002; Fuchs et al., 1994; Fuchs et al., 1997) is needed for teachers to be able to implement these interventions at high levels of fidelity. In general, professional development on how to use progress monitoring data and how to design balanced instructional opportunities specific to student needs is lacking in our current educational system. This type of professional development should be a priority for administrators when designing and implementing mathematics intervention at their school.

Professional development may have also improved fidelity of implementation with the SC. Although training was provided for teachers using the SC program, this training only consisted of one six-hour professional development session. In that session teachers were introduced to the program and learned the philosophy of the program, but they did not have the opportunity to rehearse lessons or engage in collaborative lesson study. Researchers have noted that professional development is most effective when it is designed around the task of teaching, assessing, and reflecting rather than around discussing teaching practices (Darling-Hammond, Wei, Andree, Richardson, \& Orphanos, 2009). The system seems tighter for monitoring teacher progress with the program, and clearly more targeted professional development embedded in teacher practice was needed (Sowder, 2007).

\section{Intervention and Achievement}

Although students in this study showed small gains in achievement, their gains were not outside a normal range. This finding is surprising because all students received intervention instruction in addition to their core instruction. Perhaps additional 
instruction would improve student achievement. However, that was not the case, and perhaps other phenomena may have impacted the success of the interventions.

In previous sections, a framework for mathematics intervention was provided. Evidence of this framework was not always clear in this study due to lapses in implementation fidelity. This lack of fidelity could have resulted in lower achievement gains. For example, Fuchs and others (2006) identified the following principles of effective intervention: (1 and 2) explicit instruction with a strong conceptual base; (3) instructional design to minimize learning challenges; (4) opportunity for drill and practice; (5) cumulative review; (6) motivators to help students regulate their attention and behavior; and (7) ongoing progress monitoring. All seven principles were built into both programs; however, the intention of this study was that CAI be used to enhance principles four, five, six, and seven, and that SC be used to enhance principles one and two. Fidelity of implementation may have impacted student opportunities to achieve because not all principles were evident in the classrooms that used CAI.

The teacher for the $\mathrm{NR}_{\text {CAI }}$ group reported not using the reports generated by CAI to guide instruction. Instead she reported watching what students did on the CAI and made instructional decisions based on her observations. This strategy could be problematic because the CAI program was designed to set aside concepts with which students struggled with for a period of time, so that students were not frustrated by continued lack of success. The program's reports identify these topics as places in which the teacher should provide additional instruction. If the $\mathrm{NR}_{\mathrm{CAl}}$ group teacher did not read these reports and only designed instruction based on what she saw students engaged, 
then she did not address the key areas of concern identified by the CAI progress monitoring data. The NR $\mathrm{CAI}_{\text {with SC }}$ teacher reported looking at the reports but found it difficult to make connections from the CAI to the $\mathrm{SC}$ lessons because the lessons were so scripted. Based on the results of this study, when used CAI, teachers may benefit more by designing their own lessons based on the CAI progress monitoring results.

A second area of concern related to the principles was the lack of conceptual instruction reported by the $\mathrm{NR}_{\text {CAI }}$ teacher. This characteristic violates principles one and two that recommend explicit instruction with a strong conceptual base. Most instruction was reported to be focused on procedures instead of on concepts, which may have impacted student achievement.

Finally, principles four and five may have been impacted due to the minimal number of sessions students completed on the CAI. The CAI program was designed to collect information based on student answers, which was then used to decide when the student was ready for drill and practice and what students should cumulatively review. The longer students were on the program, the more information the CAI provided, and the more accurate the program was in determining an appropriate level of challenge, what the student should practice, and what they should review. This argument could also apply to the SC used in this study. The researcher reported that the NR SC group did not complete as many lessons as expected. Drill, practice, and review were also built into the SC program, but groups did not seem to have had enough lessons to experience the benefits of that practice and review. Implications from these findings are that when using an intervention program, attention should be paid to the amount of time students spend on 
the program and that more time is of quality. Furthermore, studies involving mathematics interventions should be conducted over longer periods of time to measure the true effects of the intervention on achievement.

\section{Study Limitations}

Several limitations existed in this study. The limitations of this study include: (a) the fact that the study was not quasi-experimental; (b) fidelity of program implementation; (c) student socio-economic-status and literacy levels; and (d) the measure of long-term effects of treatment. Efforts were made to control for these confounding variables, but limitations to this study were still present.

Scheduling conflicts restricted the use of random assignment in this study and limited the ability of the researcher to examine the cause-and-effect relationships among treatment, mathematics achievement, and attitude scores. Furthermore, scheduling and complications with the CAI used in this study caused discrepancies between the number

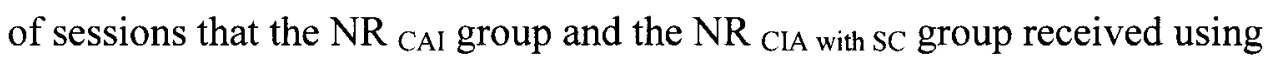
SuccessMaker. Additionally, due to the nature of the school's schedule, it was not possible to randomly assign teachers to different treatment groups. Furthermore, the teacher assigned to the $\mathrm{NR}_{\mathrm{CAl}}$ group had not been trained and certified in mathematics education, which might have affected her behavior management and teaching style.

As discussed in previous sections, fidelity of implementation presented a barrier in interpreting the results of the study. The fidelity issues included: minimal time using the CAI program, numerous behavior interruptions, insufficient use of the CAI reports to guide instruction, inconsistent implementation of scripted SC lessons, lack of teacher 
enthusiasm, lack of adequate professional development structures, and teacher attendance.

Literacy and socioeconomic levels presented another limitation because they varied from student to student and were not necessarily representative of the population. Although the pretest served as a means to control these variables by identifying a starting place for each student's growth or lack or growth, these factors could potentially influence the long-term effects of treatment.

Lastly, the long-term effects of treatment were not measured. Because these effects were not measured, whether the effects of treatment would be sustained one to two years after treatment was difficult to determine. Future studies should occur over a longer period of time and measure the long-term effects.

\section{Recommendations for Future Research}

As indicated by the review of research in chapter two, few studies on CAI have focused on subpopulations, in particular struggling learners. Additional research is needed in which a higher level of fidelity to the intervention is evident. Few studies on intervention include a focus on fidelity, and if results of the intervention are to be understood, such data might provide valuable insights. Specifically, research that documents what occurs within an intervention is needed. This research might provide insights into why the intervention is or is not supporting student learning.

Future research on the effects of different types of CAI on struggling learners' attitudes related to their liking of mathematics, or PATM, may provide guidance on the type of CAI that helps struggling students improve their affect towards mathematics. A 
more intentional look at how struggling mathematics students distinguish between SCLM and PATM, and the possible implications this distinction might have on achievement, would be valuable. Furthermore, an examination of different instructional strategies and struggling students' SCLM and PATM would provide additional information on the best ways to help students improve their attitude towards mathematics.

Finally, more research on mathematics interventions should focus on shaping a framework, such as the model suggested by Fuchs and others (2006), and on how such a framework might affect student attitude and achievement. Rather than narrowly focus on instruction, or on a particular curriculum, research focused on a framework can provide much needed insights on the elements that must be in place in order for struggling learners to achieve at higher levels.

\section{Significance of the Study}

The results of this study are relevant because CAI is quickly becoming a dominant instructional medium for working with sturggling learners. This study adds to the current research on CAI and on interventions in general in two significant ways. First related to research methodology, the most significant contribution is the need for fidelity data to accompany research on CAI. Of the literature reviewed in chapter two, only one study addressed fidelity of implementation, but it did not control for this major variable (Mathis, 2010). The results of this study revealed fidelity of implementation as a key factor in assessing the effectiveness of intervention instructional strategies. Second, struggling learners who are not identified as having a learning disability require more attention in the research. Few studies have focused on this population, and yet this study 
found that their attitude and achievement gains were resistant to change. Third, struggling learners may confuse their confidence in mathematics with their liking of mathematics.

\section{Study Conclusion}

The intention of this study was to examine the effects of different instructional types used for mathematics intervention on struggling students' mathematics achievement scores and attitudes toward mathematics. The study found that the implementation of interventions included significant off-task time and insufficient instruction on concepts when CAI was used. The results suggested that professional development on implementing intervention programs with fidelity was an essential component to an intervention system.

While the results of the study indicated no statistical effects on achievement or attitude in terms of instructional type, they revealed a likely difference in the factor structure for struggling students' mathematics attitude scores compared to general students' attitude scores. Furthermore, the factor structure changed during the course of the mathematics intervention suggesting that the intervention itself might have caused this structural change.

The results also highlight the complexity in dealing with struggling learners, and possibly learners in general. Research has confirmed a correlation between attitudes and achievement (Hammouri, 2004), but the implications for struggling learners may be multifaceted. The results of this study suggested struggling learners confused their liking, or disliking, of mathematics with their ability to do mathematics. If this is true, 
selecting an instructional type that students like or enjoy may have more impact on achievement than what theory may suggest.

No matter the situation, the results of this study suggest that intervention for struggling learners is not a futile task because it can impact students' attitude towards mathematics. While the impact may not be drastic, patterns in student scores from this study showed they were able to delineate between confidence and linking mathematics after the study as opposed to before. Attention should be paid to the instructional type selected, and students should become more involved in the selection. Furthermore, mathematics intervention should be viewed by teachers and students as a positive experience where students are given ample opportunities to grow in their mathematics understanding and learn from their misunderstandings. 


\section{REFERENCES}

Ainsworth, S., O'Malley, C., \& Wood, D. (1998). There is more than one way to solve a problem: Evaluating a learning environment that supports the development of children's multiplication skills. Learning and Instruction, 8(2), 141-157.

Baker, S., Gersten, R., \& Lee, D.-S. (2002). A synthesis of empirical research on teaching mathematics to low-achieving students. The Elementary School Journal, 103(1), 51. doi: doi:10.1086/499715

Bassoppo-Moyo, T. C. (2010). Effectiveness of using computer-assisted supplementary instturction for teaching selected algebra topics at a laboratory high school. [Article]. International Journal of Instructional Media, 37(1), 79-90.

Becker, H. J., Center for Research on, E., \& Middle Schools, B. M. D. (1990). Effects of computer use on mathematics achievement: Findings from a nationwide field experiment in grades five to eight.

Bitter, G. G., \& Hatfield, M. M. (1998). The role of technology in the middle grades. In L. Leutzinger (Ed.), Mathematics in the middle. Reston, VA: National Council of Teachers of Mathematics.

Bottge, B. A., \& Hasselbring, T. S. (1993). A comparison of two approaches for teaching complex, authentic mathematics problems to adolescents in remedial math classes. Exceptional Children, 59(6), 556-566. 
Brophy, J. (1998). Toward a model of he value aspects of motivation: Developing appreciation for particular learning and activities. Education Psychologist, 34(2), $75-85$.

Brown, S. A., Pitvorec, K., Ditto, C., \& Randall, C. (2009). Reconceiving Fidelity of Implementation: An Investigation of Elementary Whole-Number Lessons. [Article]. Journal for Research in Mathematics Education, 40(4), 363-395.

Bruner, J. S. (1969). Man: A Course of Study. In D. J. Flinders \& S. J. Thorton (Eds.), The Curriculum Studies Reader (Third ed., pp. 78-92). New York: Routledge. Burns, M. (2011). Do the Math Now. New York, NY: Scholastic Inc.

Burns, M. K., Codding, R. S., Boice, C. H., \& Lukito, G. (2010). Meta-analysis of acquisition and fluency math interventions with instructional and frustration level skills: Evidence for a skill-by-treatment interaction. [Article]. School Psychology Review, 39(1), 69-83.

CCSSI. (2010). Common Core State Standards Common Core State Standards for Mathematics: http://www.corestandards.org.

Chen, C., \& Stevenson, H. W. (1995). Motivation and Mathematics Achievement: A Comparative Study of Asian-American, Caucasian-American, and East Asian High School Students. Child Development, 66(4), 1215-1234.

Chiu, M. (2007). Mathematics as mother/basis of science in affect: Analysis of TIMSS 2003 data. Paper presented at the 31st Conference of the International Group for the Psychology of Mathematics Education. 
Choi, N., Bush, S., Hunter, A. E., \& Truitt, T. (2011). Factorial Validity of the Scores from the TIMSS 2007 Mathematics Attitude Scale. Paper presented at the American Education Research Association, New Orleans, LA.

Christensen, C. A., \& Gerber, M. M. (1990). Effectiveness of computerized drill and practice games in teaching basic math facts. Exceptionality, 1(3), 149-165.

Christmann, E., \& Badgett, J. (1997). Progressive comparison of the effects of computerassisted. [Article]. Journal of Research on Computing in Education, 29(4), 325.

Clements, D., Battista, M., \& National Council of Teachers of Mathematics. (2001). Logo and Geometry. Journal for Research in Mathematics Education Monograph Series.

Clements, D., \& Sarama, J. (1995). Design of a LOGO Environment for Elementary Geometry. Journal of Mathematical Behavior, 14(4), 381-398.

Clements, D., \& Sarama, J. (2000). Predicting Pattern Blocks On and Off the Computer. Teaching Children Mathematics, 6(7), 458-462.

Clements, D., Sarama, J., Yelland, N. J., \& Glass, B. (2008). Learning and Teaching Geometry with Computers in the Elementary and Middle School. In K. Heid \& G. W. Blume (Eds.), Research Synthesis: Research on technology and the teaching and learning of mathematics (Vol. 1). Reston, VA: National Council of Teachers of Mathematics.

Cohen, J. (1988). Statistical power analysis for the behavioral sciences (2nd ed.). Hillsdale, NJ: Erlbaum. 
Cooperstein, S. E., \& Kocevar-Weidinger, E. (2004). Beyond active learning: A constructivist approach to learning. Reference Services Review, 32(2), 141-148.

Dahlin, M. P. (2008). A Study of the Alignment of the NWEA RIT Scale with the Kentucky Commonwealth Accountability Testing System. Lake Oswego: Northwest Evaluation Association.

Darling-Hammond, L., Wei, R. C., Andree, A., Richardson, N., \& Orphanos, S. (2009). Professional learning in the learning profession:

A status report on teacher development in the united states and abroad. Palo Alto, CA: National Staff Development Council.

Dickinson, D. J., \& Butt, J. A. (1989). The Effects of Success and Failure on the On-Task Behavior of High Achieving Students. Education and Treatment of Children, I2(3), 243-252.

Driscoll, M. P. (2002). How people learn (and what technology might have to do with It): ERIC Clearinghouse on Information \& Technology, Syracuse University, 621 Skytop Rd., Suite 160, Syracuse, NY 13244-5290. Tel: 315-443-3640; Tel: 800464-9107 (Toll Free); Fax: 315-443-5448; e-mail: eric@ericit.org. For full text: http://ericit.org.

Eccles, J. S., Wigfield, A., \& Schiefele, U. (1998). Motivation to succeed. In N. Eisenberg (Ed.), Handbook of child psychology (5th ed., Vol. III, pp. 1017-1095). New York: Wiley.

Education, U. D. o. (2008). Foundations for Success: The Final Report of the National Mathematics Advisory Panel: US Department of Education. 
Eklöf, H. (2007). Self-concept and valuing of mathematics in TIMSS 2003: Scale structure and relation to performance in a Swedish setting. Scandinavian Journal of Educational Research, 51(3), 297-313. doi: 10.1080/00313830701356141

Emihovich, C., \& Miller, G. E. (1988). Effects of Logo and CAI on Black First Graders' Achievement, Reflectivity, and Self-Esteem. Elementary School Journal, 88(5), 473-487.

Fletcher-Flinn, C. M., \& Gravatt, B. (1995). The efficacy of computer assisted instruction (CAI): A meta-analysis. Journal of Educational Computing Research, 12(3), 219241.

Frenzel, A. C., Goetz, T., Lüdtke, O., Pekrun, R., \& Sutton, R. E. (2009). Emotional Transmission in the Classroom: Exploring the Relationship Between Teacher and Student Enjoyment. [Article]. Journal of Educational Psychology, 101(3), 705716. doi: $10.1037 / \mathrm{a} 0014695$

Fuchs, L. S., Fuchs, D., Hamlett, C. L., Phillips, N. B., \& Bentz, J. (1994). Classwide curriculum-based measurement: Helping general educators meet the challenge of student diversity. Exceptional Children, 60(6), 518-537.

Fuchs, L. S., Fuchs, D., Karns, K., Hamlett, C. L., Katzaroff, M., \& Dutka, S. (1997). Effects of task-focused goals on low-achieving students with and without learning disabilities. American Educational Research Journal, 34(3), 513-543.

Fuchs, L. S., Fuchs, D., Powell, S. R., Seethaler, P. M., Cirino, P. T., \& Fletcher, J. M. (2008). Intensive Intervention for Students with Mathematics Disabilities: Seven Principles of Effective Practice. Learning Disability Quarterly, 31(2), 79-92. 
Fuchs, L. S., Powell, S. R., Seethaler, P. M., Cirino, P. T., Fletcher, J. M., Fuchs, D., \& Hamlett, C. L. (2010). The effects of strategic counting instruction, with and without deliberate practice, on number combination skill among students with mathematics difficulties. Learning and Individual Differences, 20(2), 89-100.

Fuchs, L. S., Powell, S. R., Seethaler, P. M., Fuchs, D., Hamlett, C. L., Cirino, P. T., \& Fletcher, J. M. (2010). A framework for remediating number combination deficits. Exceptional Children, 76(2), 135-156.

Fuson, K. C., \& Brinko, K. T. (1985). The comparative effectiveness of microcomputers and flash cards in the drill and practice of basic mathematics facts. Journal for Research in Mathematics Education, 16(3), 225-232.

Galbraith, P., \& Haines, C. (1998). Disentangling the nexus: Attitudes to mathematics and technology in a computer learning environment. [Article]. Educational Studies in Mathematics, 36(3), 275-290.

Garson, G. D. (2011). Multivariate GLM, MANOVA, and MANCOVA Retrieved January 15, 2012, 2012

Gee, A. P. (2008). An investigation of the impact of SuccessMaker on reading and math achievement at an elementary school. (Northcentral University Ed.D.), ProQuest, UMI Dissertations Publishing. Retrieved from http://echo.louisville.edu/login?url=http://search.proquest.com/docview/30481824 $\underline{\text { 5?accountid }=14665}$ ProQuest Dissertations \& Theses (PQDT) database.

Gerber, M. M., Semmel, D. S., \& Semmel, M. I. (1994). Computer-based dynamic assessment of multidigit multiplication. Exceptional Children, 61(2), 114-125. 
Gersten, R., Chard, D. J., Jayanthi, M., Baker, S. K., Morphy, P., \& Flojo, J. (2009). Mathematics instruction for students with learning disabilities: A meta-analysis of instructional components. Review of Educational Research, 79(3), 1202-1242.

Gonzales, P., Williams, T., Jocelyn, L., Roey, S., Kastberg, D., Brenwald, S., \& National Center for Education, S. (2008). Highlights from TIMSS 2007: Mathematics and Science Achievement of U.S. Fourth- and Eighth-Grade Students in an International Context. NCES 2009-001: National Center for Education Statistics.

Green, J., Nelson, G., Martin, A. J., \& Marsh, H. (2006). The Causal Ordering of SelfConcept and Academic Motivation and Its Effect on Academic Achievement. International Education Journal, 7(4), 534-546.

Guay, F., Marsh, H. W., \& Boivin, M. (2003). Academic Self-Concept and Academic Achievement: Developmental Perspectives on Their Causal Ordering. Journal of Educational Psychology, 95(1), 124-136.

Guerrero, S., Walker, N., \& Dugdale, S. (2004). Technology in Support of Middle Grade Mathematics: What Have We Learned? [Feature]. The Journal of Computers in Mathematics and Science Teaching, 23(1), 5-20.

Hammouri, H. (2004). Attitudinal and Motivational Variables Related to Mathematics Achievement in Jordan: Findings from the Third International Mathematics and Science Study (TIMSS). Educational Research, 46(3), 241-257.

Handal, B., Handal, P., \& Herrington, T. (2006). Evaluating online mathematics resources. [Article]. Australian Primary Mathematics Classroom, 11(2), 8-14. 
Hasselbring, T. S., \& et al. (1988). Developing Math Automaticity in Learning Handicapped Children: The Role of Computerized Drill and Practice. Focus on Exceptional Children, 20(6), 1-7.

Hasselbring, T. S., Lott, A. C., \& Zydney, J. M. (2005). Technology-supported math instruction for students with disabilities: Two decades of research and development.

Hegedus, S. J., \& Kaput, J. J. (2004). An Introduction to the profound potential of connected algebra activities: Issues of representation, engagement and pedagogy.

Heid, K., \& Blume, G. W. (Eds.). (2008). Research Synthesis: Research on technology and the teaching and learning of mathematics (Vol. I). Reston, VA: National Council of Teachers of Mathematics.

Heid, K., \& Edwards, M. T. (2001). Computer Algebra Systems: Revolution or Retrofit for Today's Mathematics Classrooms? Theory into Practice, 40(2), 128-136.

Henson, R., \& Roberts, J. K. (2006). Use of exploratory factor analysis in published research: Common errors and comment on improved practice. Education and Psychological Measurement, 66(3), 393-416. doi: 10.1177/0013164405282485

Hiebert, J. (2003). What research says about the NCTM standards. In J. Kilpatrick, W. G. Martin \& D. Schifter (Eds.), A Research Companion to Prinicples and Standards for School Mathematics. Reston, VA: National Council of Teachers of Mathematics, Inc.

Hiebert, J., \& Grouws, D. A. (2007). The Effects of Classroom Mathematics Teaching on Students' Learning. In F. K. Lester (Ed.), Second handbook of research on 
mathematics teaching and learning : a project of the National Council of

Teachers of Mathematics. Charlotte, NC: Information Age Pub.

Hiele, P. M. V. (1997). Structuur (Structure). Zupthen, Netherlands: Thieme.

Howell, R., Sidorenko, E., \& Jurica, J. (1987). The effects of computer use on the acquisition of multiplicaiton facts by a student with learning disabilities. [Article]. Journal of Learning Disabilities, 20(6).

Huntley, M. A. (2009). Measuring Curriculum Implementation. [Article]. Journal for Research in Mathematics Education, 40(4), 355-362.

Individuals with Disabilities Education Improvement Act of 2004, Pub. Law No. 108446,108 th Congress (2004).

Irish, C. (2002). Using Peg- and Keyword Mnemonics and Computer-Assisted Instruction To Enhance Basic Multiplication Performance in Elementary Students with Learning and Cognitive Disabilities. Journal of Special Education Technology, 17(4), 29-40.

Jenks, M. S., \& Springer, J. M. (2005). A view of the research on the efficacy of CAI. Electronic Journal for the Integration of Technology in Education, 1(1), 43-58. doi: citeulike-article-id:363428

Johnson, I. D. (2005). Technology—friend or foe in early mathematical intervention? In S. Wagner (Ed.), PRIME: PRompt Intervention in Mathematics Education (pp. 151- 176). Columbus, OH: Ohio Resource Center for Mathematics, Science, and Reading and Ohio Department of Education. 
Kadijevich, D. (2006). Developing trustworthy TIMSS background measures: A case study on mathematics attitude. The Teaching of Mathematics, 9(2), 41-51.

Kaput, J. J. (1985). Multiplicative word problems and intensive quantities: An integrated software response.

Kaput, J. J. (1986). Information technology and mathematics: Opening new representational windows.

Kaput, J. J., \& Pattison-Gordon, L. (1987). A concrete-to-abstract softward ramp: Environments for learning multiplication, division, and intensive quantity.

Kaput, J. J., \& Thompson, P. W. (1994). Technology in mathematics education research: The first 25 years in the JRME (Vol. 25).

Kentucky Department of Education. (2001). Student Performance Level Descriptions: Kentucky Department of Education.

Kentucky Department of Education. (2007, Wednesday, January 31, 2007 at 10:11 AM). Student Performance Standards Downloads Retrieved March 25, 2010, from http://www.education.ky.gov/KDE/Instructional+Resources/Curriculum+Docume $\underline{\text { nts }+ \text { and }+ \text { Resources/Student }+ \text { Performance }+ \text { Standards/Student }+ \text { Performance }+ \text { Stan }}$ dards+Downloads.htm

Kentucky Department of Education. (2010). School report card: Westport Middle School. In W. M. School (Ed.), (2009-2010 school year ed.): Kentucky Department of Educaiton. 
Ketterlin-Geller, L. R., Chard, D. J., \& Fien, H. (2008). Making connections in mathematics: conceptual mathematics intervention for low-performing students. [Article]. Remedial \& Special Education, 29(1), 33-45.

Kirk, V. C. (2003). Investigation of the impact of integrated learning system use on mathematics achievement of elementary students. (East Tennessee State University Ed.D.), ProQuest, UMI Dissertations Publishing. Retrieved from http://echo.louisville.edu/login?url=http://search.proquest.com/docview/30532411 $\underline{0 \text { ?accountid }=14665}$ ProQuest Dissertations \& Theses (PQDT) database.

Kloosterman, P. (1988). Self-Confidence and Motivation in Mathematics. Journal of Educational Psychology, 80(3), 345-351.

Kohn, A. (1993/1999). Punished by Rewards: The Trouble with Gold Stars, Incentive Plans, A's, Praise, and Other Bribes. Boston: Houghton Mifflin.

Kroesbergen, E. H., \& Luit, J. E. V. (2003). Mathematics interventions for children with special educational needs. [Article]. Remedial \& Special Education, 24(2), 97.

Kroesbergen, E. H., \& Van Luit, J. (2003). Mathematics interventions for children with special educational needs. [Article]. Remedial \& Special Education, 24(2), 97.

Kroesbergen, E. H., \& Van Luit, J. E. H. (2005). Constructivist mathematics education for students with mild mental retardation. [Article]. European Journal of Special Needs Education, 20(1), 107-116. doi: 10.1080/0885625042000319115

Ku, H.-Y., Harter, C. A., Liu, P.-L., Thompson, L., \& Cheng, Y.-C. (2007). The effects of individually personalized computer-based instructional program on solving 
mathematics problems. [Article]. Computers in Human Behavior, 23(3), 11951210. doi: $10.1016 /$ j.chb.2004.11.017

Kulik, C.-L. C., \& Kulik, J. A. (1991). Effectiveness of Computer-Based Instruction: An Updated Analysis. Computers in Human Behavior, 7(1-2), 75-94.

Lesh, R., Post, T., \& Behr, M. (1987). Representations and translations among representations in mathematics learning and problem solving. In C. Janvier (Ed.), Problems of presentation in the teaching and learning of mathematics (pp. 3340). Hillsdale, NJ: Lawrence Erlbaum.

Lin, A., Podell, D. M., \& Tournaki-Rein, N. (1994). CAI and the development of automaticity in mathematics skills in students with and without mild mental handicaps. Computers in the Schools, 11(1), 43-58.

Maccini, P., Mulcahy, C. A., \& Wilson, M. G. (2007). A follow-up of mathematics interventions for secondary students with learning disabilities. [Article]. Learning Disabilities Research \& Practice (Blackwell Publishing Limited), 22(1), 58-74. doi: $10.1111 / j .1540-5826.2007 .00231 . x$

Maccini, P., \& Ruhl, K. L. (2000). Effects of a Graduated Instructional Sequence on the Algebraic Subtraction of Integers by Secondary Students with Learning Disabilities. Education and Treatment of Children, 23(4), 465-489.

Manning, C. A. (2004). The effect of the Math Concepts and Skills (MCS) computer program on standardized test scores at a middle school in east central Florida. (University of Central Florida Ed.D.), ProQuest, UMI Dissertations Publishing. Retrieved from 
http://echo.louisville.edu/login?url=http://search.proquest.com/docview/30508415 $\underline{1 \text { ?accountid }=14665}$ ProQuest Dissertations \& Theses (PQDT) database.

Marsh, H. W., Trautwein, U., Köller, O., \& Baumert, J. (2005). Academic Self-Concept, Interest, Grades, and Standardized Test Scores: Reciprocal Effects Models of Causal Ordering. Child Development, 76(2), 397-416.

Martin, M. O., \& Preuschoff, C. (2008). Chapter 12: Creating the TIMSS 2007 (Eklof, 2007) background indices. In J. F. Olson, M. O. Martin \& I. V. S. Mullis (Eds.), TIMSS 2007 technical report (pp. 281-338). Chestnut Hill, MA: TIMSS \& PIRLS International Study Center, Boston College.

Mathis, A. C. (2010). The effects of a research based intervention on math CRCT scores of NCLB subgroups: Implementation of SuccessMaker(TM) in eighth grade. (Mercer University Ph.D.), ProQuest, UMI Dissertations Publishing. Retrieved from http://echo.louisville.edu/login?url=http://search.proquest.com/docview/74681831 7?accountid=14665 ProQuest Dissertations \& Theses (PQDT) database.

McCloskey, A. V., \& Norton, A. H. (2009). Using Steffe's advanced fraction schemes. Mathematics Teaching in the Middle School, 15(1), 44-50.

McCollister, T. S., Burts, D. C., Wright, V. L., \& Hildreth, G. J. (1986). Effects of computer-assisted instruction and teacher-assisted instruction on arithmetic task achievement scores of kindergarten children. Journal of Educational Research, $80(2)$. 
McDermott, P. A., \& Watkins, M. W. (1983). Computerized vs. Conventional Remedial Instruction for Learning-Disabled Pupils. Journal of Special Education, 17(1), 8188.

Meelissen, M., \& Luyten, H. (2008). The Dutch gender gap in mathematics: Small for achievement, substantial for beliefs and attitudes. [Feature]. Studies in Educational Evaluation, 34(2), 82-93.

Mevarech, Z. R. (1985). Computer-assisted instuctional methods: A factorial study within mathematics disadvantaged classrooms. Journal of Experimental Education, $54(1), 22-27$

Meyer, M. R., \& Fennema, E. (1985). Proceedings of the Annual Meeting of the North American Chapter of the International Group for the Psychology of Mathematics Education (7th, Columbus, Ohio, October 2-5, 1985). In S. K. Damarin, M. Shelton \& C. International Group for the Psychology of Mathematics Education. North American (Eds.), (pp. pp. 201-206). Columbus, OH: Authors.

Middleton, B. M., \& Murray, R. K. (1999). The impact of instructional technology on student academic achievement in reading and mathematics. [Article]. International Journal of Instructional Media, 26(1), 109.

Middleton, J., \& Spanias, P. (1999). Motivation for achievement in mathematics: Findings, generalizations, and criticisms of the research. [Article]. Journal for Research in Mathematics Education, 30(1), 65. 
Midgley, C., Feldlaufer, H., \& Eccles, J. S. (1989). Student/Teacher Relations and Attitudes toward Mathematics before and after the Transition to Junior High School Child Development (Vol. 60, pp. 981-992).

Mintz, K. S. (2000). A comparison of computerized and traditional instruction in elementary mathematics. (The University of Alabama Ph.D.), ProQuest, UMI Dissertations Publishing. Retrieved from http://echo.louisville.edu/login?url=http://search.proquest.com/docview/30457777 3? accountid $=14665$ ProQuest Dissertations \& Theses (PQDT) database.

Moyer, P. S., \& Bolyard, J. J. (2002). Exploring representation in the middle grades: Investigations in geometry with virtual manipulatives. The Australian Mathematics Teacher, 58(1), 19-25.

NCTM. (2000). Priciples and standards for school mathematics. Reston, VA: National Council of Teachers of Mathematics.

Nguyen, D. M., Hsieh, Y.-C., \& Allen, G. D. (2006). The impact of web-based assessment and practice on students' mathematics learning attitudes. Journal of Computers in Mathematics and Science Teaching, 25(3), 251-279.

Nicaud, J. F., Bitta, M., Chaachoua, H., Inamdar, P., \& Maffei, L. (2006). Experiments with Aplusix in four countries. International Journal for Technology in Mathematics Education, 13(2), 79-88.

No Child Left Behind Act of 2001, Public Law 107-110, 107th Congress (2001).

Norwich, B. (2007). Handbook of competence and motivation. [Book Review]. British Journal of Educational Psychology, 77(3), 744-745. 
NRC. (2001). Developing proficiency in teaching mathematics. In J. Kilpatrick, J.

Swafford \& B. Findell (Eds.), Adding it Up: helping children learn mathematics.

Washington, DC: National Academy Press.

NWEA. (2004). Reliability and Validity Estimates NWEA Achievement Level Tests and Measures of Academic Progress. Lake Oswego: Northwest Evaluation Association.

NWEA. (2009). Technical manual for Measures of Academic Progress and Measures of Academic Progress for primary grades. Lake Oswego, OR: Northwest Evaluation Association.

Olive, J., \& Lobato, J. (2008). The Learning of Rational Number Concepts Using Technology. In K. Heid \& G. W. Blume (Eds.), Research Synthesis: Research on technology and the teaching and learning of mathematics (Vol. I). Reston, VA: National Council of Teachers of Mathematics.

Olson, J. F., Martin, M. O., Mullis, I. V. S., Foy, P., Erberber, E., \& Preuschoff, C. (2008). Chapter 10: Reviewing the TIMMS item statistics. In J. F. Olson, M. O. Martin \& I. V. S. Mullis (Eds.), TIMSS 2007 technical report (pp. 193-224). Chestnut Hill, MA: TIMSS \& PIRLS International Study Center, Boston College.

Olusi, F. I. (2008). Using computer to solve mathematics by junior secondary school students in Edo state Nigeria. [Article]. College Student Journal, 42(3), 748-755.

Ozel, S., Yetkiner, Z. E., \& Capraro, R. M. (2008). Technology in K-12 mathematics classrooms. School Science \& Mathematics, 108(2), 80-85. 
Palmer, H. (1973). Three evaluation reports of computer assisted instruction in drill-andpractice mathematics (pp. 23).

Palmor, H. (1973). Three Evaluation reports of computer assisted instruction in drill-andpractice mathematics (pp. 23).

Papanastasiou, E. C., \& Ferdig, R. E. (2006). Computer use and mathematical literacy: An analysis of existing and potential relationships. Journal of Computers in Mathematics and Science Teaching, 25(4), 361-371.

Pearce, M., \& Norwich, B. (1986). A comparative evaluation of direct teaching and computer-assisted methods to teach number estimation skills to children with moderate learning difficulties. European Journal of Special Needs Education, $1(1), 13-22$.

Pearson. (2006). Correlation NWEA Learning Continuum Measures of Academic Progress (MAP)

Mathematics 6 SuccessMaker ${ }^{\circledR}$ Enterprise Foundation \& ExploreWare Courses.

Pearson Digital Learning. (2005a). Reference Manual for Math Concepts and Skills 2:

Pearson Digital Learning.

Pearson Digital Learning. (2005b). SuccessMaker Enterprise Math Concepts and Skills 2:

Pearson Digital Learning.

Pellegrino, J. W., \& Goldman, S. R. (1987). Information Processing and Elementary Mathematics. Journal of Learning Disabilities, 20(1), 23-32. doi:

$10.1177 / 002221948702000105$ 
Pierce, R., Ball, L., \& Stacey, K. (2009). Is It Worth Using CAS for Symbolic Algebra Manipulation in the Middle Secondary Years? Some Teachers' Views. International Journal of Science and Mathematics Education, 7(6), 1149-1172.

Podell, D. M., \& et al. (1992). Automatization of Mathematics Skills via ComputerAssisted Instruction among Students with Mild Mental Handicaps. Education and Training in Mental Retardation, 27(3), 200-206.

Presland, A., \& Wishart, J. (2004). Secondary school pupils' motivations to use an Integrated Learning System. [Other]. 35, 663-668. doi: 10.1111/j.00071013.2004.00423.x

Rasanen, P., Salminen, J., Wilson, A. J., Aunio, P., \& Dehaene, S. (2009). Computerassisted intervention for children with low numeracy skills. Cognitive Development, 24(4), 450-472.

Reed, H. C., Drijvers, P., \& Kirschner, P. A. (2010). Effects of attitudes and behaviours on learning mathematics with computer tools. [Article]. Computers \& Education, 55(1), 1-15. doi: 10.1016/j.compedu.2009.11.012

Reimer, K., \& Moyer, P. S. (2005). Third-graders learn about fractions using virtual manipulatives: A classroom study. [Feature]. The Journal of Computers in Mathematics and Science Teaching, 24(1).

Relich, J. (1984). Learned helplessness in arithmetic: An attributional approach to increased self-efficacy and division skills. Paper presented at the Psychology of Mathematics Education, Sydney, Australia. 
Rivera, D. M., \& Bryant, B. R. (1992). Mathematics Instruction for Students with Special Needs. Intervention in School and Clinic, 28(2), 71-86.

Saphier, J., Haley-Speca, M. A., \& Gower, R. R. (2008). The Skillful Teacher: Research for Better Teaching, Inc.

Scarlato, M. C., \& Burr, W. A. (2002). Teaching Fractions to Middle School Students. Journal of Direct Instruction, 2(1), 23-38.

Scheiter, K., Gerjets, P., \& Schuh, J. (2010). The Acquisition of Problem-Solving Skills in Mathematics: How Animations Can Aid Understanding of Structural Problem Features and Solution Procedures. Instructional Science: An International Journal of the Learning Sciences, 38(5), 487-502.

Seo, Y.-J., \& Bryant, D. P. (2009). Analysis of studies of the effects of computer-assisted instruction on the mathematics performance of students with learning disabilities. [Article]. Computers \& Education, 53(3), 913-928. doi:

10.1016/j.compedu.2009.05.002

Shavelson, R. A. (1996). Statistical reasoning for the behavior sciences. Needham Height, MA: Allyn and Bacon.

Slavin, R. E., \& Lake, C. (2008). Effective programs in elementary mathematics: A bestevidence synthesis. [Article]. Review of Educational Research, 78(3), 427-515.

Slavin, R. E., Lake, C., \& Groff, C. (2009). Effective programs in middle and high school mathematics: A best-evidence synthesis. Review of Educational Research, 79(2), 839-911. 
Souter, M. T. (2002). Integrating technology into the mathematics classroom: An action research study. $l(1)$. Retrieved from teach.valdosta.edu/are/Artmanscrpt/vol1no1/souter_am.pdf

Sowder, J. T. (2007). The mathematical education and development of teachers. In F. K. Lester (Ed.), Second handbook of research on mathematics teaching and learning : a project of the National Council of Teachers of Mathematics. Charlotte, NC: Information Age Pub.

Steffe, L. P. (2004). On the construction of learning trajectories of children: The case of commensurate fractions. Mathematical Thinking and Learning An International Journal, 6(2), 129-162.

Stevens, J. P. (2009). Applied multivariate statistics for the social sciences. New York, NY: Routledge.

Suh, J. M. (2010). Tech-knolwedgy \& diverse learners. [Article]. Mathematics Teaching in the Middle School, 15(8), 440-447.

Tatar, D., Roschelle, J., Knudsen, J., Shechtman, N., Kaput, J., \& Hopkins, B. (2008). Scaling up innovative technology-based mathematics. Journal of the Learning Sciences, $17(2), 248-286$.

Taylor, L. (1993). Vygotskian Influences in Mathematics Education, with Particular Reference to Attitude Development. Focus on Learning Problems in Mathematics, 15(2-3), 3-17. 
Taylor, M., Pountney, D., \& Malabar, I. (2007). Animation as an Aid for the Teaching of Mathematical Concepts. Journal of Further and Higher Education, 31(3), 249261.

Thrall, T., \& Tingey, B. (2003). SuccessMaker Motion: A Research Summary: Pearson Digital Learning.

Tienken, C. H., \& Maher, J. A. (2008). The influence of computer-assisted instruction on eighth grade mathematics achievement. RMLE Online: Research in Middle Level Education, 32(3), 1-13.

Tienken, C. H., \& Wilson, M. J. (2007). The impact of computer assisted instruction on seventh-grade students' mathematics achievment. Planning and Changing, 38(3), 181-190.

Tsung-Yen, C., \& Wei-Fan, C. (2009). Effect of Computer-Based Video Games on Children: An Experimental Study. Journal of Educational Technology \& Society, 12(2), 1-10.

Tucker, T. H. (2009). The relationship between computer-assisted instruction and alternative programs to enhance fifth-grade mathematics success on the annual Texas Assessment of Knowledge and Skills. (University of North Texas Ed.D.), ProQuest, UMI Dissertations Publishing. Retrieved from http://echo.louisville.edu/login?url=http://search.proquest.com/docview/30495930

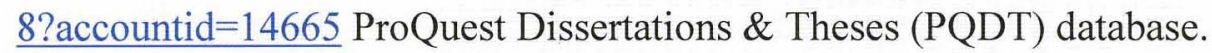

Urbina, S. (2004). Essentials of psychological testing. Hoboken, NJ: John Wiley \& Sons, Inc. 
Van de Walle, J. A., Karp, K. S., \& Bay-Williams, J. M. (2010). Elementary and middle school mathematics: Teaching developmentally. Boston: Pearson Education Inc. Van Eck, R. (2006). The Effect of Contextual Pedagogical Advisement and Competition on Middle-School Students' Attitude toward Mathematics and Mathematics Instruction Using a Computer-Based Simulation Game. Journal of Computers in Mathematics and Science Teaching, 25(2), 165-195.

Vygotsky, L. S. (1978). Mind in Society: Development of Higher Psychological Processes: Harvard University Press.

Waxman, H. C., Connell, M. L., \& Gray, J. (2002, September 26, 2010). A quantitative synthesis of recent research on the effects of teaching and learning with technology on student outcomes.

Wenglinsky, H., \& Educational Testing Service, P. N. J. P. I. C. (1998). Does It Compute? The Relationship between Educational Technology and Student Achievement in Mathematics.

Wigfield, A., \& Eccles, J. (2002). The development of competence beliefs, expectancies or success, and achievement values from childhood through adolescence. In A. Wigfield \& J. Eccles (Eds.), Development of achievement motivation (pp. 92120). New York: Academic Press.

Wigfield, A., Harold, R., Eccles, J., Blumenfeld, P., Aberbach, A., Freedman-Doan, C., \& Yoon, K. S. (1992). The structure of children's ability perceptions and achievement values: Age, gender, and domain differences Paper presented at the American Educational Research Association, San Francisco. 
Wigfield, A., \& Tonks, S. (2002). Development of Achievment Motivation. San Diego: Academic Press.

Wilson, R., Majsterek, D., \& Simmons, D. (1996). The effects of computer-assisted versus teacher-directed instruction on the multiplication performance of elementary students with learning disabilities. Journal of Learning Disabilities, 29(4), 382-390.

Woodward, J., Baxter, J., \& Robinson, R. (1999). Rules and reasons: Decimal instruction for academically low achieving students. Learning Disabilities Research and Practice, 14(1), 15-24.

Xin, F., \& Rowan Coll. of New Jersey, G. S. E. D. (1996). The Effects of ComputerAssisted Cooperative Learning in Mathematics in Integrated Classrooms for Students with and without Disabilities. Final Report.

Xin, Y. P., Jitendra, A. K., \& Deatline-Buchman, A. (2005). Effects of Mathematical Word Problem-Solving Instruction on Middle School Students with Learning Problems. Journal of Special Education, 39(3), 181-192.

Zbiek, R. M., Heid, M. K., \& Dick, T. P. (2007). Research on technology in mathematics education: A perspective of constructs. In F. K. Lester Jr (Ed.), Second handbook of research on mathematics teaching and learning (pp. 1169-1207). Reston, VA: National Council of Teachers of Mathematics. 


\section{APPENDICES}

\section{Appendix A}

TIMSS (2007) Student Questionnaire

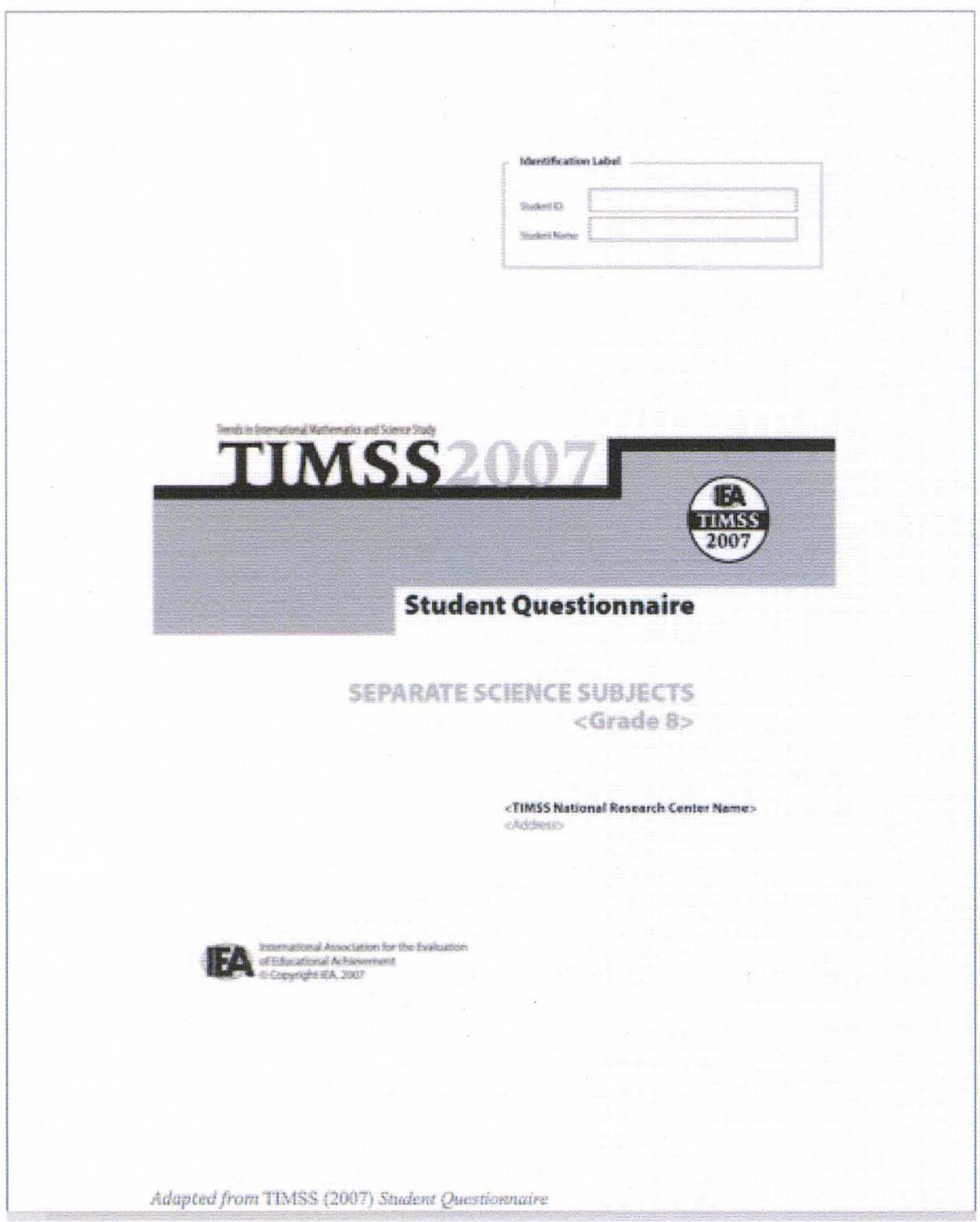




\section{General Directions}

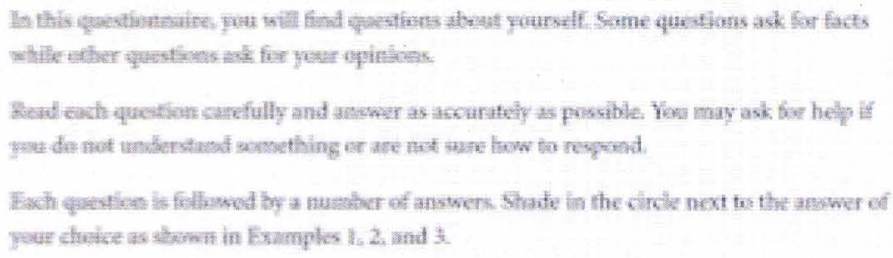

\section{Example 1}

Dos you go to whtowit?

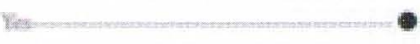

Som

\section{Example 2}

Hives stike do yee do these things?

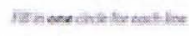

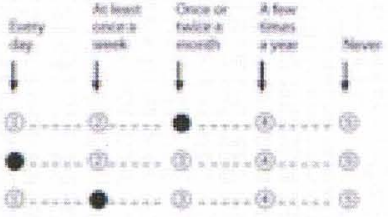




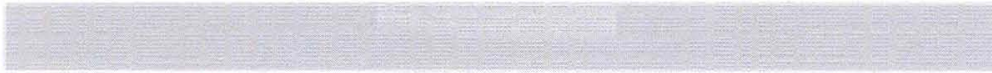

\section{Example 3}

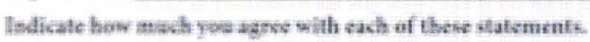

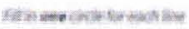

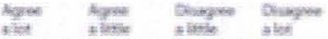

$1+1$

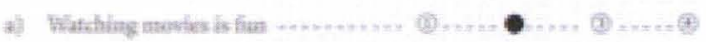

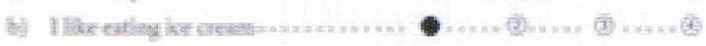

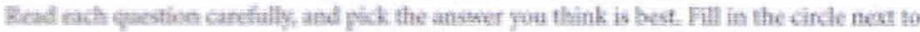
oe bebow pour answer. If you decide to change an answer to a question fut ant " $\mathrm{x}$ " ower your

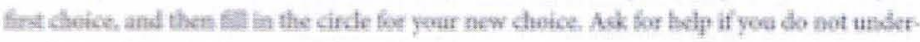

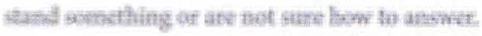

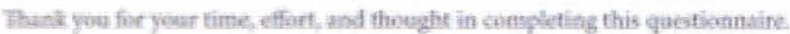


1.

Do you have any of these things at your home?

Fiv in ene cirele for wash fine

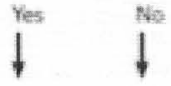

a)

Intcrnet cumpection -..............

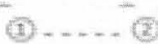

b) Computer (do not indude

Plastation, GameCube", XBox",

or other TV/video game computers) - (1) ...... (2)

2.

How much do you agree with these statements about learning mathematics?

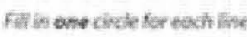

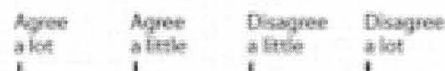

$1+1$

a) I am very comfortable working on (3) ..... (2) ..... (3) ...... (4) the computer.

b) I have good computer skills. (9) $\ldots \ldots$ (2) $\ldots \ldots=$ (3) $\ldots \ldots$ (9)

3.

How often do you use the computer?

$$
\text { Firin one circle only }
$$

Every Day

1-3 Times a Week-

Every Two Weeks.

Once a Month-........................................

Adapted from TIMSS (2007) Student Quertornaire 
4.

Hew mush do you agree with these statements about learning mathematics?

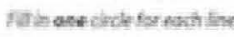

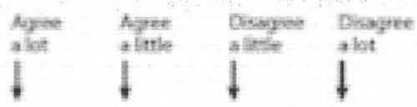

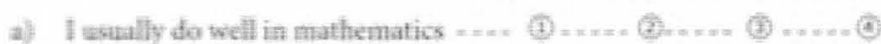

by I would like to take more mothermatios fin scherel .

(1) ........... (0) ..... (4)

c) Muthemutics is mate dificult for me then for many of my dussmates ...... (1) ..... (2) .... (3) ..... (6)

df 1 enfoy learning mathematies ......... (3) ...... (2) ..... (5) ...... (9)

द) Mathematics is not one of

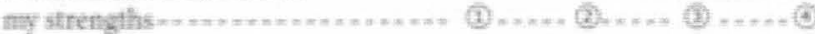

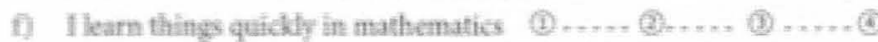

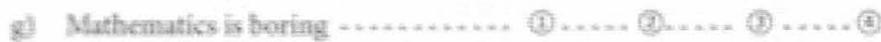

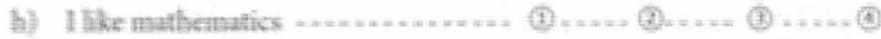

5.

How much do you agree with these statements about mathematics?

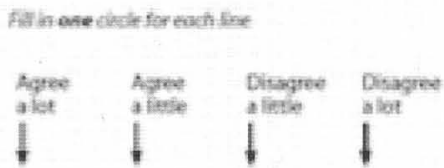

a) Ithink learning mathernatics will help me is any disity life?

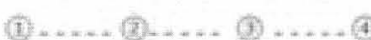

b. I seed mathematics to

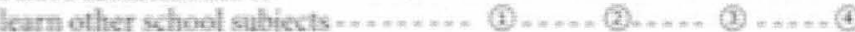

c) I need to do well in mathematic to get into the cuatversity? of my aboutee (1) ...... (7) ....

di) I need to do well in mathematics to

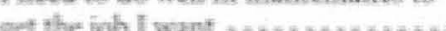
(9) $\ldots \ldots=$ (4) $\ldots \ldots$ 6 $\ldots \ldots \ldots$

Adapted from TTMSS (2007) Stadon Questiannaire 


\section{CAI Observation Tool}

CAI Observation Tool:

\begin{tabular}{|c|c|c|c|c|}
\hline Date: & & & & \\
\hline Period: & & & & \\
\hline Teacher & & & & \\
\hline Grade: & $6^{\text {th }}$ & & $7^{\text {th }}$ & \\
\hline Group: & SuccessMc & & $\begin{array}{l}\text { Do the Mat } \\
\text { SuccessMa }\end{array}$ & \\
\hline $\begin{array}{l}\text { Approximate time on } \\
\text { SuccessMaker }\end{array}$ & & & & \\
\hline $\begin{array}{l}\text { Number of Student-Teacher } \\
\text { Interactions }\end{array}$ & & & & \\
\hline $\begin{array}{l}\text { Type of student-teacher } \\
\text { interactions? }\end{array}$ & $\begin{array}{l}\text { Mostly } \\
\text { Technical }\end{array}$ & $\begin{array}{l}\text { Mostly } \\
\text { Behavioral }\end{array}$ & $\begin{array}{l}\text { Mostly } \\
\text { Conceptual }\end{array}$ & $\begin{array}{l}\text { Mostly } \\
\text { Procedural }\end{array}$ \\
\hline $\begin{array}{l}\text { If interaction was } \\
\text { instruction, what was the } \\
\text { topic? }\end{array}$ & & & & \\
\hline Fraction of students on-task & & & & \\
\hline Notes: & & & & \\
\hline
\end{tabular}




\section{CAI Student-Teacher Interaction Log}

CAI Student-Teacher Interaction Log

Directions: Record each interaction you have with students while they are using

SuccessMaker.

Types of Interactions:

Behavioral (B)-

A student is not meeting behavior expectations.

Examples Include:

- The student is not on-task

- The student is on a different website or computer program

- The student is talking

- The student is sleeping

Technical (T)-

A student needs assistance with their computer or the software.

Examples Include:

- The computer freezes

- They need assistance longing onto the computer

- The software isn't loading 
- They need assistance logging onto the software

- The software freezes

\section{Conceptual (C)-}

A student needs assistance related to a mathematical concept. Also indicate if manipulatives or a picture were used.

Examples include:

- Meaning of operations

- Relationships between operations Ex. The inverse relationship between multiplication and division

- Meaning of Vocabulary Ex. The denominator tells us the size of the pieces or set

- Forming generalizations: Ex. The fractions $1 / 5,2 / 10$, and $3 / 15$ are equivalent because they all represent the same fractional amount and I can prove that with multiplication and division.

- Connecting different representations: Ex. Multiplication can be represented with a rectangular array, with groups of an object or with numbers.

Procedural (P)-

A student needs assistance related to a mathematical procedure. Also indicate if manipulatives or a picture were used.

Examples include:

- Using the traditional algorithm for Addition, Subtraction, Multiplication, or Division 
- Teaching students a series of steps to solve a problem: Ex. Steps for Problem Solving- Underline the key words, circle the numbers, cross out the numbers....

- Using steps to solve an equation. Ex. $54=\mathrm{x}+12$ Telling a student to "subtract 12 from both sides"

Student: Jaelyn D.

\begin{tabular}{|c|c|c|c|c|}
\hline Date & $\begin{array}{l}\text { Type of } \\
\text { Interaction: } \\
\text { Behavioral } \\
\text { (B) } \\
\text { Technical } \\
\text { (T) } \\
\text { Conceptual } \\
\text { (C) } \\
\text { Procedural } \\
\text { (P) }\end{array}$ & $\begin{array}{l}\text { Did you use } \\
\text { manipulatives } \\
\text { (M) or } \\
\text { pictures (P) to } \\
\text { help explain } \\
\text { the concept or } \\
\text { procedure? }\end{array}$ & $\begin{array}{l}\text { How long } \\
\text { was the } \\
\text { interaction? }\end{array}$ & Teacher Notes: \\
\hline $9 / 14$ & $\mathrm{~T}$ & & & Forgot password \\
\hline $10 / 2$ & $C$ & $M$ & $5 \mathrm{~min}$. & $\begin{array}{l}\text { Didn't understand the } \\
\text { meaning of the denominator }\end{array}$ \\
\hline $10 / 4$ & $\mathrm{P}$ & & & \\
\hline $10 / 15$ & B & & $30 \mathrm{sec}$ & $\begin{array}{l}\text { Jaelyn was talking and I } \\
\text { redirected her }\end{array}$ \\
\hline
\end{tabular}




\section{Structured Curriculum Observations Tool}

Structured Curriculum Observation Tool:

Do the Math

\begin{tabular}{|l|l|l|}
\hline Date: & \multicolumn{2}{|l|}{} \\
\hline Period: & \multicolumn{2}{|l|}{} \\
\hline Teacher & $6^{\text {th }}$ & $7^{\text {th }}$ \\
\hline Grade: & Do the Math & Do the Math \& SuccessMaker \\
\hline Group: & & \\
\hline Approximate length & & \\
\hline Number of Students & & \\
participating in & & \\
lesson
\end{tabular}




\section{Appendix B}

Figure 3

Histogram for MAP Scores for CAI Group

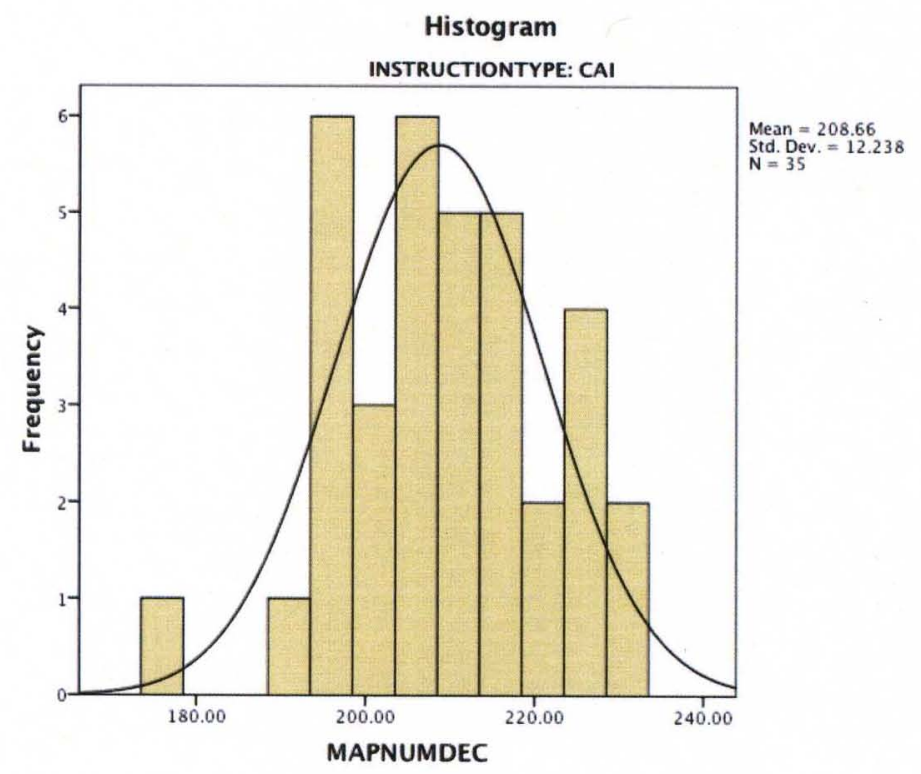




\section{Figure 4}

\section{Histogram for MAP Scores for SC Group}

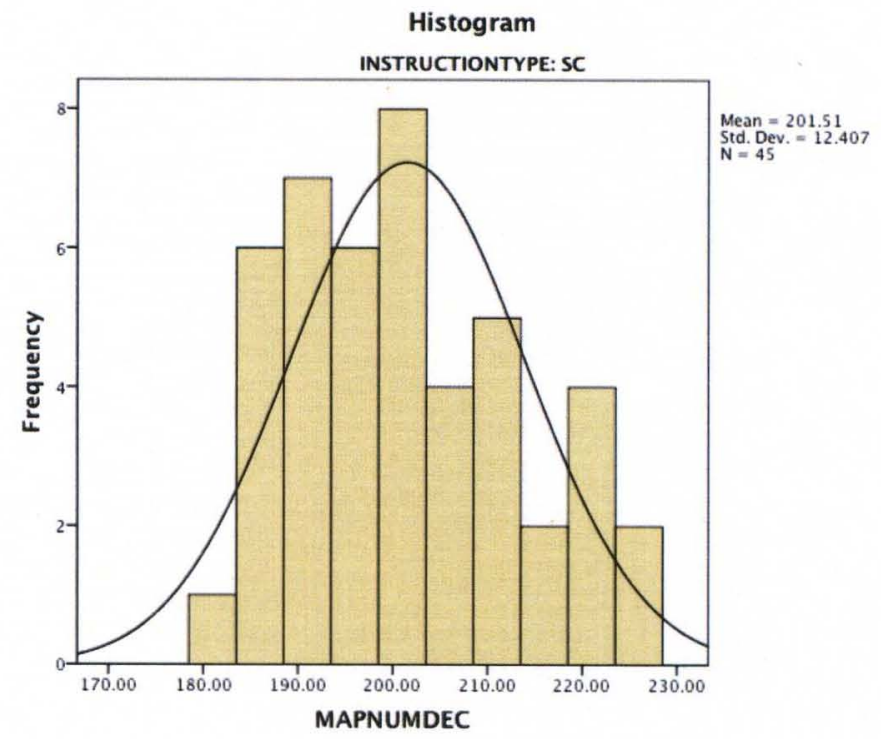

\section{Figure 5}

Histogram for MAP Scores for CAI with SC Group

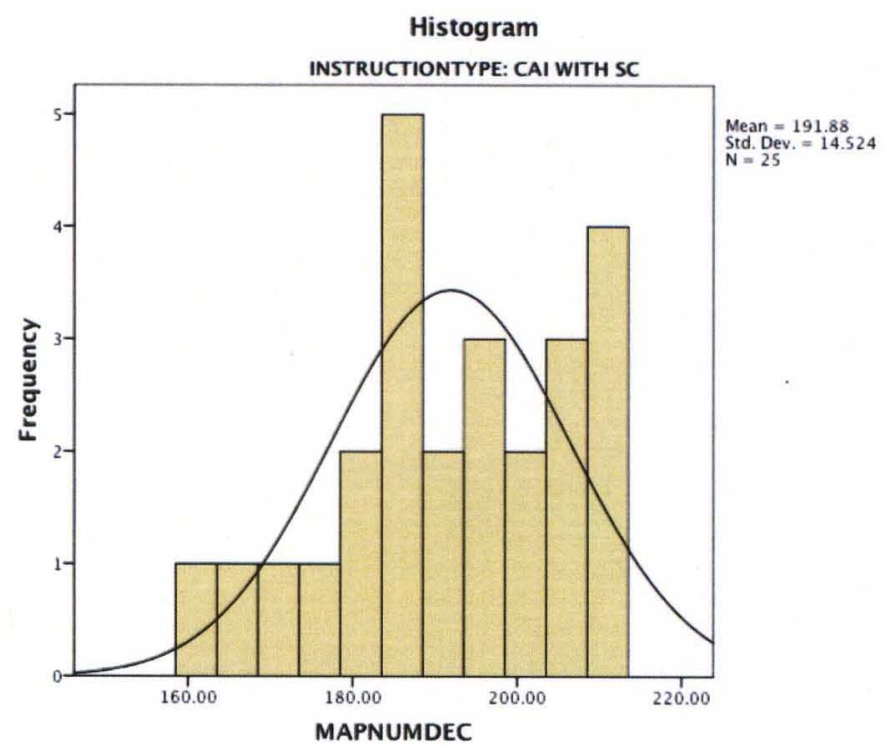


Figure 6

Scatter plot of MAP Pre and Post-test Scores

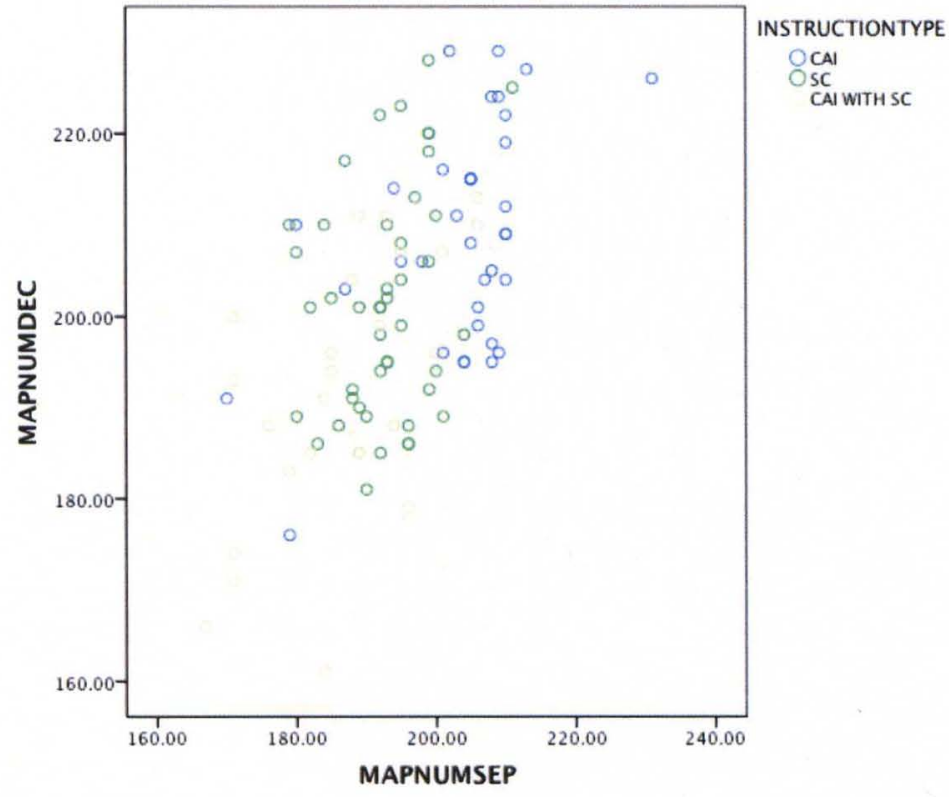




\section{Figure 7}

Scatter plot of Pre and Post-mean Scores Overall Attitude Towards Mathematics

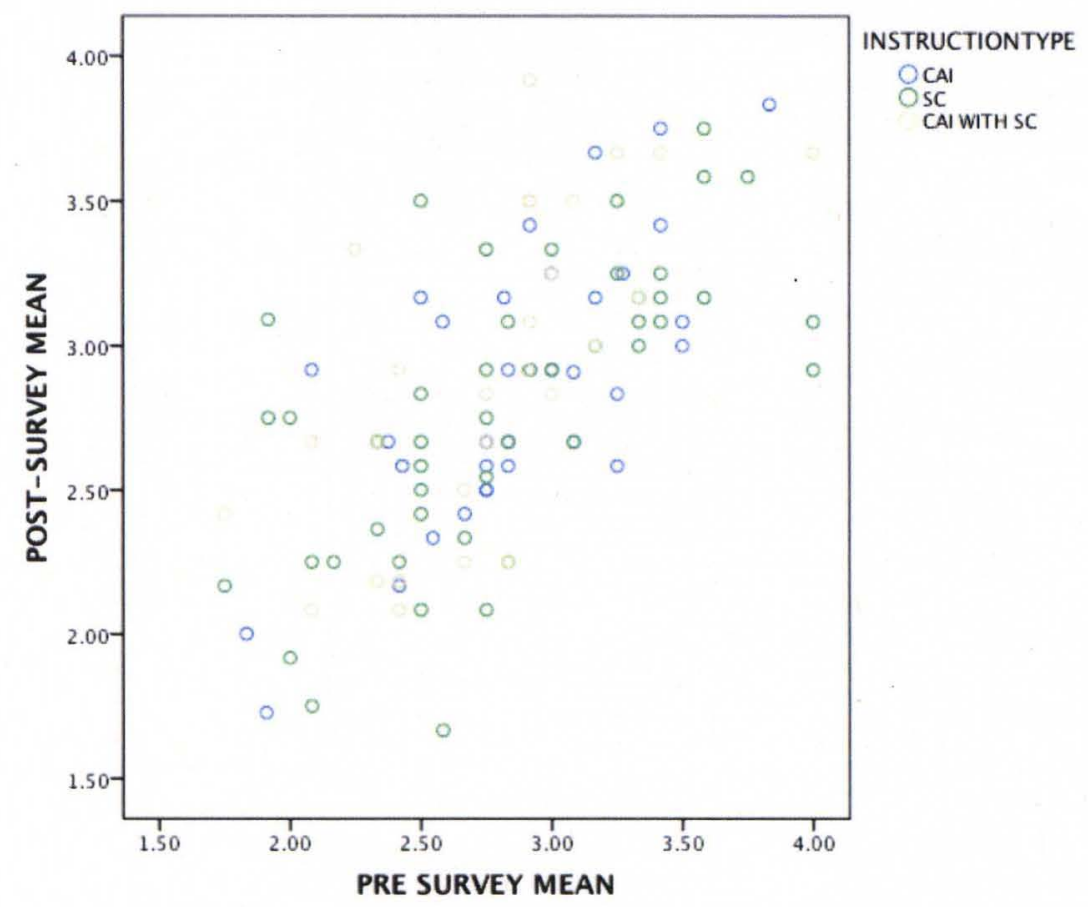




\section{Figure 8}

Scree Plot for Pre-Survey of Attitude Towards Mathematics

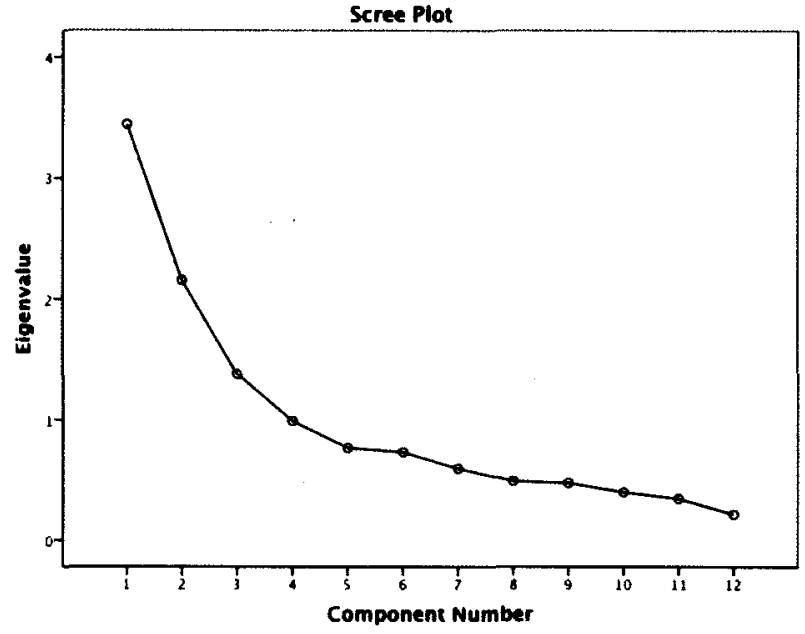

Figure 9

Scree Plot for Post-Survey of Attitude Towards Mathematics

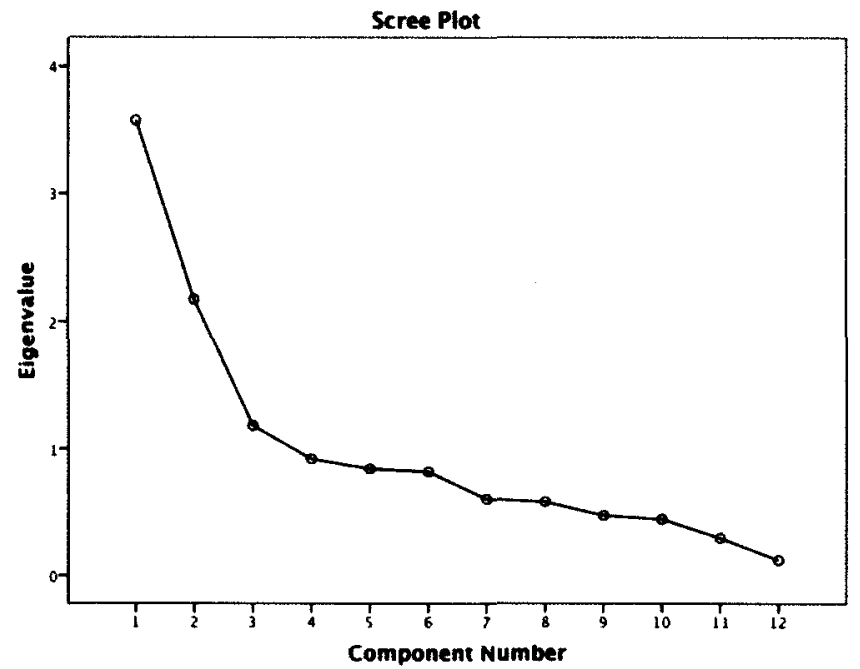




\title{
CURRICULUM VITAE
}

\author{
Amy E. Hunter Ph. D \\ Jefferson County Public Schools \\ Analytical \& Applied Sciences \\ Louisville, KY 40207 \\ Cell Phone: 502-777-9572 \\ Email: amy.hunter@jefferson.kyschools.us
}

\section{Education}

2012

Doctor of Philosophy, Curriculum and Instruction: Mathematics Education University of Louisville

4.0 GPA

Dissertation Title: The Effects of Computer Assisted Instruction and Structured Curriculum on Struggling Mathematics Students

2006 Master of Arts in Teaching, University of Louisville 4.0 GPA

2002 Bachelor of Science in Accountancy and Information Systems, Arizona State University

3.5 GPA

Curriculum and Professional Development Design Experience Mathematics Resource Teacher, Jefferson County Public Schools, Louisville Kentucky (2010-present)

- Designed curriculum maps for grades 6-7. This included deconstructed standards, and evaluating program alignment, and researching, collecting, and sometimes creating teaching material

- Designed and managed development of a standards-based mathematics intervention curriculum (K-8)

- Created and evaluated district-level common assessments ensuring alignment to standards 
- Designed and provided mathematics specific professional development for a cohort for mathematics teachers of exceptional children (ECE Mathematics Cohorts)

- Designed and implemented an evaluation methodology to evaluate the effectiveness of the ECE Mathematics Cohorts

- Consulted middle and elementary schools on mathematics intervention instruction

- Designed and delivered professional development workshops on: Analyzing Formative Assessment Data, Question Mapping, Mathematics Response to Intervention, Standards-based unit planning

University of Louisville (2009)

- Developed middle grades financial literacy curriculum

- Developed elementary summer camp inter-disciplinary curriculum integrating mathematics, writing, and technology

\section{University Teaching Experience}

\section{University of Louisville}

Elementary Mathematics Methods (EDTP 604) (2009)

- Taught P-5 mathematics methods to pre-service graduate level elementary teacher candidates

Summer Portfolio Institute Leader (EDAP 611) (2009)

- Taught a group of graduate level teachers as they prepared to teach a summer institute; this course focused on developing curriculum that integrated mathematics, writing, science, and technology for students elementary and middle grades

\section{K-12 Teaching Experience}

\section{Mathematics Resource Teacher, Jefferson County Public Schools, Louisville} Kentucky (2010- present)

- Modeled, co-taught, and co-planned lessons with teachers to improve instruction and student achievement

- Assisted Lassiter Middle School in implementing professional learning communities (PLC)

- Conducted embedded professional development monthly with Lassiter Middle school mathematics and mathematics intervention teachers

- Assisted Lassiter, Frost, Johnson, and Conway Middle Schools with designing and implementing mathematics intervention

- Assisted teachers, instructional coaches and administrators with data analysis and program evaluation

Title I Resource Teacher, T. T. Knight Middle School, Louisville Kentucky (20082010) 
- Designed mathematics intervention plan; including organization of assessments, curriculum, student groupings, and intervention instruction

- Researched and designed professional development model for teaching staff, which utilizes professional learning communities (PLC) to foster collaboration

- Organized and managed data collection and analysis for school

- Designed template, trained administrators, and managed collection of administrator observations through E-walk system

- Coordinated and managed creation of Comprehensive School Improvement Plan (CSIP)

- Implemented a book study on writing to earn in math

- Designed and delivered professional development workshops on the following topics: 5 Representations in Math, Answering Math Open Response Questions Using the TAPE Graphic Organizer; Accelerated Math in the Connect Math Classroom, $6^{\text {th }}$ Grade Team Behavior Management, Implementing Technology Throughout The Unit Plan, Analyzing Student Work, Analyzing Data Using the "Why" Protocol

Mathematics Teacher, T.T. Knight Middle School, Louisville Kentucky (2003-2010)

- Taught middle school mathematics grade 6

- Taught intervention and mathematics recovery grades 6,7 , and 8

- District level presenter: Connected Math Project 2 Summer Institute and Fall "Just In Time" Workshops

\section{Publication Contributions}

Walle, J. A. V. D., Karp, K. S. \& Bay-Williams, J. M. (2007) Elementary and middle school mathematics: Teaching developmentaly, (Boston, Pearson Education Inc.)

- Wrote curriculum connections highlighted throughout the book and online www.myeducationlab.com

Bay-Williams, J. M., Martinie, S. L. (2008) Math and Nonfiction, Grades 6-8, (Sausalito, Math Solutions)

- Wrote lesson for book Numbers: Facts, Figures and Fiction (p144)

\section{Submitted Publications}

Hunter, A. E., \& Bay-Williams, J. M. (2011). Integrating technology in response to intervention in mathematics.

\section{Publications In Progress}

Choi, N., Bush, S., English, A., \& Truitt, T. (2011). Factorial validity of the scores from 
the TIMSS 2007 mathematics attitude scale.

\section{Peer-Reviewed Presentations}

Hunter, A. E. (2012, April). Managing the Differentiated Classroom: Mathematicians Workshop. Presentation at the Annual Meeting of the National Council of Teachers of Mathematics. Philadelphia, PA.

Bush, S., \& Hunter, A. E. (2012, April). Analyzing Middle School Students' AlgebraRelated Misconceptions and Errors. Presentation at the Annual Meeting of the National Council of Teachers of Mathematics. Philadelphia, PA.

Hunter, A. E. \& Hunter, S. (2011, November). Concrete, Semi-Abstract, and AbstractWays to Make Sense of the KCAS for Mathematics. Presentation at the 46th Annual Exceptional Children's Conference. Louisville, KY.

Bush, S., \& Hunter, A. E. (2011, October). Analyzing Middle School Students' AlgebraRelated Misconceptions and Errors. Presentation to be at the Regional Meeting of the National Council of Teachers of Mathematics. St. Louis, MO.

Hunter, A. E. \& Bush, S. (2011, October). Technology, Transformations, 2D Animation, and Treasures- Making Geometry Come Alive! Presentation at the Regional Meeting of the National Council of Teachers of Mathematics. St. Louis, MO.

Hunter, A. E. (2011, October). Fraction Operations in the Common Core. Presentation at the Annual Meeting of the Kentucky Council of Teachers of Mathematics. Bowling Green, KY.

Choi, N., Bush, S., Hunter, A. E., \& Truitt, T. (2011, April). Factorial Validity of the Scores from the TIMSS 2007 Mathematics Attitude Scale. Presentation at the Annual Meeting of the American Education Research Association. New Orleans, LA.

Higgins, R., Hunter, A. E., \& Bush, S. (2011, April). Geometry and the Real WorldBudget Math Trips. Presentation given at the Annual Meeting of the National Council of Teachers of Mathematics. Indianapolis, IN.

Hunter, A. E. (2011, February). Fraction Operations in the Common Core. Presentation at the Kentucky Center for Mathematics Annual Conference. Lexington, KY.

Bush, S., \& English, A. (2010, October). Technology, Transformations, and Treasures. Presentation at the Annual Meeting of the Kentucky Council of Teachers of Mathematics. Somersville, KY. 
English, A., \& Bush, S. (2010, October). Implementing a Technologically Efficient Middle School Response to Intervention (RTI) Program. Presentation at the Annual Meeting of the Kentucky Council of Teachers of Mathematics. Somersville, KY.

Bush, S. \& English, A. (2009, October). Dollars and Sense! Developing Financially Literate Students. Presentation at the Annual Meeting of the Kentucky Council of Teachers of Mathematics. Bourbon, KY.

Hunter, A. E. (2009, October). Pathways to Proficiency: A Middle School Response to Intervention (RTI) Program. Presentation at the Annual Meeting of the Kentucky Council of Teachers of Mathematics. Bourbon, KY.

\section{Fellowships and Grants}

Graduate Student Travel Award (2011). University of Louisville: American Education Research Association Conference, $\$ 450$

Louisville Writing Project Fellow and Presenter, 2007

Groundwork Education in Math and Science (GEMS) Fellow, 2007

\section{National Service}

Mathematics Teaching in the Middle School-Manuscript Reviewer 2011-present

National Education Association Delegate to the National Assembly, 2007, 2008, 2009, and 2010

\section{Local Service}

The Middle Grades Mathematics Intervention Program (MGMIP), 2011-present

Secretary, Kentucky Council of Teachers of Mathematics, 2011-present

Visibility Chair, Kentucky Council of Teachers of Mathematics, 2011- present

Products Chair, Kentucky Council of Teachers of Mathematics, 2011-present

Appointed Member, Jefferson County Public Schools Committee Improving Instruction, 2011 
Appointed Member, Committee for Mathematics Achievement, 2009-present

Kentucky Education Association Delegate to the State Assembly, 2008, 2009, 2010, and 2011

\section{K-12 Service}

Mathematics Department Chair, 2006-2010

Connected Mathematics Project 2 Pilot Cadre, 2006

\section{Other Professional Experience}

Assistant Account Manager, Doe Anderson Advertising and Public Relations Agency, 2002-2003

\section{Professional Affiliations}

Greater Louisville Council of Teachers of Mathematics - Member

Kentucky Council of Teachers of Mathematics -Secretary, Visibility Chair, Products Chair

National Council of Teachers of Mathematics - Member

\section{Scholarships, Honors, Awards}

Common Core Standards Immersion Institute Participant (2012)

National Council of Teachers of Mathematics Presenter (2010, 2011, and 2012)

Kentucky Center for Mathematics Presenter (2011)

American Education Research Association Presenter (2011)

Kentucky Council of Teachers of Mathematics Presenter (2009 and 2010)

Connected Mathematics Project 2 Leadership Cadre Member (2008)

Kentucky Teacher Intern Program (KTIP) Mentor (2008, 2009, 2010, and 2011)

GE Foundation Conference Participant (2006)

University of Louisville Outstanding Student Teacher (2006)

Jefferson County Public Schools CHAMPS Classroom Management All-star (2006)

\section{Professional Licensures}


Kentucky Teacher License in Mathematics 5-9 (2003-present)

Kentucky Mathematics Consultant (2010-present) 